\title{
VARIABILIDADE DE PROPRIEDADES FÍSICO-MECÂNICAS EM LOTES DE MADEIRA SERRADA DE EUCALIPTO PARA A CONSTRUÇÃO CIVIL
}

\author{
RODRIGO AUGUSTO DIAS RODRIGUES
}

\author{
Dissertação apresentada à Escola Superior de \\ Agricultura "Luiz de Queiroz", Universidade de São \\ Paulo, para obtenção do título de Mestre em Ciências, \\ Área de Concentração: Ciência e Tecnologia de \\ Madeiras.
}

P I R A C I C A B A

Estado de São Paulo - Brasil

Fevereiro - 2002 


\title{
VARIABILIDADE DE PROPRIEDADES FÍSICO-MECÂNICAS EM LOTES DE MADEIRA SERRADA DE EUCALIPTO PARA A CONSTRUÇÃO CIVIL
}

\author{
RODRIGO AUGUSTO DIAS RODRIGUES \\ Engenheiro Florestal
}

Orientador: PROF. DR. JOSÉ NIVALDO GARCIA

\begin{abstract}
Dissertação apresentada à Escola Superior de Agricultura "Luiz de Queiroz", Universidade de São Paulo, para obtenção do título de Mestre em Ciências, Área de Concentração: Ciência e Tecnologia de Madeiras.
\end{abstract}

PIR A C IC A B A

Estado de São Paulo - Brasil

Fevereiro - 2002 


\title{
Dados Internacionais de Catalogação na Publicação (CIP)
} DIVISÃO DE BIBLIOTECA E DOCUMENTAÇÃO - ESALQ/USP

\author{
Rodrigues, Rodrigo Augusto Dias \\ Variabilida de de propriedades físic o-mecânic as em lotes de madeira \\ serrada de eucalipto para a construção civil / Rodrigo Augusto Dias \\ Rodrigues. - - Piracic aba, 2002. \\ 76 p. : il. \\ Dissertação (mestrado) - - Escola Superior de Agricultura Luiz de \\ Queiroz, 2002. \\ Bibliografia. \\ 1. Construção civil 2. Estrutura da madeira 3. Euc a lipto 4. Ma deira \\ serrada 5. Tecnologia da madeira I. Título
}

CDD 674.142

"Permitida a cópia total ou parcial deste documento, desde que citada a fonte - O autor" 


\section{Dedico}

Ao meu pai João Carlos Rodrigues, à minha mãe Iva Helena Dias Rodrigues,

ao meu irmão Thiago Dias Rodrigues e à minha avó Iva Kronka Dias por todo carinho, incentivo e apoio a mim proporcionados.

Ao Prof. Dr. João Cesar Hellmeister por todo seu ensinamento e incentivo na pesquisa da madeira. 


\section{AGRADECIMENTOS}

Ao Professor Doutor José Nivaldo Garcia e ao Professor Doutor Nilson Franco (IPT) pela orientação, por seus ensinamentos, incentivos e confiança em mim depositado.

Ao Prof. Doutor Adriano Wagner Ballarin, pelos ensinamentos e disposinibilização do Laboratório de Resistência de Materiais da Faculdade de Ciências Agronômicas/Unesp - Botucatu.

Aos técnicos de laboratório Paulo de Assis (IPT) e Ailton (FCA) pelo trabalho e orientação na execução dos ensaios.

Aos Professores do Curso de Ciência e Tecnologia de Madeiras pelos ensinamentos durante todo o período.

Aos colegas Fernando Henrique V. de Andrade, Gofredo Mathiesen Júnior e Rodrigo de Andrade Furlan, pelos transportes da madeira.

À Tatiana Pacheco Nunes, Maria Almerinda e toda família pela ajuda recebida.

Aos fornecedores de madeira para o estudo: Indústria Madeireira Baggio, Casa Modular, Serraria Poletti, Serraria Chiari, Serraria Senhora do Rócio, Serraria Citriodora, Serraria Zanata, Faidiga Madeireira.

Ao CNPq pela concessão da bolsa de mestrado. 


\section{SUMÁRIO}

Página

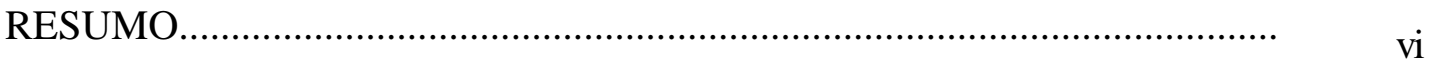

SUMMARY .................................................................................... viii

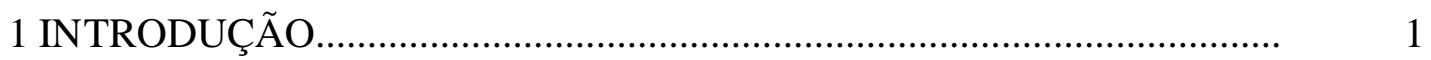

2 REVISÃO DE LITERATURA...............................................................

2.1 Propriedades físicas e mecânicas da madeira............................................. 4

2.1.1 Propriedades físicas da madeira.......................................................... 5

2.1.2 Propriedades mecânicas da madeira..................................................... 8

2.1.3 Ensaios normalizados.................................................................. 11

3 MATERIAL E MÉTODOS................................................................ 14

3.1 Amostragem...................................................................................... 15

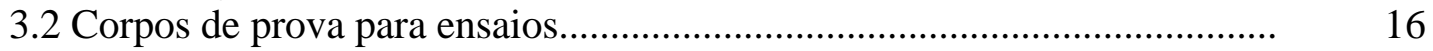

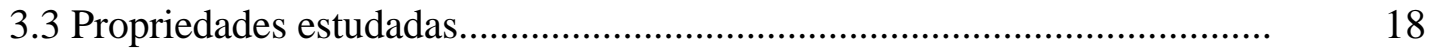

3.3.1 Densidades...................................................................................... 19

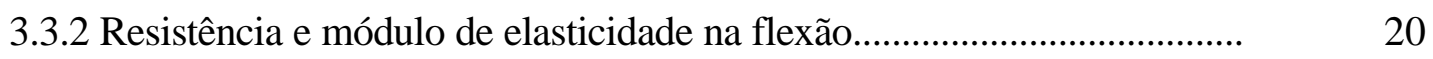

3.3.3 Resistência e módulo de elasticidade na compressão paralela às fibras segundo a NBR 7190/97.................................................................. 24

3.3.1 Resistência à compressão paralela - qualificação, segundo a NBR

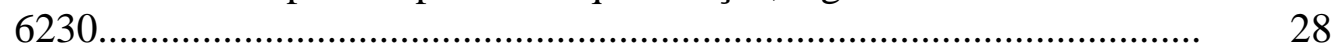

3.3.4 Resistência ao cisalhamento.............................................................. 29

3.4 Análise estatística............................................................................ 31

4 RESULTADOS E DISCUSSÃO ............................................................ 33

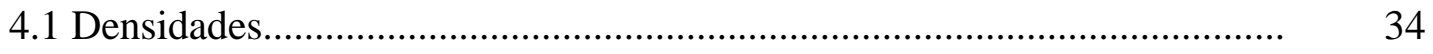

4.2 Flexão estática.................................................................................. 41

4.3 Compressão paralela às fibras................................................................. 47

4.3.1 Compressão paralela às fibras - qualificação......................................... 56

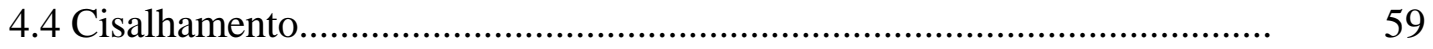

4.5 Discussões gerais............................................................................. 64

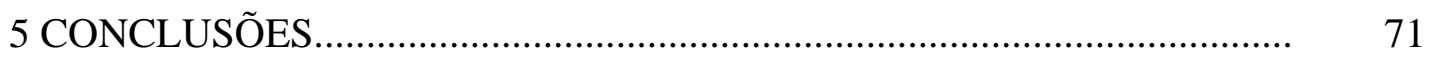

REFERÊNCIAS BIBLIOGRÁFICAS....................................................... 72 


\title{
VARIABILIDADE DE PROPRIEDADES FÍSICO-MECÂNICAS EM LOTES DE MADEIRA SERRADA DE EUCALIPTO PARA A CONSTRUÇÃO CIVIL
}

\author{
Autor: RODRIGO AUGUSTO DIAS RODRIGUES \\ Orientador: Prof. Dr. JOSÉ NIVALDO GARCIA
}

\section{RESUMO}

O gênero Eucalyptus vem alcançando boa posição no mercado de madeira sólida, devido à sua alta produtividade em madeira de qualidade mecânica satisfatória, que redunda em grande disponibilidade de matéria prima para a construção civil. A atualização da norma brasileira para projetos de estruturas de madeira (NBR 7190/97), introduziu modificações importantes como a proposição de classes de resistência para as propriedades da madeira, metodologias melhores fundamentadas para execução de ensaios de caracterização e condições mais concretas de verificação da segurança das estruturas quanto aos seus estados limites. No presente trabalho foram utilizados doze lotes de madeira serrada de eucalipto comercializadas na forma de vigas, onde foram estudadas as propriedades físicas e mecânicas da madeira para a classificação dos lotes nas classes de resistência propostas pela norma. Para a densidade básica e densidade aparente, os lotes se enquadraram nas quatro classes indicadas na norma NBR 7190/97 (C20, C30, C40 e C60). Para resistência à compressão paralela às fibras cinco lotes qualificaram-se na classe C40 e sete lotes na classe superior C60. Em relação ao módulo de elasticidade na compressão paralela às fibras um lote se enquadrou na classe inferior C20, 2 lotes na classe C30, seis lotes na classe C40 e três na classe C60. Para a 
resistência ao cisalhamento um lote se enquadrou na classe C40 e os demais na classe C60. Pôde-se verificar que os lotes de madeira serrada não podem ser diretamente classificados em uma mesma classe de resistência por todas as mecânicas da madeira.

Palavras-chaves: eucalipto, estrutura de madeira, propriedades mecânicas, variabilidade. 


\title{
VARIABILITY OF PHYSICAL AND MECHANICAL PROPERTIES IN LOTS OF EUCALIPTO LUMBER FOR THE BUILDING CONSTRUCTION
}

\author{
Author: RODRIGO AUGUSTO DIAS RODRIGUES \\ Adviser: Prof. Dr. JOSÉ NIVALDO GARCIA
}

\section{SUMMARY}

The Eucalyptus genus has been reaching good position in the solid wood market due to its high productivity in wood of satisfactory mechanical quality, providing great availability for the building construction. The up date of the Brazilian Norm for projects of wood structures (NBR 7190/97), has introduced important modifications as the proposition of resistance grades for the properties of the wood, better methodologies for permitting the wood characterization and more concrete conditions to evaluate the structures safety in relation to its limit conditions. In the present work twelve lots of sawn wood of eucalyptus marketed in the form of beams were used for studying physical and mechanical properties of wood in order to classify the lots in the grade classes of mechanical quality proposed by the norm. It was verified that a set of wood cannot be directly classified into the same quality class according to all wood characteristics.

Keywords: eucalyptus, wooden structures, mechanical properties, variability. 


\section{INTRODUÇÃO}

A madeira pode ser considerada como um dos materiais mais utilizado pelo homem devido, principalmente, à grande diversidade de aplicações. No Brasil, com o desenvolvimento industrial e tecnológico, deu-se o conseqüiente incremento da utilização da madeira tanto como recurso para produção de energia quanto de madeira beneficiada. Estes fatores contribuíram em grande parte para a exploração predatória das reservas naturais.

À medida que cresce a pressão sobre a utilização racional de madeiras tropicais e, ao mesmo tempo, o esgotamento das reservas nativas, surge a necessidade de novas fontes de matéria-prima para abastecer os diversos setores que dependem da madeira. $\mathrm{O}$ reflorestamento foi a maneira encontrada para recuperar as florestas sendo inicialmente realizado com espécies nativas, porém estas apresentavam baixas produtividades, problemas de adaptação a novos sítios e surgimento de pragas e doenças.

Atualmente os reflorestamentos são grandes fontes de abastecimento de madeiras para fins industriais sendo o gênero Eucalyptus o mais plantado pelo seu grande potencial de adaptação em distintas regiões apresentando alta produtividade de madeira de qualidade satisfatória, que por estes motivos está tendo uma grande participação no mercado de madeira sólida.

O primeiro plantio realizado no Brasil foi no Estado do Rio Grande do Sul em 1868, mas deve-se à Companhia Paulista de Estradas de Ferro, a implantação do gênero eucalipto, em 1903, na região de Jundiaí/SP onde começaram os primeiros estudos sobre o reflorestamento de espécies exóticas, visando a produção de lenha para geração de energia para as locomotivas a vapor, e dormentes para as estradas de ferro (Andrade, 1961). 
A partir de 1966, com a implantação da Política de Incentivos Fiscais ao reflorestamento, instituída pelo Governo Federal, ocorreu um grande aumento das áreas reflorestadas com vários gêneros, dentre eles o eucalipto, fortalecendo as empresas de base florestal. Porém os plantios foram realizados de forma desorganizada e após a extinção dos incentivos (1988), houve o declínio das áreas reflorestadas no país.

Atualmente existem aproximadamente 2,9 milhões de hectares reflorestados com o gênero Eucalyptus no Brasil, distribuídos conforme indicado na Tabela 1 (SBS, 1996), sendo que Minas Gerais concentra 51,7\% deste total e São Paulo 19,4\%.

Tabela 1. Áreas, em hectares, plantadas com eucalipto, no Brasil.

\begin{tabular}{lcc}
\hline Estado & 1999 & $\%$ \\
\hline Amapá & 12.500 & 0,4 \\
Bahia & 213.400 & 7,2 \\
Espírito Santo & 152.330 & 5,1 \\
Mato Grosso do Sul & 80.000 & 2,7 \\
Minas Gerais & 1.535 .290 & 51,7 \\
Pará & 45.700 & 1,5 \\
Paraná & 67.000 & 2,3 \\
Rio Grande do Sul & 115.900 & 3,9 \\
Santa Catarina & 41.550 & 1,4 \\
São Paulo & 574.150 & 19,4 \\
Outros & 128.060 & 4,3 \\
Total & 2.965 .880 & 100 \\
\hline
\end{tabular}

Fonte: SBS, 1996.

A aplicação adequada da madeira de eucalipto, assim como de qualquer material, está relacionada diretamente com o conhecimento das suas características, pois a determinação dos valores das diversas propriedades possibilita maior economia e segurança no emprego do material.

A primeira iniciativa de caracterização da madeira no Brasil foi da Escola Politécnica de São Paulo em 1904, onde foram realizados estudos sobre a resistência à compressão, flexão e determinação da densidade de massa de diversas espécies nativas.

Por volta de 1930, o Instituto de Pesquisas Tecnológicas (IPT) publicou seus Métodos para Ensaios de Madeiras, nos quais fundamentou o desenvolvimento da pesquisa objetivando a caracterização de espécies de madeira produzidas no país. Esses 
métodos foram divididos em: a) Ensaios Físicos (umidade, densidade de massa e retratibilidade) e b) Ensaios Mecânicos (compressão paralela, flexão estática, choque, tração, fendilhamento, dureza e cisalhamento).

Em 1940, a então recém instalada Associação Brasileira de Normas Técnicas adotou os Métodos de Ensaios para Madeira, do IPT, transformando-os no MB-26/40: (NBR 6230) Método Brasileiro para Ensaios Físicos e Mecânicos de Madeiras.

O Laboratório de Madeiras e Estruturas de Madeiras (LaMEM) da Escola de Engenharia de São Carlos - USP, em 1987, contribuiu para a caracterização de madeiras com propostas de métodos de ensaio para a determinação das características físicas, de resistência e de elasticidade da madeira.

Baseado nestes métodos, o LaMEM iniciou, pesquisa buscando determinar as características físicas de resistência e de elasticidade da madeira de 16 espécies de Eucalyptus, cultivadas no Estado de São Paulo. Essa pesquisa, além de utilizar um método de ensaio atualizado, adotou uma amostragem a partir de vários troncos de árvore para cada espécie, buscando uma maior representatividade para os valores obtidos. Estes valores são utilizados atualmente como referência para diversas pesquisas. Estes conhecimentos adquiridos, somados as experiências da Escola Politécnica, levaram a elaboração da nova norma brasileira: Projeto de estruturas de madeira (NBR 7190/97) que trata no Anexo B da determinação das propriedades das madeiras para projetos de estruturas.

Segundo Oliveira (1997), um material tão complexo como a madeira do gênero Eucalyptus, somente poderá ser utilizado, em condições de igualdade com as madeiras tradicionais, ou substituí-las, caso se tenha conhecimentos científicos de suas características, propriedades, bem como de suas variações, peculiares a cada espécie, condição de crescimento e, principalmente, idade de corte das árvores.

O presente trabalho teve por objetivo principal estudar as propriedades físicas e mecânicas da madeira de eucalipto, disponíveis no mercado madeireiro, para construção civil. Para o desenvolvimento completo do trabalho foi estudada a variabilidade das características físico-mecânicas existente dentro e entre lotes de madeira serrada bem como a classificação destes lotes em classes de resistência. 


\section{REVISÃO DE LITERATURA}

\subsection{Propriedades físicas e mecânicas da madeira}

A madeira pode ser considerada um excelente material estrutural, reconhecida por sua resistência mecânica elevada e baixa densidade quando comparado com outros materiais, como o aço para construção (Kollmann \& Côté Jr., 1968).

Segundo Bauer (1979), o emprego da madeira de uma determinada espécie numa determinada obra somente poderá ser conduzida, com economia e segurança, se forem conhecidos e levados em conta os valores estatísticos e a dispersão que definem a variabilidade de suas propriedades.

Esse conhecimento indispensável é adquirido dos resultados de numerosos ensaios de qualificação do material sobre amostras representativas do lote de madeira, da espécie ou do gênero.

Tais ensaios de qualificação devem levar em consideração todos os fatores de alteração das características do material como:

$\Rightarrow$ a estrutura anatômica e a constituição do tecido lenhoso, responsáveis pelo comportamento físico-mecânico da madeira, que varia de espécie para espécie;

$\Rightarrow$ a densidade de massa, também variável dentro de espécies, está estreitamente relacionada as demais propriedades da madeira (Estados Unidos, Forest Products Laboratory 1974);

$\Rightarrow$ a localização da amostra na árvore, que diferenciam as suas direções radial e longitudinal; 
$\Rightarrow$ as variações que decorrem do procedimento desenvolvido na execução dos ensaios como a forma, dimensões dos corpos-de-prova, orientação das solicitações em relação aos anéis de crescimento, velocidade de aplicação das cargas nas solicitações mecânicas e as condições de vinculação dos corpos de prova à maquina de ensaio (Bauer, 1979).

\subsubsection{Propriedades físicas da madeira}

As propriedades físicas mais estudadas são: umidade, densidades básica e aparente e estabilidade dimensional (retração ou inchamento). A umidade da madeira é um importante índice para qualificar a madeira no sentido de verificar a umidade de um lote de madeira que está sendo comercializado (Hellmeister, 1983). A estabilidade dimensional da madeira, representada pelo valor absoluto da contração volumétrica e pela relação das contrações nos sentidos radial e tangencial, também é de grande importância para a qualificação de peças de madeira.

Dentre as propriedades da madeira a densidade de massa se destaca como o melhor índice para qualificar a madeira, pois se correlaciona com várias outras características e segundo Hellmeister (1983), é a propriedade mais significativa para caracterizar madeiras destinadas à construção civil ou à fabricação de chapas.

No meio científico existem vários estudos referentes à densidade da madeira do gênero Eucalyptus, principalmente no que se refere à sua variabilidade como os realizados por Busnardo et al., 1987; Ferreira et al., 1979; Vital et al., 1984; Brasil, 1972, entre outros. Esses trabalhos estão, geralmente, voltados à determinação da qualidade da madeira para produção de celulose e papel ou carvão.

A despeito da variação da densidade ser relativamente acentuada entre gêneros, devem-se considerar as variações existentes entre espécies pertencentes ao mesmo gênero, bem como entre árvores de um mesmo povoamento (Busnardo et al., 1987).

Ferreira et al. (1979), estudando a variabilidade da densidade em populações comerciais de eucalipto, destacaram que a da variação dentro de uma mesma população é maior que entre populações dentro de uma mesma localidade ou mesmo entre populações de locais diferentes. Os resultados obtidos mostraram que as populações de 
Eucalyptus grandis e Eucalyptus saligna foram bastante heterogêneas para esta característica.

A variabilidade das propriedades da madeira dentro de uma espécie de Eucalyptus pode estar associada ao material genético, condições edafo-climáticas, sistema de implantação e condução das florestas, ritmo de crescimento e idade da floresta, entre outros (Busnardo et al., 1987).

É evidenciado na literatura que o aumento da densidade da madeira de eucalipto varia com a idade, e que segundo Ribeiro \& Zani Filho (1993), tais incrementos de densidade variam entre espécies, havendo uma tendência de estabilização após certa idade da árvore. Vital et al. (1984), estudando a madeira de Eucalyptus grandis, confirmaram o aumento sistemático da densidade com a idade da árvore. Ferreira (1968) e Ferreira (1970) também verificou a tendência para o aumento da densidade em função da idade do talhão, em plantações de Eucalyptus alba, E. saligna e E. grandis.

Brasil (1972) verificou diferenças altamente significativas na densidade básica do Eucalyptus propinqua aos 5 anos de idade em dois locais do Estado de São Paulo, sendo que na região onde o ritmo de crescimento foi menor, os valores de densidade básica foram superiores. Ainda neste trabalho a autora observou uma variação individual bastante alta para a espécie. Resultados similares haviam sido obtidos por Brasil \& Ferreira (1971) para E. alba, E. saligna e E. grandis. Albino (1983), estudando 12 espécies de Eucalyptus, chegou a mesma conclusão dos autores citados acima.

A variação da densidade da madeira, no sentido medula-casca, em quase todas as espécies de Eucalyptus, segue um padrão, evidenciado em diversos trabalhos na literatura onde a densidade aumenta da medula para a casca. Tomazello (1985) estudando árvores de 10 anos de idade, concluiu que para a madeira de E. grandis e E. pilularis a densidade básica aumenta da medula para a casca. Brasil \& Ferreira (1972) também encontraram o mesmo padrão de variação para E. grandis. Oliveira (1997), estudando sete espécies de Eucalyptus, também encontrou este mesmo padrão de variação, sendo que o Eucalyptus tereticornis apresentou maior uniformidade e o Eucalyptus pilularis apresentou maior dispersão entre amostras. 
A variação da densidade no sentido base-topo não segue um padrão definido, variando de espécie para espécie, dentro do gênero Eucalyptus. Por este motivo discutese, rotineiramente se a utilização de amostras de madeira retiradas ao nível do DAP para determinação de uma propriedade, representa a árvore para essa propriedade.

Ferreira (1970) estudou a madeira de Eucalyptus alba e Eucalyptus saligna para determinação da variação da densidade básica em relação à altura da árvore e concluiu que a densidade básica média para as espécies analisadas varia linearmente em função da altura, e que a dispersão individual entre árvores era bastante acentuada.

Brasil (1972), trabalhando com Eucalyptus propinqua concluiu que a densidade cresce até um ponto de máximo, próximo à altura média da árvore, quando volta a decrescer em direção à copa.

A Figura 1, obtida por Oliveira (1997), mostra a variação da densidade no eixo ao longo da altura da árvore de sete espécies de Eucalyptus, onde observa-se comportamento diferente para cada espécie estudada, sendo que a maior variação foi encontrada no E. grandis, de cerca de $0.10 \mathrm{~g} / \mathrm{cm}^{3}$.

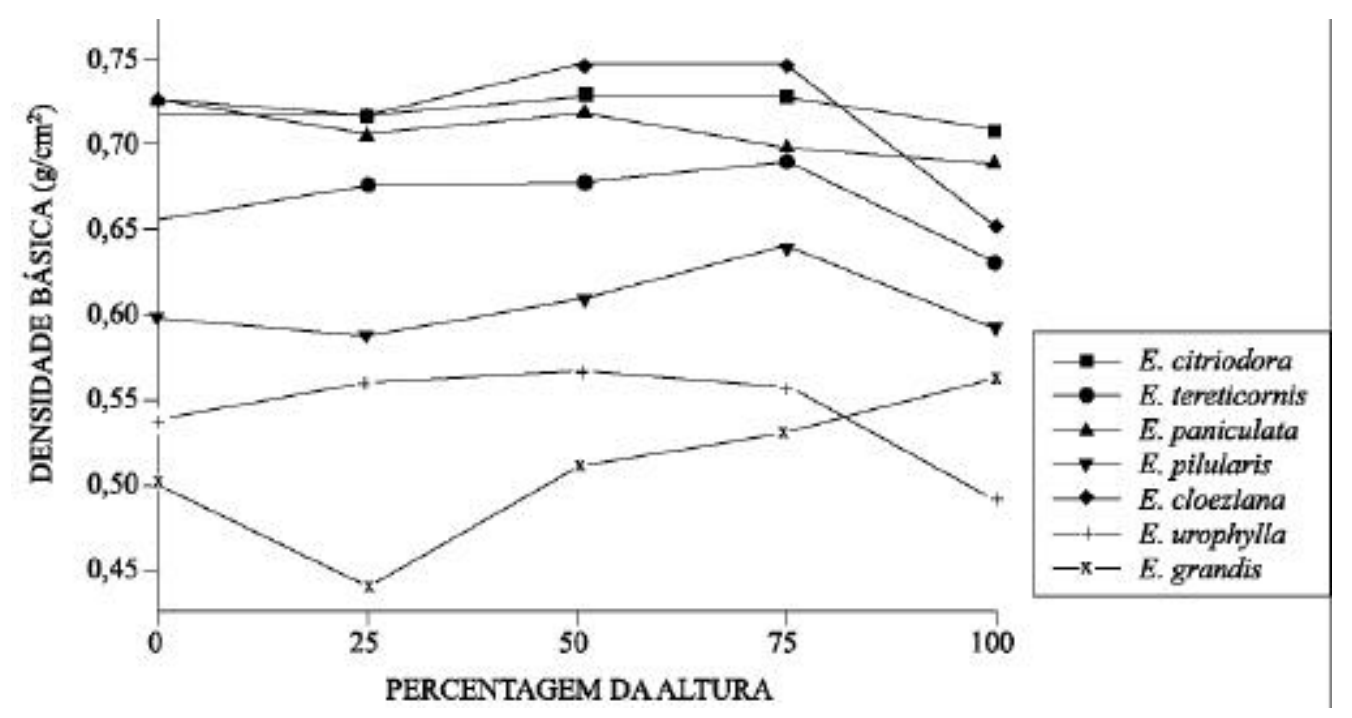

Figura 1 - Variações da densidade básica $\left(\mathrm{g} / \mathrm{cm}^{3}\right)$ da madeira ao bngo do tronco, de 7 espécies de eucalipto.

Fonte: Oliveira (1997) - Adaptada 


\subsubsection{Propriedades mecânicas da madeira}

São as características de resistência e de elasticidade da madeira. Grande número de aplicações da madeira em Engenharia Civil exige perfeito conhecimento destas características que são adquiridas através de ensaios de compressão, flexão, tração, cisalhamento e outros.

A resistência é determinada, convencionalmente, pela máxima tensão que pode ser aplicada a corpos de prova isentos de defeitos do material considerado. A tensão máxima é definida quando do aparecimento de fenômenos particulares de comportamento. Além dos quais há restrição de emprego do material em elementos estruturais. De modo geral estes fenômenos são os de ruptura ou de deformação específica excessiva (NBR 7190/97).

A rigidez do material é expressa pelo módulo de elasticidade, determinado na fase de comportamento elástico-linear. $\mathrm{O}$ módulo de elasticidade $\left(\mathrm{E}_{\mathrm{w} 0}\right)$ na direção paralela às fibras é medido no ensaio de compressão paralela às fibras e o módulo de elasticidade $\mathrm{E}_{\mathrm{W} 90}$ na direção normal às fibras é medido no ensaio de compressão normal às fibras. Na falta de determinação experimental específica permite-se adotar a eq. (1), indicada pela NBR 7190/97:

$$
\mathrm{E}_{\mathrm{w} 90}=\frac{1}{20} \mathrm{E}_{\mathrm{w} 0}
$$

Trabalhos experimentais do "U. S. Forest Products Laboratory" (Estados Unidos, Forest Products Laboratory 1974), levaram a dedução da eq. (2), que estabelece relações entre densidade básica e qualquer propriedade mecânica considerada.

$$
\mathrm{R}=\mathrm{C} \mathrm{D}^{\mathrm{n}}
$$

onde: $\mathrm{R}$ - resistência

C - coeficiente variável com a espécie de madeira; 
D - densidade básica;

n - expoente constante para cada tipo de solicitação mecânica.

A Figura 2 apresenta os resultados obtidos em ensaios de qualificação, à compressão, de mais de 200 espécies, realizados no IPT, citado por Bauer (1979), que conduziram à fórmula de correlação (3):

$$
\sigma c_{15}=(663 \mathrm{D}-1.04) \mathrm{kg} / \mathrm{cm}^{2}
$$

onde: $\sigma c_{15}$ - resistência a compressão a $15 \%$ de umidade;

D - densidade de massa a $15 \%$ de umidade.

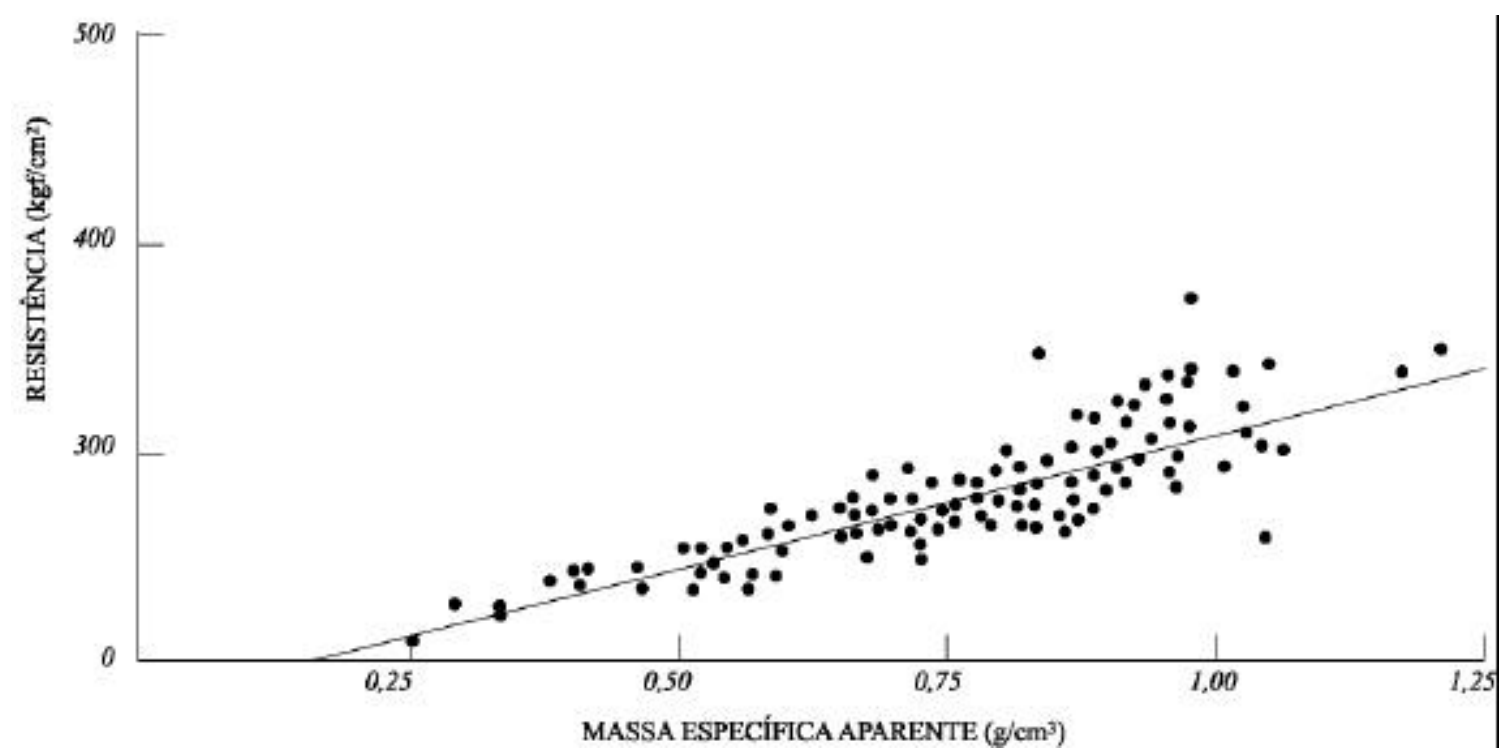

Figura 2 - Relação entre massa específica aparente e compressão paralela para 200 espécies de madeira.

Fonte: Bauer (1979) - Adapatada

A variabilidade das propriedades mecânicas da madeira dificulta a sua aplicação como material estrutural, principalmente diante de materiais como o aço e o concreto. $\mathrm{O}$ coeficiente de variação $(\mathrm{CV})$ do escoamento do aço para construção geralmente é inferior a 0,04 e o da resistência do concreto oscila usualmente entre 0,10 e 0,15 (Fusco, 
1976). Para a madeira, segundo Freitas (1978) e Rocco Lahr (1990), os valores dos coeficientes de variação para as propriedades de resistência são da ordem de 0,18 num teor de umidade em torno de $12 \%$.

Na Tabela 2 estão apresentados os valores médios usuais de resistência e de rigidez de 15 espécies de eucalipto, cujos ensaios foram realizados no Laboratório de Madeiras e de Estruturas de Madeiras (LaMEM) da Escola de Engenharia de São Carlos - USP. Pode-se observar a grande variabilidade existente entre as espécies, como por exemplo, a massa específica aparente que varia, em valores médios, de 640 a 1087 $\mathrm{kg} / \mathrm{m}^{3}$.

Tabela 2. Valores médios de propriedades da madeira de 15 espécies de eucalipto.

\begin{tabular}{lccccc}
\hline Nome científico & Dap $(12 \%)$ & $\mathrm{f}_{\mathrm{c} 0}$ & $\mathrm{f}_{\mathrm{v}}$ & $\mathrm{E}_{\mathrm{c} 0}$ & $\mathrm{n}$ \\
\hline Eucalyptus camaldulensis & 899 & 48,0 & 9,0 & 13286 & 18 \\
Eucalyptus alba & 705 & 47,3 & 9,5 & 13409 & 24 \\
Eucalyptus citriodora & 999 & 62,0 & 10,7 & 18421 & 68 \\
Eucalyptus cloeziana & 822 & 51,8 & 10,5 & 13963 & 21 \\
Eucalyptus dunnii & 690 & 48,9 & 9,8 & 18029 & 15 \\
Eucalyptus grandis & 640 & 40,3 & 7,0 & 12813 & 103 \\
Eucalyptus maculata & 931 & 63,5 & 10,6 & 18099 & 53 \\
Eucalyptus maidene & 924 & 48,3 & 10,3 & 14431 & 10 \\
Eucalyptus microcorys & 929 & 54,9 & 10,3 & 16782 & 31 \\
Eucalyptus paniculata & 1087 & 72,7 & 12,4 & 19881 & 29 \\
Eucalyptus propinqua & 952 & 51,6 & 9,7 & 15561 & 63 \\
Eucalyptus punctata & 948 & 78,5 & 12,9 & 19360 & 70 \\
Eucalyptus saligna & 731 & 46,8 & 8,2 & 14933 & 67 \\
Eucalyptus tereticornis & 899 & 57,7 & 9,7 & 17198 & 29 \\
Eucalyptus urophylla & 739 & 46,0 & 8,3 & 13166 & 86 \\
\hline Dap(ing
\end{tabular}

$\operatorname{Dap}_{(12 \%)}=$ massa específica aparente a $12 \%$ de umidade $\left(\mathrm{kg} / \mathrm{m}^{3}\right)$;

$\mathrm{f}_{\mathrm{c} 0}=$ resistência à compressão paralela às fibras $(\mathrm{MPa})$;

$\mathrm{f}_{\mathrm{v}}=$ resistência ao cisalhamento $(\mathrm{MPa})$;

$\mathrm{E}_{\mathrm{c} 0}=$ módulo de elasticidade longitudinal obtido no ensaio de compressão paralela às fibras (MPa);

$\mathrm{n}=$ número de corpos de prova ensaiados.

Fonte: NBR 7190/97 - Adaptada 


\subsubsection{Ensaios normalizados}

A caracterização tecnológica de madeiras extraídas de essências florestais é feita através de ensaios físicos e mecânicos normalizados. Cada norma de ensaio apresenta uma metodologia para a determinação de uma mesma característica física ou mecânica. Basicamente, a metodologia refere-se à amostragem, marcação, dimensões e formato dos corpos de prova e ensaio propriamente dito para caracterização do material (Franco, 1986).

Os ensaios, normalizados, geralmente consistem no levantamento de dados correspondentes ao carregamento lento e contínuo de corpos de prova especialmente preparados e das deformações resultantes. A determinação do módulo de elasticidade e das tensões limite de proporcionalidade e limite de resistência na flexão e compressão são as mais importantes para aplicações estruturais (Franco, 1986).

Atualmente cada centro de pesquisa adota sua norma de preferência. Entre as mais utilizadas estão: Comissão Panamericana de Normas Técnicas (COPANT), American Society for Testing and Materials (ASTM) e Associação Brasileira de Normas Técnicas (ABNT).

A atual norma brasileira, Projetos de Estruturas de Madeira - NBR 7190/97, trata em seu anexo B dos métodos de ensaio para determinação das propriedades físicas e mecânicas das madeiras, sendo que estes métodos visam a caracterização completa das madeiras, a caracterização mínima e a caracterização simplificada, de acordo com a espécie a ser estudada.

Esta norma, revisada em 1997, sofreu grandes mudanças em relação à anterior, principalmente no que se refere ao enfoque dos métodos. A anterior era baseada em métodos determinísticos e a atual, em métodos probabilísticos onde valores característicos de uma propriedade determinam a classe de resistência de um certo lote ou espécie de madeira.

A separação dos lotes de madeira em classes de resistência tem por objetivo o emprego de madeiras com propriedades padronizadas, orientando a escolha do material para elaboração, principalmente, de projetos estruturais. Segundo Sales (1996), a 
classificação por classes de resistência permite ao projetista utilizar a madeira disponível na região de construção da estrutura, desde que os valores das propriedades mecânicas dos lotes a serem empregados se enquadrem na classe definida no projeto. As classes de resistência especificadas para as dicotiledôneas encontram-se na Tabela 3, produto do trabalho realizado por Sales (1996), utilizado pela NBR 7190/97.

Alguns sistemas de classes de resistência utilizados atualmente possuem um número de classes maior do que aquele que a NBR 7190/97 propõe, como por exemplo, o EUROCODE (1995) que apresenta nove classes para coníferas e seis classes para dicotiledôneas e na Austrália, as madeiras podem ser agrupadas em doze classes.

Levando-se em consideração o grande número de espécies utilizadas no Brasil, tanto nativas como exóticas, somente o uso de métodos para classificação visual e mecânica poderia justificar a adoção de um maior número de classes. O sistema de produção e comercialização, hoje em prática no Brasil, inviabiliza a elaboração de critérios mais refinados para classificação de madeiras.

Analisando os valores encontrados na Tabela 2 para as propriedades físicas e mecânicas dos Eucalyptus, podemos observar que as diferentes espécies deste gênero se enquadram nas quatros classes indicadas na NBR 7190/97, cabendo uma análise mais cuidadosa no momento de adquirir esta matéria prima para o uso na construção civil. 
Tabela 3. Classes de resistência das dicotiledôneas na umidade padrão de $12 \%$.

\begin{tabular}{cccccc}
\hline Classes & $\begin{array}{c}\mathrm{f}_{\mathrm{c} 0 \mathrm{k}} \\
(\mathrm{MPa})\end{array}$ & $\begin{array}{c}\mathrm{f}_{\mathrm{Vk}} \\
(\mathrm{MPa})\end{array}$ & $\begin{array}{c}\mathrm{E}_{\mathrm{c} 0, \mathrm{~m}} \\
(\mathrm{MPa})\end{array}$ & $\begin{array}{c}\rho_{\text {bas,m }} \\
\left(\mathrm{kg} / \mathrm{m}^{3}\right)\end{array}$ & $\begin{array}{c}\rho_{\mathrm{ap}, \mathrm{m}} \\
\left(\mathrm{kg} / \mathrm{m}^{3}\right)\end{array}$ \\
\hline C 20 & 20 & 4 & 9500 & 500 & 650 \\
C 30 & 30 & 5 & 14.500 & 650 & 800 \\
C 40 & 40 & 6 & 19.500 & 750 & 950 \\
C 60 & 60 & 8 & 24.500 & 800 & 1000 \\
\hline
\end{tabular}

Fonte: NBR 7190/97 - Adaptada

$\mathrm{f}_{\mathrm{c} 0 \mathrm{k}}=$ resistência à compressão paralela, valor característico;

$\mathrm{f}_{\mathrm{vk}}=$ resistência ao cisalhamento, valor característico;

$\mathrm{E}_{\mathrm{c} 0, \mathrm{~m}}=$ módulo de elasticidade na compressão paralela, valor médio;

$\rho_{\text {bas,m }}=$ densidade básica da madeira, valor médio;

$\rho_{\mathrm{ap}, \mathrm{m}}=$ densidade aparente, valor médio.

Como exemplos, analisando a Tabela 2, para os valores médios da densidade aparente a $12 \%$ de umidade e do módulo de elasticidade na compressão paralela às fibras o Eucalyptus camaldulensis se enquadra na classe C30 pela densidade aparente e C20 pela compressão, o Eucalyptus citriodora classifica-se na C40 pela densidade e C30 pela compressão, enquanto que o Eucalyptus saligna classifica-se na C20 pela densidade e C30 pela compressão. 


\section{MATERIAL E MÉTODOS}

Foram utilizados 12 lotes de madeira serrada provenientes de diferentes produtores, objetivando a caracterização da madeira de eucalipto comercializada atualmente para os diversos usos na construção civil. A abordagem foi feita através da investigação de algumas propriedades tecnológicas desses lotes levando-se em consideração a metodologia da NBR 7190/97, bem como a metodologia da NBR 6230.

Os fornecedores de madeira serrada para este estudo foram:

- Indústria Madeireira Baggio - Jumirim/SP (Lote 1G)

- Casa Modular - Taquarivaí/SP (Lote $2 \mathrm{H})$

- Serraria Poletti Ltda - Bragança Paulista/SP (Lotes 3G e 3S)

- Serraria Chiari - São Carlos/SP (Lotes 4G, 4S e 4C)

- Faidiga Madeira - Bauru/SP (Lotes 5B e 5V)

- Serraria Nossa Senhora do Rócio - Piracicaba/SP (Lote 6V)

- Serraria Citriodora - Piracicaba/SP (Lote 7C)

- Serraria Zanata - Charqueada/SP (Lote 8V)

Sendo um dos objetivos deste trabalho o estudo da variabilidade das propriedades tecnológicas de lotes de madeira serrada de espécies de eucalipto, esta amostragem teve o intuito de abranger o maior número de espécies, onde foram contempladas principalmente as espécies: E. grandis, E. saligna e E. citriodora. 
Os fornecedores de madeira para o estudo são representados de serrarias de pequeno porte, que produzem madeira serrada de eucalipto para construção civil na forma de vigas e caibros.

As espécies de três fornecedores, não foram identificadas, sendo simplesmente conhecidas como eucalipto branco e eucalipto vermelho. São os casos dos lotes 5B (madeira clara), 5V (madeira avermelhada), 6V (madeira avermelhada) e 8V (madeira vermelha). $\mathrm{O}$ lote $2 \mathrm{H}$ era segundo seu fornecedor, um híbrido de $E$. saligna $\mathrm{x}$ E. alba. Os lotes $1 \mathrm{G}, 3 \mathrm{G}$ e $4 \mathrm{G}$ representaram a madeira do E. grandis; os lotes $3 \mathrm{~S}$ e $4 \mathrm{~S}$ foram da espécie E. saligna; enquanto que os lotes $4 \mathrm{C}$ e $7 \mathrm{C}$ foram da espécie E. citriodora.

\subsection{Amostragem}

Sempre que possível, a amostragem foi realizada de acordo com a NBR 7190/97, para a caracterização mínima de um lote de madeira serrada. Foram amostradas, aleatoriamente, 12 barras de madeira de lotes com volumes inferiores a $12 \mathrm{~m}^{3}$. As barras amostradas possuíam dimensões suficientes para a extração dos corpos de prova necessários. Esta amostragem foi realizada de forma a abranger o maior número possível de espécies de eucalipto comercializadas atualmente para construção civil.

Desta forma foram amostrados 12 lotes de madeira assim distribuídos:

- Lote 1G - 12 vigas de 6 x $12 \mathrm{~cm}$

- Lote 2H - 10 vigas de 6 × $16 \mathrm{~cm}$

- Lote 3G-12 vigas de $6 \times 12 \mathrm{~cm}$

- Lote 3S - 12 vigas de 6 × $12 \mathrm{~cm}$

- Lote 4C - 12 vigas de $6 \times 16 \mathrm{~cm}$

- Lote $4 \mathrm{~S}-12$ vigas de $6 \times 16 \mathrm{~cm}$

- Lote 4G-12 vigas de $6 \times 16 \mathrm{~cm}$

- Lote 5B - 13 vigas de $6 \times 12 \mathrm{~cm}$

- Lote 5V - 12 vigas de $6 \times 12 \mathrm{~cm}$

- Lote 6V - 12 caibros de $5 \times 6 \mathrm{~cm}$

- Lote 7C - 5 caibros de $5 \times 6 \mathrm{~cm}, 5$ vigas de $6 \times 12 \mathrm{~cm}$ e 5 vigas de $6 \times 16 \mathrm{~cm}$ 
- Lote 8V - 12 vigas de 6 x $12 \mathrm{~cm}$

Foram amostrados cerca de $2 \mathrm{~m}^{3}$ de madeira, num de 156 peças de aproximadamente $1,80 \mathrm{~m}$ de comprimento. A Figura 3 representa algumas peças de madeira serrada bruta amostradas.

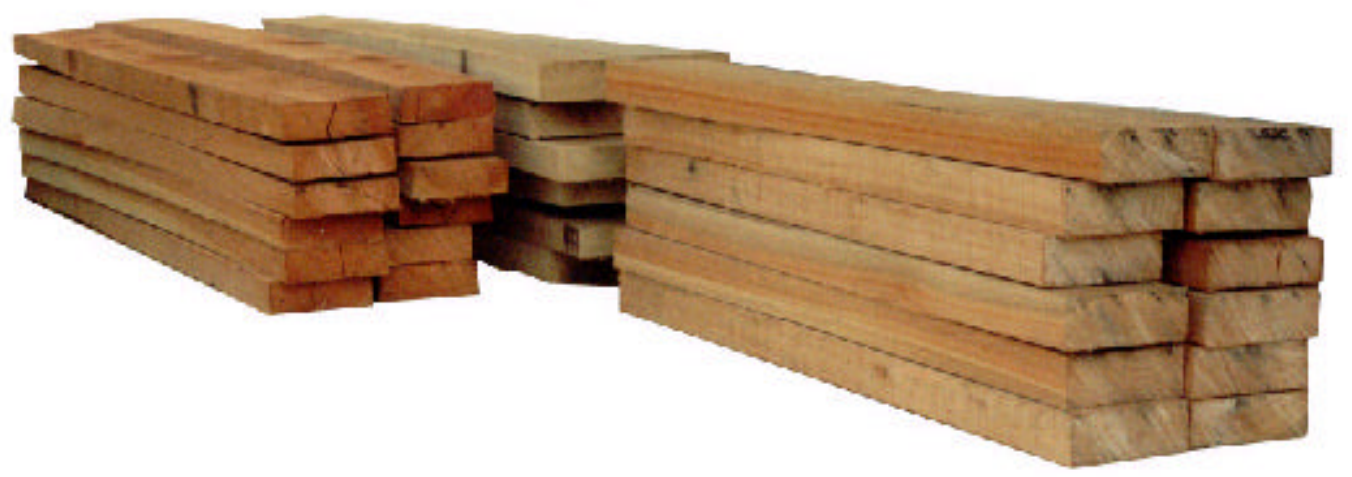

Figura 3 - Vigas de eucalipto amostradas para realização de ensaios físicos e mecânicos.

\subsection{Corpos de prova para ensaios}

Os corpos de prova foram retirados de regiões afastadas das extremidades das peças, de pelo menos 5 vezes a menor dimensão da seção transversal da peça considerada, mas nunca inferior a $30 \mathrm{~cm}$ de acordo com a NBR 7190/97 (Figura 4). 


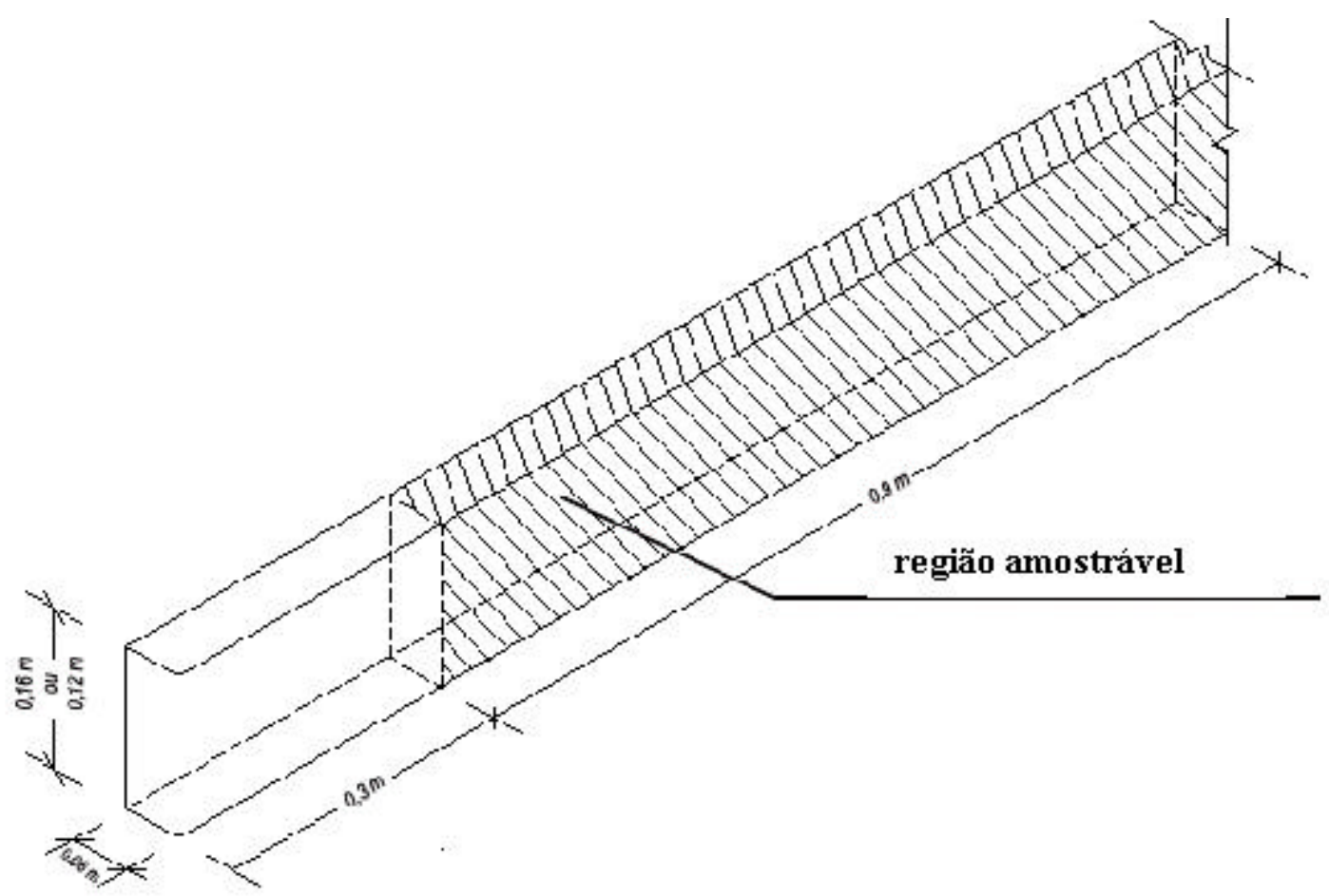

Figura 4 - Porção eliminada da extremidade de cada viga e a parte utilizada para confecção de corpos de prova.

Após a retirada das extremidades, operação realizada na serraria onde foi realizada a coleta do material, as vigas foram serradas para separar uma peça de aproximadamente $60 \mathrm{~cm}$ para posterior retirada dos corpos de prova para os ensaios com madeira saturada, conforme ilustra a Figura 5. Para tanto as peças de $60 \mathrm{~cm}$ foram encaminhadas ao IPT e armazenadas em água para completa saturação.

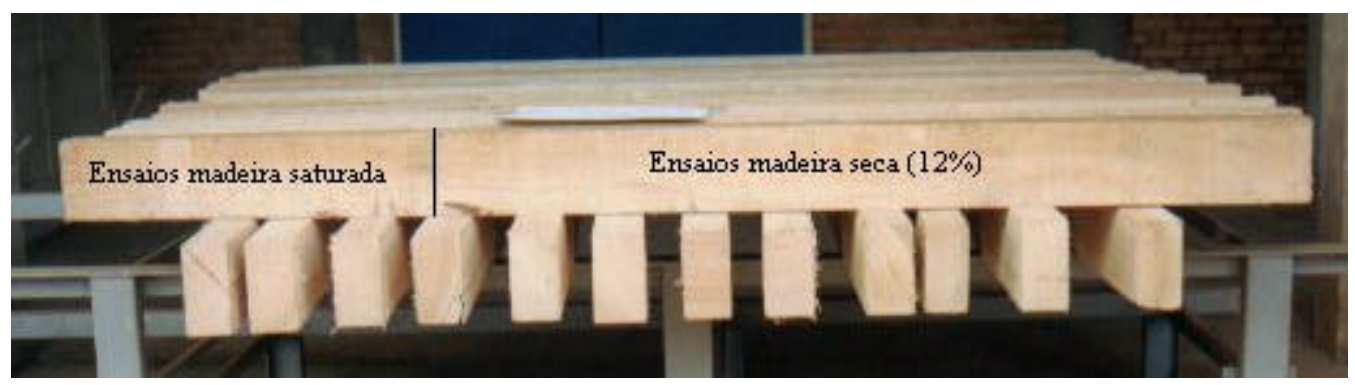

Figura 5 - Vigas identificadas para extração dos corpos de prova para ensaios com madeira saturada e madeira seca. 
As partes restantes das vigas com aproximadamente $1,20 \mathrm{~m}$ foram empilhadas para secagem ao ar, com os devidos cuidados para não afetar a qualidade dessas peças. A confecção dos corpos de prova foi realizada na marcenaria do Instituto de Pesquisas Tecnológicas (IPT - São Paulo) e na marcenaria da Faculdade de Ciências Agronômicas (FCA - UNESP - Botucatu).

\subsection{Propriedades estudadas}

A caracterização dos lotes de madeira serrada foi feita por meio da determinação das variáveis, em ensaios realizados de acordo com o anexo B da NBR 7190/97, descritas a seguir:

a) densidade básica (Db ou $\rho_{\text {bas }}$ ) e densidade aparente (Dap ou $\rho_{\text {ap }}$ ) a $12 \%$ de umidade;

b) resistência àflexão $\left(f_{M}\right)$ a $12 \%$ de umidade;

c) módulo de elasticidade na flexão $\left(\mathrm{E}_{\mathrm{M}}\right)$ a $12 \%$ de umidade;

d) resistência à compressão paralela às fibras $\left(\mathrm{f}_{\mathrm{c} 0}\right)$ a $12 \%$ de umidade;

e) módulo de elasticidade na compressão paralela às fibras $\left(\mathrm{E}_{\mathrm{c} 0}\right)$ a $12 \%$ de umidade

f) resistência ao cisalhamento paralelo às fibras $\left(\mathrm{f}_{\mathrm{v}}\right) \mathrm{a} 12 \%$ de umidade.

Também foram realizados ensaios baseados na metodologia da antiga norma NBR 6230, e ensaios complementares como:

a) compressão paralela simples com madeira verde $(\mathrm{U}>35 \%)$ e madeira seca ao ar $(\mathrm{U}=12 \%)$;

b) compressão paralela às fibras e módulo de elasticidade com madeira verde (U>35\%);

c) cisalhamento com madeira verde com aplicação de carga nos planos longitudinaltangencial e longitudinal-radial. 
Os ensaios de compressão, cisalhamento e flexão de acordo com a NBR 7190/97 foram realizados no Laboratório de Resistência de Materiais da Faculdade de Ciências Agronômicas de Botucatu (FCA - UNESP) e aqueles de acordo com a NBR 6230 foram realizados no Laboratório de Propriedades Físicas e Mecânicas da Madeira do Instituto de Pesquisas Tecnológicas (IPT).

\subsubsection{Densidades}

A densidade básica é uma massa específica convencional definida pela razão entre a massa completamente seca de uma amostra e o seu volume verde, como mostra a eq. (4):

$$
\rho_{b a s}=\frac{m_{s}}{V_{v e r d e}}
$$

onde:

$\mathrm{m}_{\mathrm{s}}=$ massa da madeira completamente seca, em $\mathrm{g}$;

$\mathrm{V}_{\text {verde }}=$ volume da madeira saturado de água, $\mathrm{em}^{\mathrm{cm}}$.

O volume verde ou volume saturado foi determinado pelo método hidrostático onde o empuxo é dado pelo volume do fluído (água) deslocado quando da imersão do corpo de prova e também, diretamente pelo produto das dimensões dos corpos de prova medidas com paquímetro. Os resultados foram comparados para detectarem-se possíveis diferenças entre os métodos. A massa seca foi determinada por pesagem, após a secagem da madeira, em estufa.

A densidade aparente, $\rho_{\text {ap }}$ ou Dap, é convencionalmente, definida pela razão entre a massa e o volume do corpo de prova medidos na mesma condição de umidade, dada pela eq. (5). O teor de umidade estabelecido pela NBR 7190/97 é de $12 \%$. 


$$
\rho_{a p}=\frac{m_{12}}{V_{12}}
$$

onde:

$\mathrm{m}_{12}=$ massa da madeira a $12 \%$ de umidade, em $\mathrm{g}$;

$\mathrm{V}_{12}=$ volume da madeira a $12 \%$ de umidade, $\mathrm{em}^{3}$.

Os corpos de prova, tanto para determinação da densidade básica quanto da densidade aparente foram confeccionados na forma prismática de seção transversal retangular de 2,0 cm x 3,0 cm e comprimento, ao longo das fibras, de 5,0 cm.

\subsubsection{Resistência e módulo de elasticidade na flexão estática}

A resistência da madeira à flexão $\left(\mathrm{f}_{\mathrm{M}}\right)$ é um valor convencional, dado pela máxima tensão que pode atuar em um corpo de prova no ensaio de flexão simples, calculado pela eq. (6):

$$
\mathrm{f}_{\mathrm{M}}=\frac{\mathrm{M}_{\max }}{\mathrm{W}_{\mathrm{e}}}
$$

onde:

$$
\mathrm{M}_{\max }=\text { máximo momento aplicado ao corpo-de-prova, em Nm; }
$$

$\mathrm{W}_{\mathrm{e}}=$ módulo de resistência elástico da seção transversal do corpo de prova, dado por $\mathrm{bh}^{2} / 6$;

$\mathrm{b}, \mathrm{h}=$ lados da seção transversal do corpo de prova sendo $\mathrm{h}$ paralelo à direção da carga aplicada. 
A rigidez da madeira à flexão é caracterizada pelo módulo de elasticidade determinado no trecho linear do diagrama carga x deslocamento, indicado na Figura 6.

O módulo de elasticidade foi determinado pela eq. (7) onde o trecho entre parênteses representa a inclinação da reta secante à curva carga $\mathrm{x}$ deslocamento no meio do vão, definida pelos pontos $\left(\mathrm{F}_{10 \%} ; \mathrm{v}_{10 \%}\right)$ e $\left(\mathrm{F}_{50 \%} ; \mathrm{v}_{50 \%}\right)$ correspondentes respectivamente a $10 \%$ e $50 \%$ da carga máxima de ensaio, estimada por meio de um corpo de prova gêmeo.

$$
\mathrm{E}_{\mathrm{M}}=\frac{\left(\mathrm{F}_{\mathrm{M}, 50 \%}-\mathrm{F}_{\mathrm{M}, 10 \%}\right) \mathrm{L}^{3}}{\left(\mathrm{v}_{50 \%}-\mathrm{v}_{10 \%}\right) 4 \mathrm{bh}^{3}}
$$

onde:

$\mathrm{F}_{\mathrm{M}, 10 \%}$ e $\mathrm{F}_{\mathrm{M}, 50 \%}=$ cargas correspondentes a $10 \%$ e $50 \%$ da carga máxima estimada, aplicadas ao corpo de prova, em $\mathrm{N}$;

$\mathrm{V}_{10 \%} \mathrm{e} \mathrm{V}_{50 \%}=$ deslocamentos medidos no meio do vão, correspondentes às cargas $\mathrm{F}_{\mathrm{M}, 10 \%}$ e $\mathrm{F}_{\mathrm{M}, 50 \%} \mathrm{em} \mathrm{m}$;

b e $\mathrm{h}=$ medida dos lados da seção transversal do corpo-de-prova, sendo $\mathbf{h}$ medido na direção da carga aplicada, em $\mathrm{m}$.

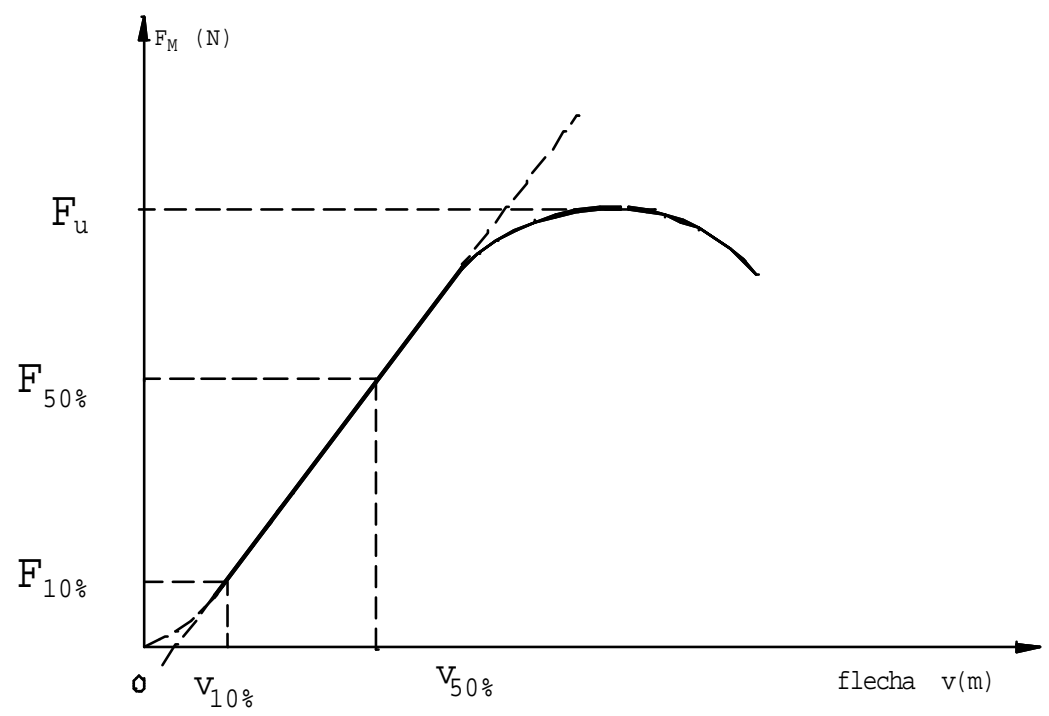

Figura 6 - Diagrama carga $\left(\mathrm{F}_{\mathrm{M}}\right) \mathrm{x}$ deslocamento (flecha), na flexão.

Fonte: NBR 7190/97 
Os corpos de prova tinham forma prismática, com seção transversal quadrada de $5,0 \mathrm{~cm}$ de lado e comprimento, na direção paralela às fibras, de $115 \mathrm{~cm}$, como mostra a Figura 7, apresentada de preferência, a direção tangencial aos anéis de crescimento, para orientar o plano de aplicação de cargas. A Figura 8 mostra o ensaio de flexão sendo executado numa máquina universal.
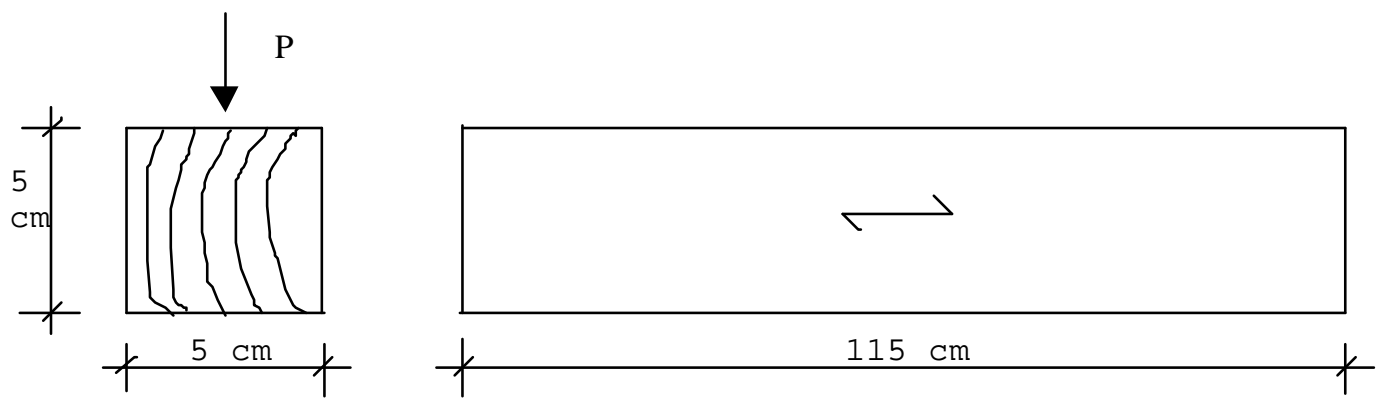

Figura 7 - Corpo de prova para o ensaio de flexão estática.

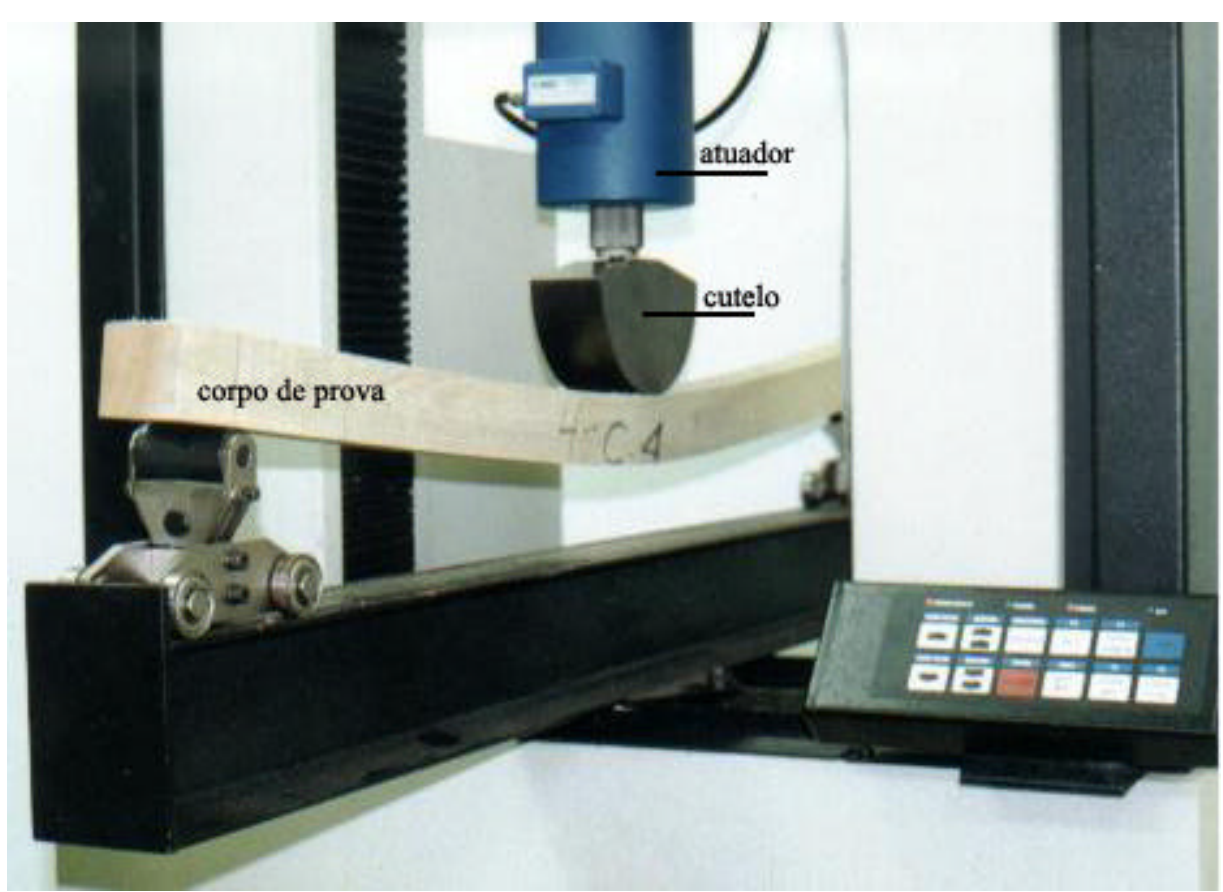

Figura 8 - Ensaio de flexão. 
Os ensaios foram realizados no Laboratório de Resistência dos Materiais da Faculdade de Ciências Agronômicas de Botucatu (FCA - UNESP), numa máquina universal de ensaios, automatizada, que através de um programa apresentava os resultados na forma de um relatório que continha os valores observados e o respectivo gráfico de tensão x deslocamento.

\section{Procedimentos:}

1 - para a determinação da resistência convencional e do módulo de elasticidade na flexão, as medidas dos lados do corpo de prova foram feitas com precisão de $0,1 \mathrm{~mm}$

2 - no ensaio, o corpo de prova foi simplesmente apoiado em cutelos articulados, com vão livre entre apoios de $21 \mathrm{~h}$, sendo o equilíbrio horizontal do sistema garantido pelo atrito da madeira com o cutelo;

3 - para a determinação da rigidez, a resistência foi estimada $\left(\mathrm{f}_{\mathrm{M} \text {,est }}\right)$ pelo ensaio destrutivo de um corpo-de-prova, selecionado da mesma amostra investigada;

4 - o carregamento consistiu em uma carga concentrada aplicada por meio de um cutelo acoplado ao atuador, com uma taxa de carregamento de $10 \mathrm{MPa}$ por minuto;

5 - a partir da resistência estimada da amostra, o carregamento foi aplicado com um ciclo de carga e descarga, para diminuir o tempo de ensaio. A Figura 9 mostra o diagrama de carregamento sendo que a linha contínua representa o procedimento utilizado e a linha pontilhada representa o procedimento da NBR 7190/97; 


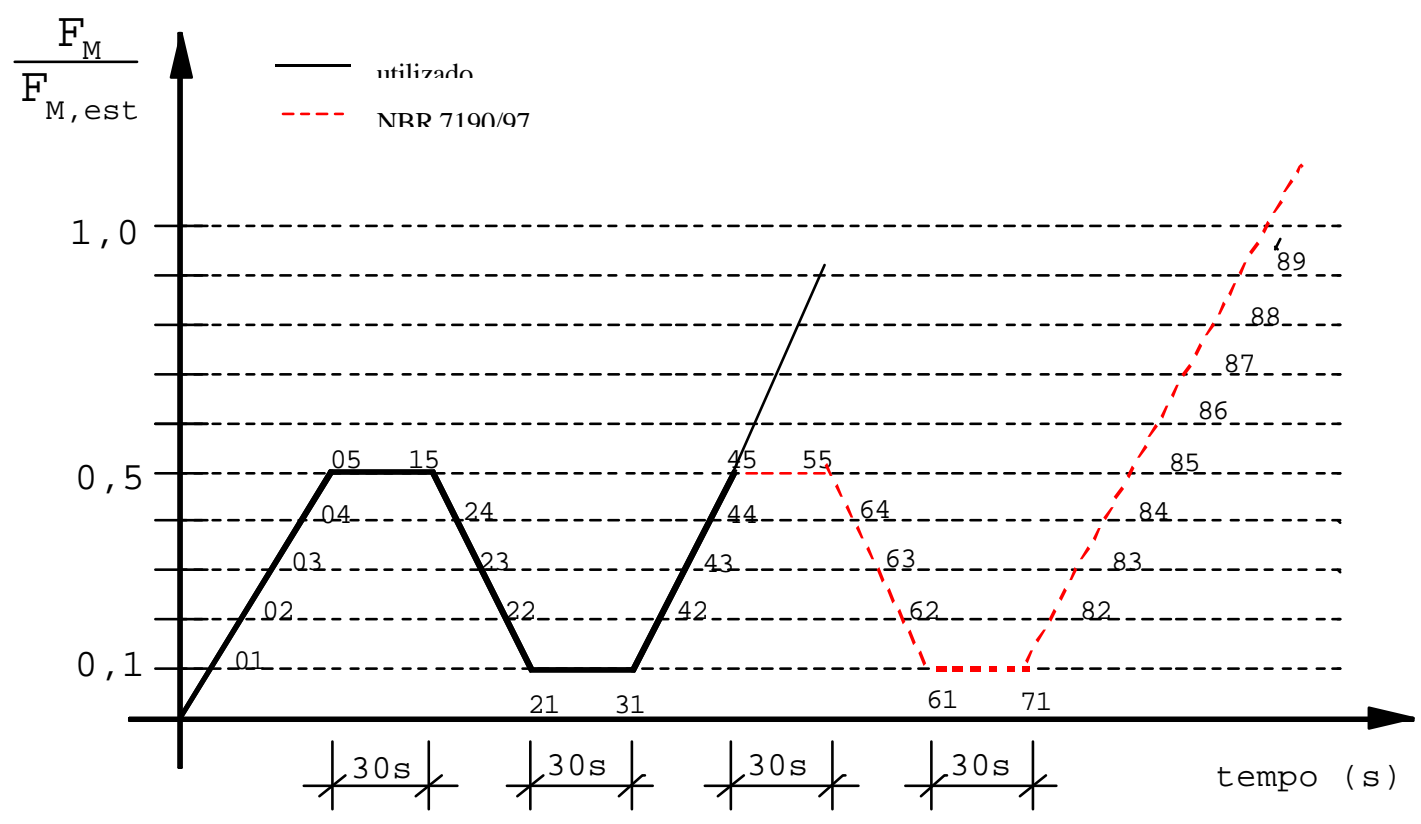

Figura 9 - Diagrama de carregamento para determinação da rigidez àflexão.

6 - as medidas dos deslocamentos verticais no meio do vão foram feitas para todos os pontos do diagrama de carregamento especificado na Figura 9, sendo a mensuração realizada automaticamente pela máquina de ensaio com precisão de $0,01 \mathrm{~mm}$.

\subsubsection{Resistência e módulo de elasticidade na compressão paralela às fibras segundo a NBR 7190/97}

A resistência à compressão paralela às fibras $\left(\mathrm{f}_{\mathrm{c} 0}\right)$ é dada pela máxima tensão de compressão que pode atuar em um corpo-de-prova com seção transversal quadrada de 5,0 cm de lado e 15,0 cm de comprimento, sendo dada pela eq. (8):

$$
f_{c 0}=\frac{f_{c 0, \max }}{A}
$$

onde:

$\mathrm{f}_{\mathrm{c} 0}=$ resistência à compressão paralela às fibras, em MPa . 
$\mathrm{f}_{\mathrm{c} 0 \text {, max }}=$ máxima força de compressão aplicada ao corpo-de-prova durante o ensaio, em $\mathrm{N}$;

$\mathrm{A}=$ área da seção transversal comprimida, em metro quadrado $\left(\mathrm{m}^{2}\right)$;

A rigidez da madeira na direção paralela às fibras é determinada pelo seu módulo de elasticidade na compressão, obtido do trecho linear do diagrama tensão deformação específica, indicado na Figura 10, sendo expresso em MPa.

O módulo de elasticidade foi determinado pela inclinação da reta secante à curva tensão deformação, definida pelos pontos $\left(\sigma_{10 \%} ; \varepsilon_{10 \%}\right)$ e $\left(\sigma_{50 \%} ; \varepsilon_{50 \%}\right)$, correspondentes, respectivamente, a $10 \%$ e $50 \%$ da resistência à compressão paralela às fibras medida no ensaio, sendo dado pela eq. (9):

$$
\mathrm{E}_{\mathrm{c} 0}=\frac{\sigma_{50 \%}-\sigma_{10 \%}}{\varepsilon_{50 \%}-\varepsilon_{10 \%}}
$$

onde:

$\sigma_{10 \% \text { e }} \sigma_{50 \%}=$ tensões de compressão correspondentes a $10 \%$ e $50 \%$ da resistência $\mathrm{f}_{\mathrm{c} 0}$,

$\varepsilon_{10 \%}$ e $\varepsilon_{50 \%}=$ deformações específicas medidas no corpo-de-prova, correspondentes às tensões de $\sigma_{10 \%}$ e $\sigma_{50 \%}$. 


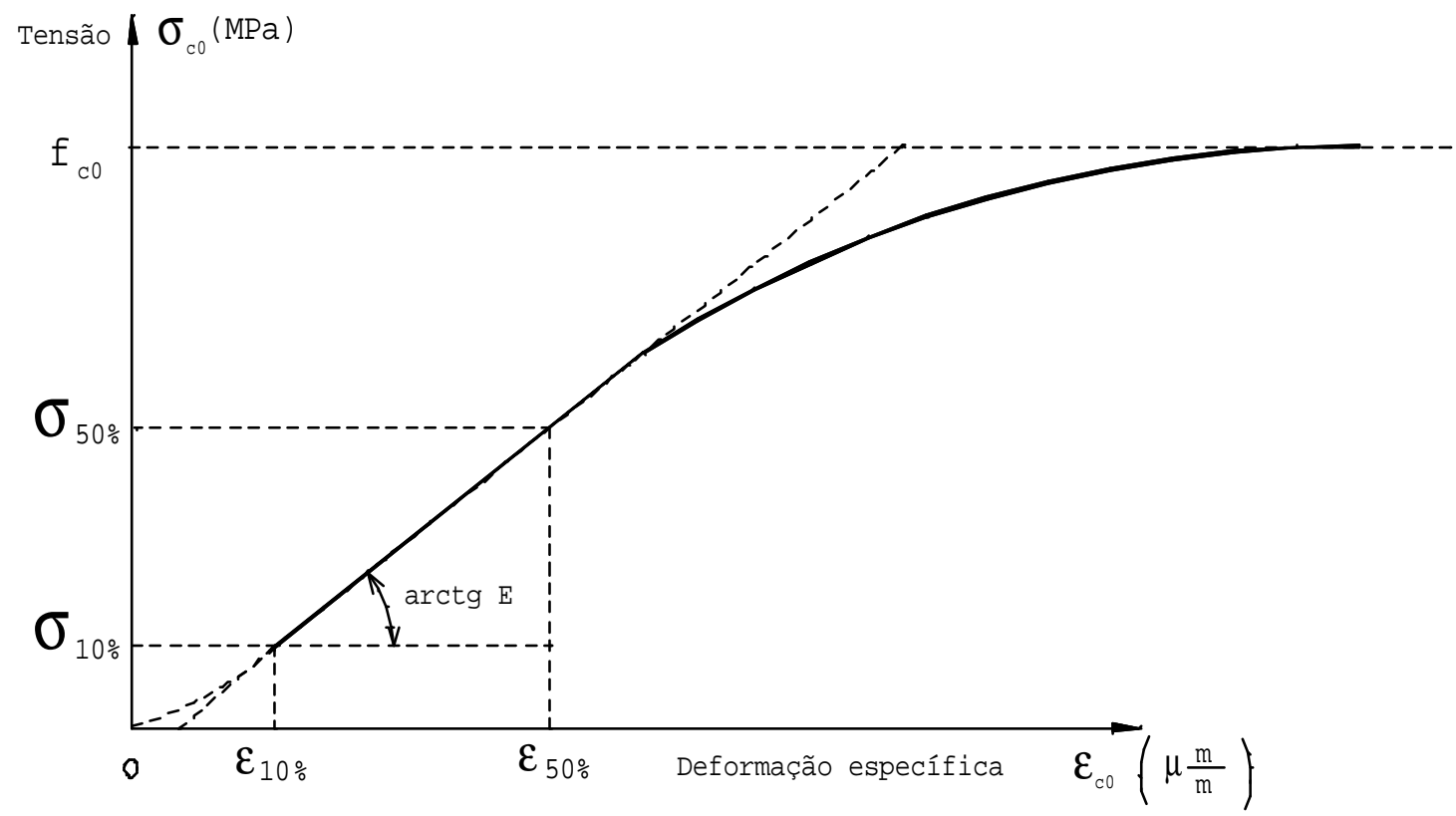

Figura 10 - Diagrama tensão ( $\left.0_{\mathrm{c} 0}\right)$ - deformação específica (å.) para determinação do módulo de elsaticidade na compressão paralela às fibras.

Fonte: NBR 7190/97

Os corpos de prova tinham forma prismática com seção transversal quadrada de $5,0 \mathrm{~cm}$ de lado e comprimento de $15 \mathrm{~cm}$, como representado na Figura 11, para os ensaios realizados segundo a NBR 7190/97, na condição de umidade de $12 \%$ e seção transversal quadrada de $6,0 \mathrm{~cm}$ de lado e comprimento de $20 \mathrm{~cm}$, para os ensaios realizados com madeira verde (U>35\%), de acordo com a NBR 6230.
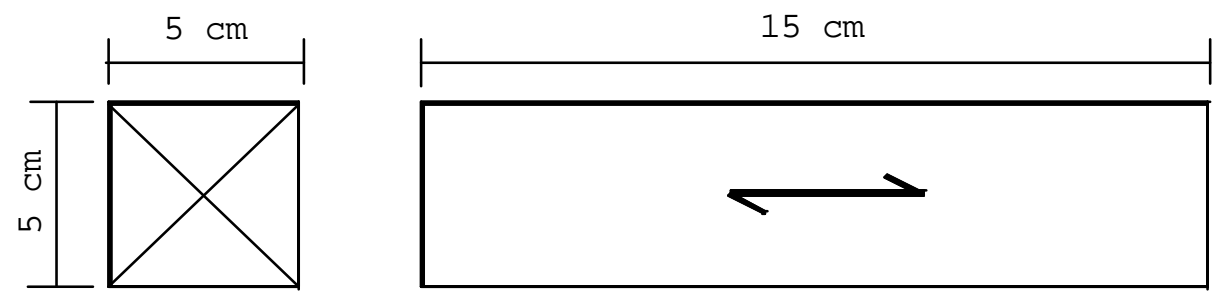

Figura 11 - Corpo-de-prova para o ensaio de compressão paralela às fibras, segundo a NBR 7190/97. 


\section{Procedimentos:}

1 - as medidas dos lados do corpo de prova foram feitas com precisão de $0,1 \mathrm{~mm}$;

2 - as medidas de deformações foram feitas nas duas faces opostas do corpo de prova;

3 - para determinação do módulo de elasticidade (NBR 7190/97) foi utilizado o clipgage, com precisão de 0,001mm, fixado por meio de duas pontas metálicas que se prendem no corpo de prova, com distância nominal de $10 \mathrm{~cm}$ entre as duas linhas de fixação. Para os ensaios com madeira saturada (NBR 6230) foram utilizados relógios comparadores (Figura 12);

4 - foi utilizada uma rótula entre o atuador e o corpo de prova para o ajuste do corpo de prova na máquina de ensaio;

5 - a resistência foi determinada com carregamento monotônico crescente a uma taxa próximo de $10 \mathrm{MPa}$ por minuto;

6 - para determinação do módulo de elasticidade na compressão paralela, a resistência da madeira foi estimada $\left(\mathrm{f}_{\mathrm{c} 0 \text {,est }}\right)$ pelo ensaio destrutivo de um corpo de prova selecionado da mesma amostra investigada;

7 - conhecida a resistência estimada da amostra $\left(\mathrm{f}_{\mathrm{c} 0 \text {,est }}\right)$ o carregamento foi aplicado com um ciclo de carga e descarga para os ensaios, cujo diagrama é idêntico ao ciclo de carregamento do ensaio de flexão (Figura 9);

8 - os registros das cargas e das deformações foram feitos para cada ponto do diagrama de carregamento, utilizando somente o primeiro ciclo de carga e descarga. 

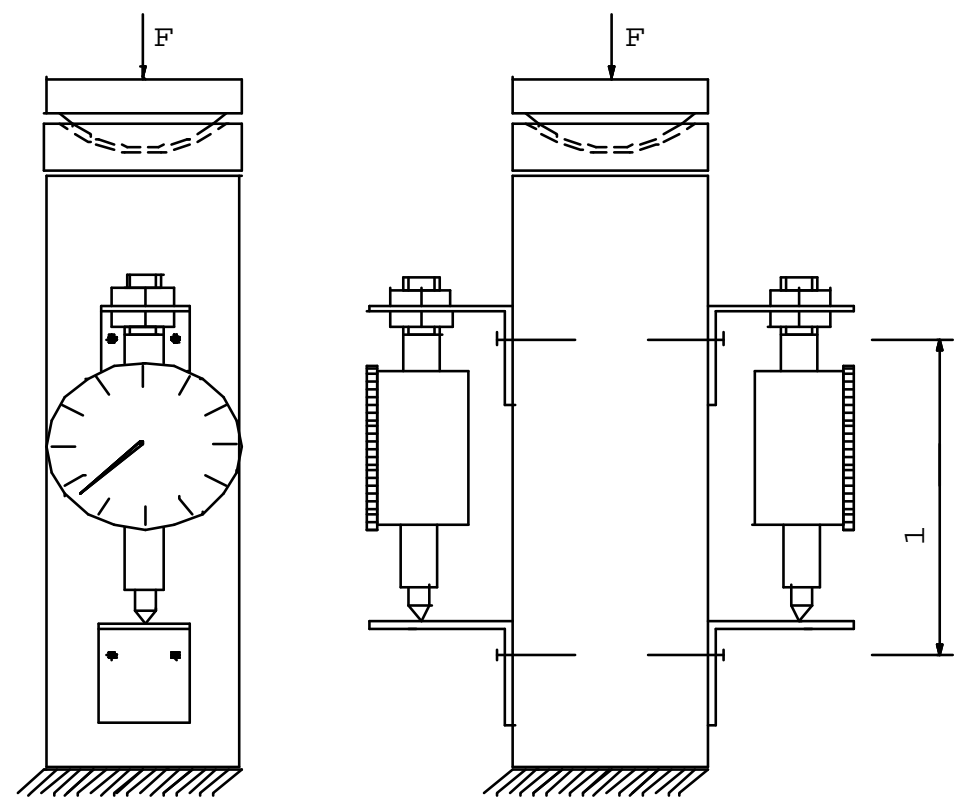

Figura 12 - Corpo de prova instrumentado para o ensaio de compressão paralela às fibras.

Fonte: NBR 7190/97

\subsubsection{Resistência à compressão paralela às fibras - qualificação, segundo a NBR 6230}

Foram realizados ensaios de compressão paralela às fibras segundo a NBR 6230, com madeira verde (U>35\%) e madeira seca ao ar $(\mathrm{U}=12 \%)$ com o intuito de verificar a possível correlação dos seus resultados com os resultados dos ensaios de compressão paralela de acordo com a NBR 7190/97.

\section{Procedimentos:}

1 - as medidas dos lados do corpo de prova foram feitas com precisão de $0,1 \mathrm{~mm}$;

2 - a resistência fi determinada com carregamento crescente a uma taxa em torno de 10 MPa por minuto.

Os corpos de prova tinham forma prismática de seção transversal quadrada de 2,0 $\mathrm{cm}$ de lado e comprimento de $3 \mathrm{~cm}$. Os ensaios foram realizados no IPT (Figura 13). 


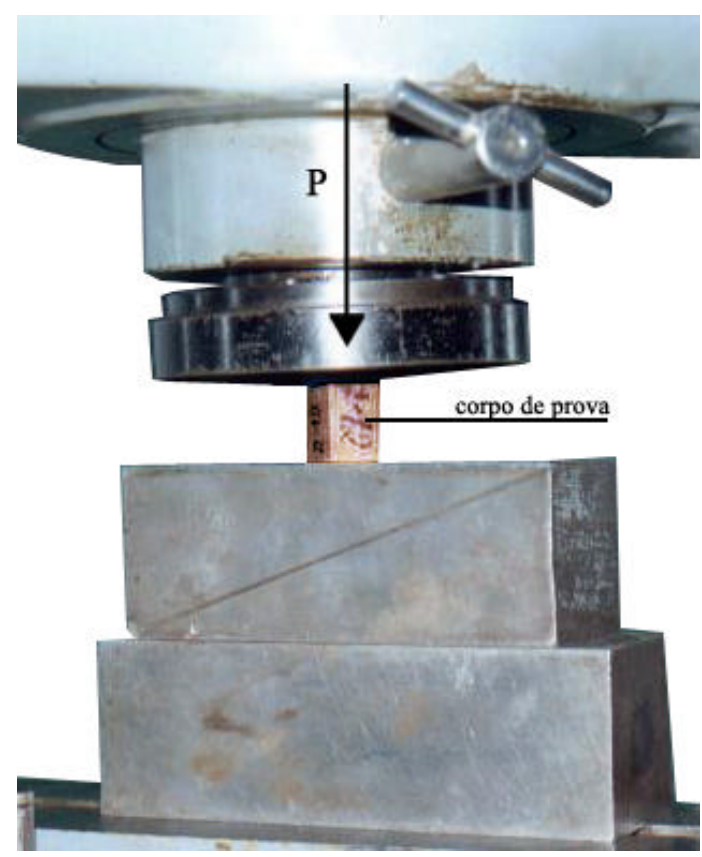

Figura 13 - Ensaio para determinação da resistência à compressão paralela às fibras qualificação, segundo a NBR 6230.

\subsubsection{Resistência ao Cisalhamento}

A resistência ao cisalhamento da madeira $\left(f_{v}\right)$ é dada pela máxima tensão de cisalhamento que pode atuar na seção crítica de um corpo de prova prismático, sendo dada pela eq. (10):

$$
f_{v}=\frac{f_{v 0, \max }}{A_{v 0}}
$$

onde:

$\mathrm{f}_{\mathrm{v} 0, \max }=$ máxima força cisalhante aplicada ao corpo de prova, em N;

$\mathrm{A}_{\mathrm{v} 0}=$ área inicial da seção crítica do corpo de prova, num plano paralelo às fibras, em $\mathrm{m}^{2}$. 
O corpo de prova para o ensaio de cisalhamento tinha a forma indicada na Figura 14, com o plano da seção solicitada ao cisalhamento orientado perpendicularmente aos anéis de crescimento da madeira (normal ao eixo 3), segundo a NBR 7190/97.

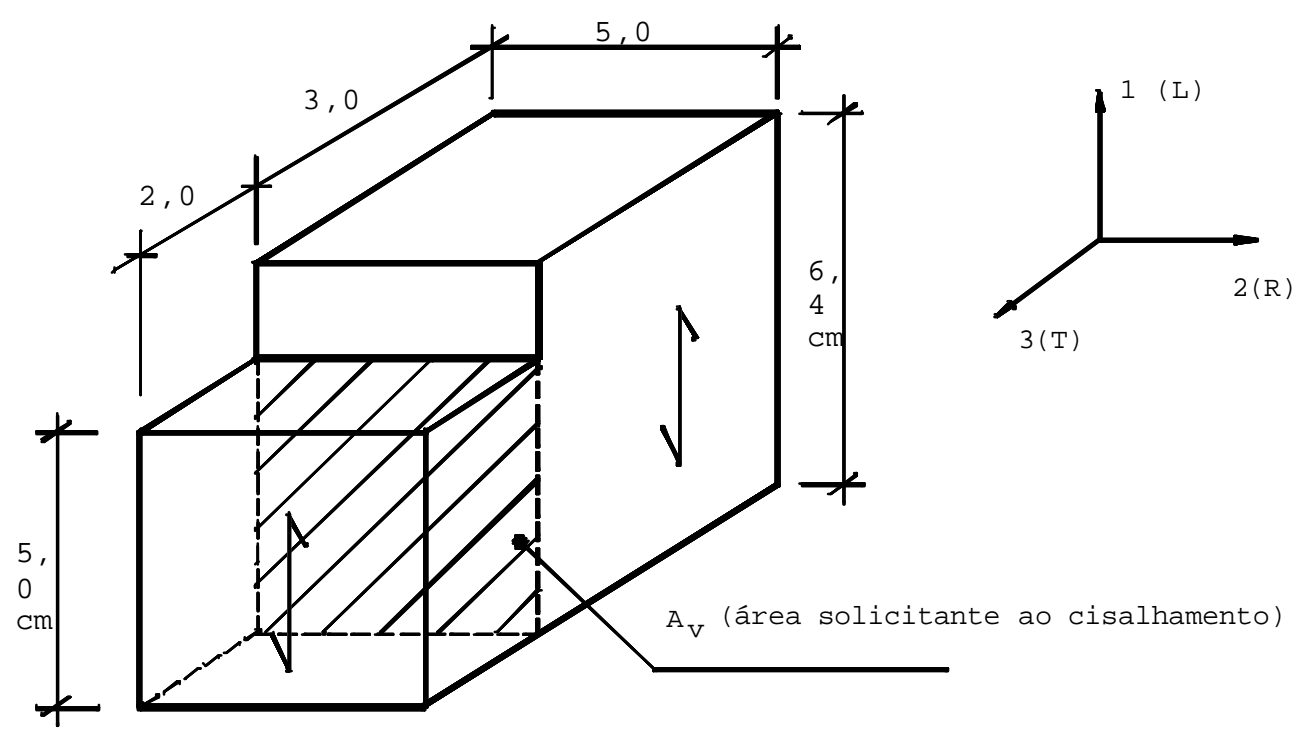

Figura 14 - Corpo de prova para ensaio de cisalhamento na direção paralela às fibras segundo a NBR 7190/97.

Para esta propriedade foram realizados os ensaios segundo a NBR 7190/97 (Figura 15) na condição de umidade de $12 \%$, no Laboratório de Resistência de Materiais da Faculdade de Ciências Agronômicas de Botucatu (FCA - UNESP), e também foram realizados ensaios com madeira verde no Laboratório de Propriedades Físicas e Mecânicas da Madeira do Instituto de Pesquisas Tecnológicas (IPT). Foram utilizados dois métodos de aplicação de carga, no plano longitudinal-tangencial e longitudinalradial, para se verificar a influência do plano de aplicação de carga nesta propriedade.

\section{Procedimentos:}

1 - as medidas da área da seção de cisalhamento dos corpos de prova foram feitas com precisão de 0,1 mm; 
2 - foi utilizado uma rótula entre o atuador e o corpo de prova para o ajuste do corpo de prova na máquina de ensaio;

3 - o carregamento foi monotônico crescente correspondente a uma taxa de 2,5 MPa por minuto;

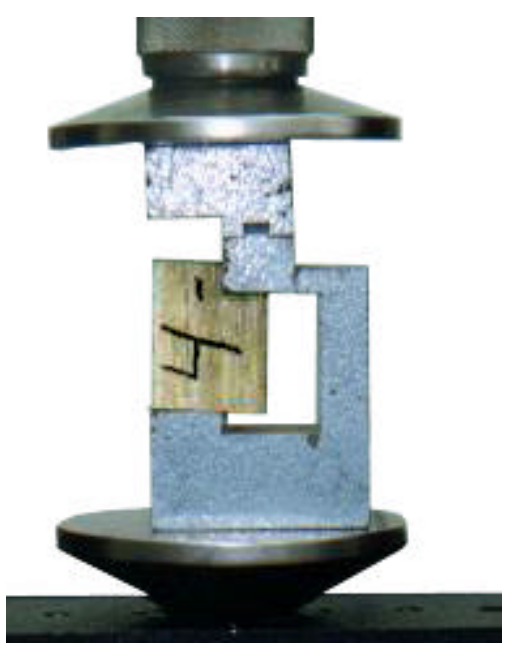

Figura 15 - Arranjo do ensaio de cisalhamento paralelo às fibras segundo a NBR $7190 / 97$.

\subsection{Análise estatística}

Os dados foram obtidos nos ensaios avaliados estatisticamente através de análises descritivas e gráficas. Foram construídos histogramas para representar a distribuição de freqüências, utilizando-se a mesma metodologia do trabalho de Sales (1996). Os dados foram agrupados em intervalos de mesma amplitude, sendo o número de intervalos (k) dado pela eq. (11).

$$
\mathrm{k}=1+3,3 \log \mathrm{n}
$$

onde $\mathrm{n}=$ número total de dados 
Para verificação da validade da distribuição normal para representar os valores das propriedades em estudo, foi aplicado o teste não paramétrico Kolmogorov-Smirnov, no qual obteve-se um valor crítico para cada propriedade, que foi comparado com o valor crítico tabelado (d), dado pela eq. (12), para o nível de confiança desejado, que foi de $95 \%$. Sendo o valor crítico experimental inferior ao tabelado, não se rejeita a hipótese de que a distribuição observada dos dados é a distribuição normal.

$$
d=\frac{1,36}{\sqrt{n}}
$$

onde:

$$
\begin{aligned}
& d=\text { valor crítico tabelado; } \\
& \mathrm{n}=\text { número total de dados }
\end{aligned}
$$

Para a comparação entre lotes foram realizadas análises de variância. Foi aplicado também, o Teste Tukey, na tentativa de organizar os lotes em grupos homogêneos. Foram testadas correlações entre variáveis através de regressões lineares. Todas as análises foram feitas utilizando-se os programas Statistica 5.0 e Excel 7.0. 


\section{RESULTADOS E DISCUSSÃO}

Os resultados são apresentados pelos valores médios e valores característicos, de acordo com a propriedade em questão. O valor característico refere-se ao valor característico inferior, ou seja, menor que o valor médio e representa o valor que tem apenas 5\% de probabilidade de não ser atingido em um dado lote de madeira.

Os valores característicos das propriedades da madeira foram estimados pela eq. (13), conforme a NBR 7190/97:

$$
x_{w k}=\left[2 \frac{x_{1}+x_{2}+\ldots+x_{\frac{n}{2}-1}}{\frac{n}{2}-1}-x_{\frac{n}{2}}\right] 1,1
$$

Os resultados devem ser colocados em ordem crescente $\mathrm{x}_{1} \leq \mathrm{x}_{2} \leq \ldots . \leq \mathrm{x}_{\mathrm{n}}$, desprezando-se o valor mais alto se o número de corpos de prova for ímpar, não se tomando para $\mathrm{x}_{\mathrm{wk}}$ valor inferior a $\mathrm{x}_{1}$, nem superior a 0,7 do valor médio $\left(\mathrm{x}_{\mathrm{m}}\right)$. $\mathrm{O}$ valor característico foi utilizado principalmente na classificação dos lotes em classes de resistência e foi calculado para os valores de compressão paralela às fibras e cisalhamento. 
Para os ensaios realizados com madeira seca ao ar, foi utilizada a fórmula de correção dos valores de resistência e módulos de elasticidade para o teor de umidade padrão de $12 \%$. Para isto foram tirados os valores da umidade da madeira pelo método gravimétrico, e utilizada a eq. (14) conforme a NBR 7190/97:

$$
f_{12}=f_{U \%}\left[1+\frac{3(U \%-12)}{100}\right]
$$

onde:

$\mathrm{f}_{12}=$ resistência corrigida para a umidade padrão $12 \%$;

$U \%=$ umidade da madeira do corpo de prova;

$\mathrm{f}_{\mathrm{U} \%}=$ resistência obtida no ensaio com umidade $\mathrm{U} \%$.

\subsection{Densidades}

Os valores médios de lote e respectivos coeficientes de variação para densidade básica e densidade aparente estão apresentados na Tabela 4 e representados graficamente na Figura 16.

Pela análise de variância realizada para todos os corpos de prova ensaiados, bem como para cada lote individualizado, verificou-se que não houve diferença significativa entre os dois métodos de determinação do volume do corpo de prova para os valores das densidades básica e aparente, ao nível de confiança de 0,01. Os valores obtidos foram ligeiramente inferiores aos obtidos pela imersão em água, para $97 \%$ dos corpos de prova ensaiados.

Portanto, somente os resultados obtidos através da medição por paquímetro foram considerados nas comparações subsequentes, pois este método é indicado na NBR $7190 / 97$.

Os valores médios da densidade básica variaram de $0,540 \mathrm{~g} / \mathrm{cm}^{3}$ a $0,805 \mathrm{~g} / \mathrm{cm}^{3}$, enquanto que a variação da densidade aparente com umidade em torno de $12 \%$ ficou entre $0,671 \mathrm{~g} / \mathrm{cm}^{3}$ e $1,03 \mathrm{~g} / \mathrm{cm}^{3}$, significando amplitudes totais de 0,265 e $0,359 \mathrm{~g} / \mathrm{cm}^{3}$, 
respectivamente. Esta variação está próxima daquela encontrada por Sales (1996), que estudou 7 espécies de eucalipto dentre as dicotiledôneas para proposição de classes de resistência.

Observando a Tabela 3, referente às classes de resistência das dicotiledôneas, conclui-se que a madeira serrada de eucalipto do presente trabalho se enquadra, de acordo com os limites definidos pela NBR 7190/97, em todas as classes de resistências.

Tabela 4. Valores médios e coeficientes de variação para densidade básica (Db) e densidade aparente (Dap 12\%) da madeira de eucalipto.

\begin{tabular}{ccccc}
\hline Lotes & $\begin{array}{c}\text { Db } \\
\left(\mathrm{g} / \mathrm{cm}^{3}\right)\end{array}$ & $\begin{array}{c}\text { C.V. } \\
(\%)\end{array}$ & $\begin{array}{c}\text { Dap (12\%) } \\
\left(\mathrm{g} / \mathrm{cm}^{3}\right)\end{array}$ & $\begin{array}{c}\text { C.V. } \\
(\%)\end{array}$ \\
\hline $1 \mathrm{G}$ & 0,540 & 5,87 & 0,671 & 5,95 \\
$2 \mathrm{H}$ & 0,653 & 12,39 & 0,842 & 12,71 \\
$3 \mathrm{G}$ & 0,561 & 14,00 & 0,702 & 15,68 \\
$3 \mathrm{~S}$ & 0,545 & 16,02 & 0,684 & 17,83 \\
$4 \mathrm{G}$ & 0,596 & 10,09 & 0,763 & 4,56 \\
$4 \mathrm{~S}$ & 0,700 & 13,17 & 0,763 & 11,90 \\
$4 \mathrm{C}$ & 0,736 & 5,56 & 0,897 & 7,15 \\
$5 \mathrm{~B}$ & 0,805 & 5,03 & 0,883 & 5,70 \\
$5 \mathrm{~V}$ & 0,659 & 10,89 & 0,764 & 8,75 \\
$6 \mathrm{~V}$ & 0,721 & 9,78 & 0,905 & 9,42 \\
$7 \mathrm{C}$ & 0,757 & 5,51 & 0,849 & 4,36 \\
$8 \mathrm{~V}$ & 0,801 & 1,80 & 1,030 & 4,34 \\
\hline
\end{tabular}




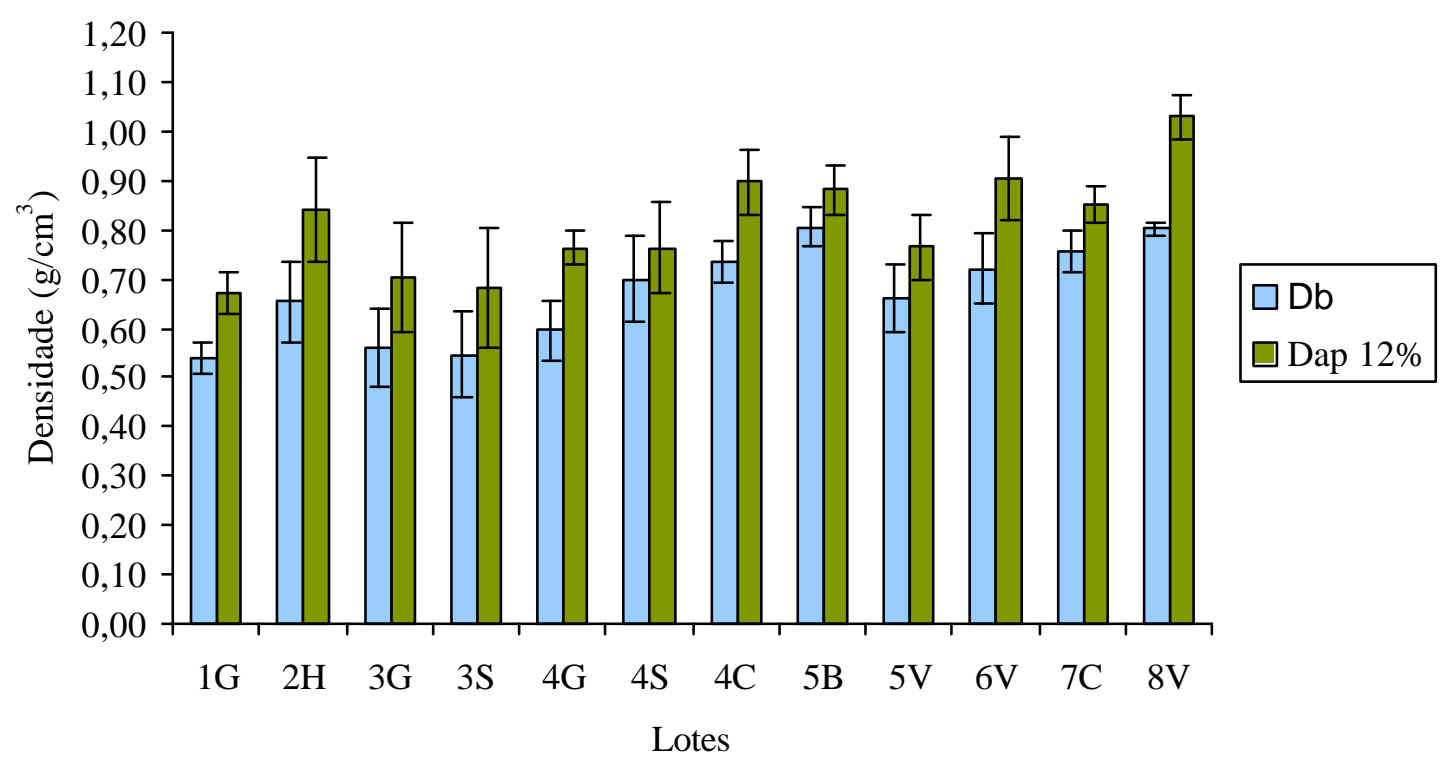

Figura 16 - Densidade básica (Db) e aparente a 12\% de umidade (Dap) de 12 diferentes lotes de madeira de eucalipto.

Verificando as relações entre a densidade aparente a $12 \%$ de umidade e a densidade básica, na tabela do Anexo E da NBR 7190/97, observa-se que esta relação varia de 1,20 a 1,33. Os lotes 4S, 5B e 7C apresentaram relação entre 1,09 e1,12, menor que a variação encontrada tanto para espécies de eucalipto como para espécies nativas. Justamente estes lotes apresentaram as menores médias de umidade saturada dos corpos de prova para densidade básica da madeira.

Este fato deve estar relacionado à determinação do volume saturado do corpo de prova, onde amostras coletadas com baixa umidade não têm capacidade de atingir o volume saturado ou volume verde (total real) o que leva à estimativa de densidades mais altas. Isto pode estar relacionado ao colapso de células, retração da madeira durante o processo de secagem e pela presença de extrativos na madeira. Por este motivo, somando a uma melhor distribuição de frequiências (Figura 20), será utilizada somente a densidade aparente para uma discussão mais detalhada, principalmente na comparação entre as propriedades da madeira. 
A Figura 17 permite observar-se as dispersões dos valores da densidade básica e densidade aparente da madeira para cada lote em estudo. De uma maneira geral os valores obtidos para esta propriedade estão compatíveis com os encontrados na experimentação com eucalipto.
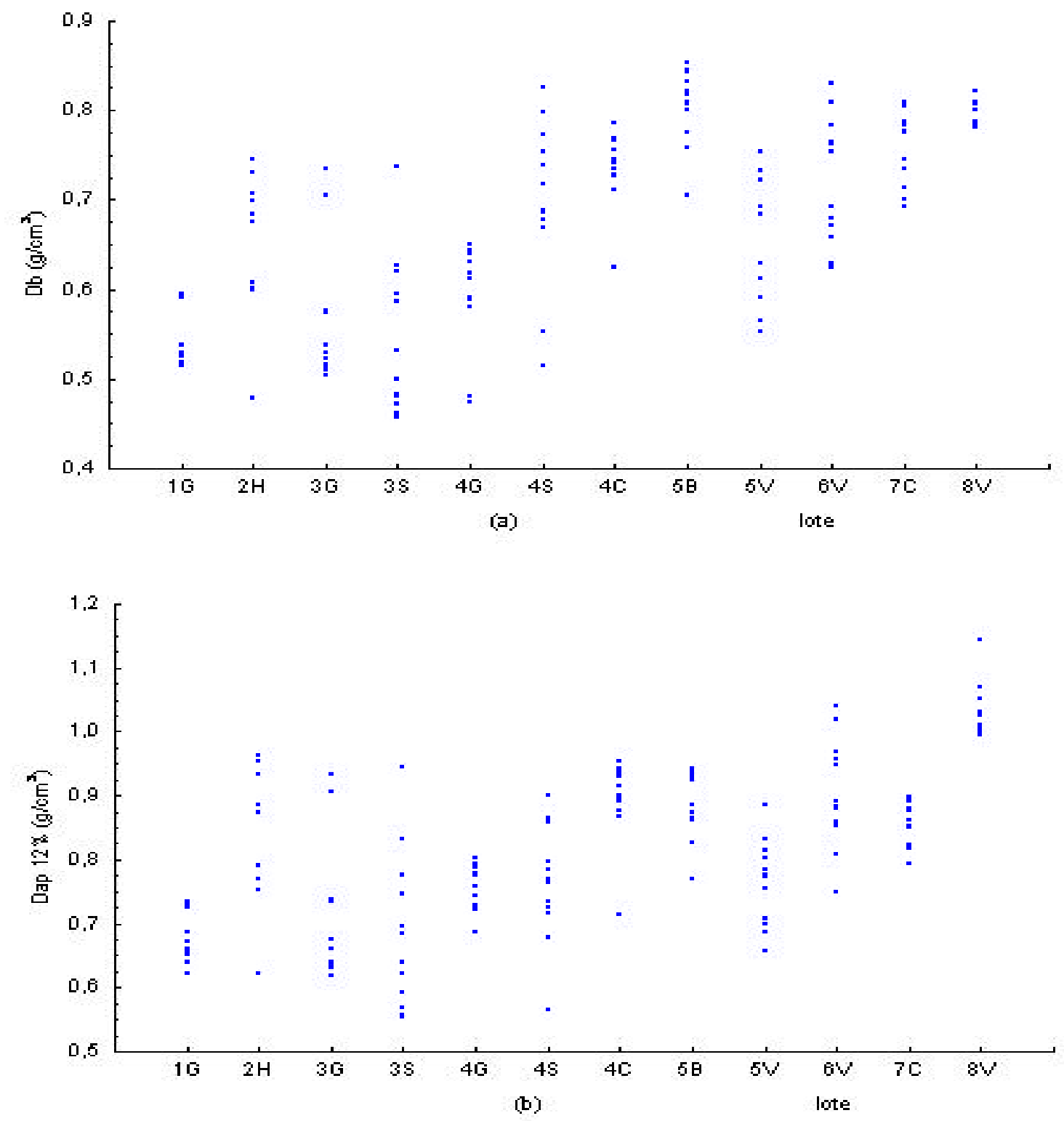

Figura 17 - Densidade básica (Db) (a) e densidade aparente a 12\% de umidade (Dap) (b) de lotes de madeira de eucalipto. 
A Figura 18 apresenta as distribuições de frequiências dos dados de densidades básica e aparente, para 8 classes.
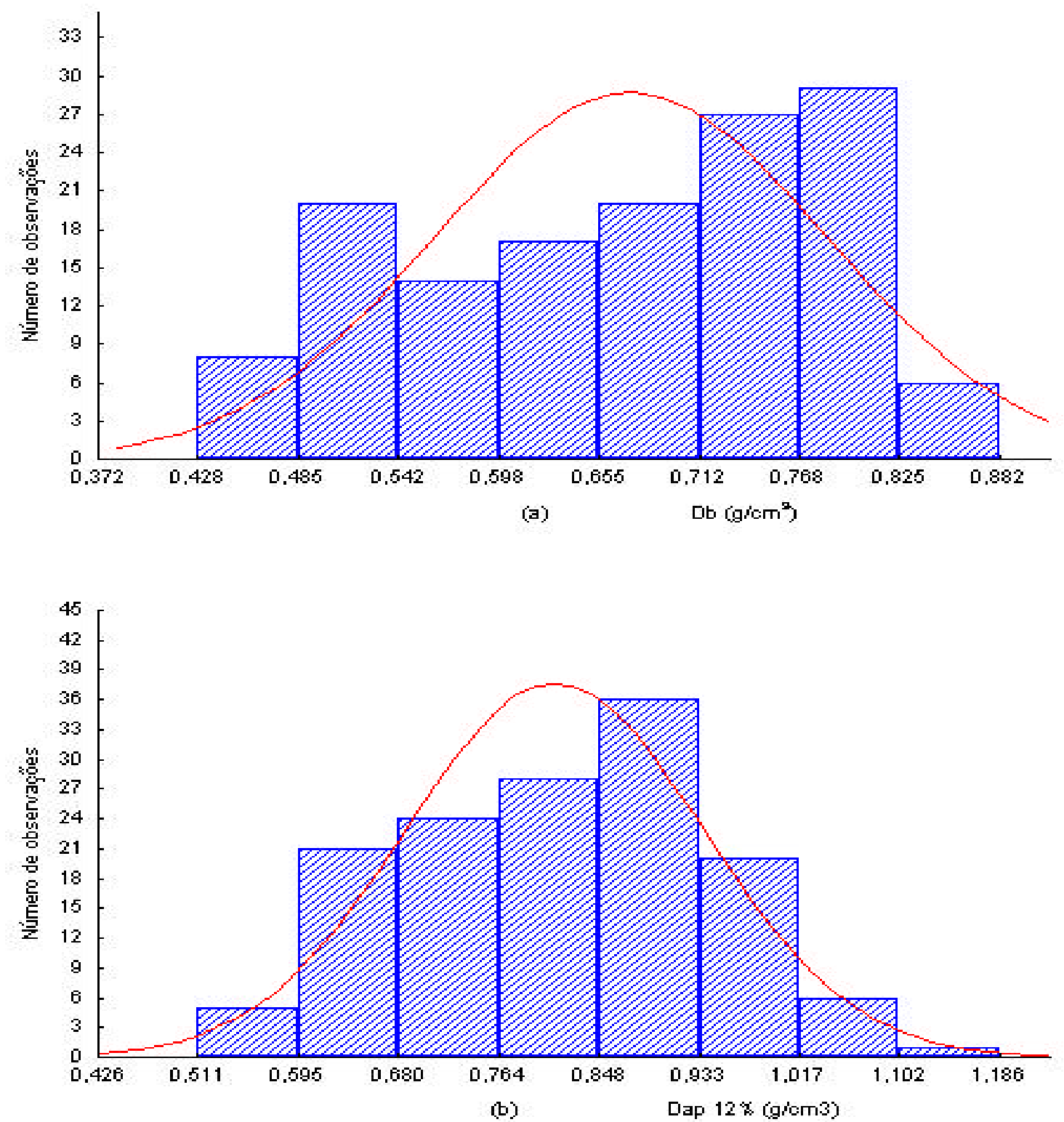

Figura 18 - Distribuição de frequiências dos valores de densidade básica (Db) (a) e densidade aparente à $12 \%$ de umidade (Dap) (b) de lotes de madeira de eucalipto. 
O valor crítico experimental obtido nos testes de Kolmogorov-Smirnov foi de 0,079 para densidade básica e de 0,068 para densidade aparente, enquanto que o valor crítico tabelado é de 0,115 . Como o valor crítico experimental é inferior ao valor crítico tabelado, pode-se admitir a distribuição normal de frequiências como satisfatória para representar os valores obtidos nos ensaios de densidade básica e aparente da madeira, sendo que a curva esperada normal ajusta-se melhor para a densidade aparente.

Pela análise da variância e aplicação do teste Tukey, para um nível de confiança de 0,05, pode-se observar a formação de 4 grupos homogêneos como mostra a Tabela 5.

Tabela 5. Grupos homogêneos, de densidade aparente a $12 \%$ de umidade formados pelo teste de Tukey de lotes de madeira de eucalipto.

\begin{tabular}{|c|c|c|c|c|c|c|}
\hline \multirow{2}{*}{ Lotes } & \multirow{2}{*}{ Dap,m } & \multicolumn{5}{|c|}{ Grupos } \\
\hline & & 1 & 2 & 3 & 4 & Adotado \\
\hline $1 G$ & 0,671 & XXXX & & & & 1 \\
\hline $3 \mathrm{~S}$ & 0,684 & $\mathrm{xxxx}$ & & & & 1 \\
\hline $3 G$ & 0,702 & $\mathrm{xxxx}$ & & & & 1 \\
\hline $4 \mathrm{G}$ & 0,763 & $\mathrm{xxxx}$ & $\mathrm{xxxx}$ & & & 2 \\
\hline $4 \mathrm{~S}$ & 0,763 & $\mathrm{xxxx}$ & Xxxx & & & 2 \\
\hline $5 \mathrm{~V}$ & 0,764 & $\mathrm{xxxx}$ & $\mathrm{xxxx}$ & & & 2 \\
\hline $2 \mathrm{H}$ & 0,842 & & $\mathrm{xxxx}$ & $\operatorname{xxxx}$ & & 2 \\
\hline $7 \mathrm{C}$ & 0,849 & & $\mathrm{xxxx}$ & $\mathrm{xxxx}$ & & 2 \\
\hline $5 B$ & 0,883 & & & $\mathrm{xxxx}$ & & 3 \\
\hline $4 C$ & 0,897 & & & $\operatorname{xxxx}$ & & 3 \\
\hline $6 \mathrm{~V}$ & 0,905 & & & $\mathrm{XxXX}$ & & 3 \\
\hline $8 \mathrm{~V}$ & 1,030 & & & & XXXX & 4 \\
\hline
\end{tabular}

Dap, $\mathrm{m}=$ valor médio da densidade aparente a $12 \%$ de umidade, em $\mathrm{g} / \mathrm{cm}^{3}$.

Observa-se que a classificação de lotes pela densidade aparente a 12\% em grupos homogêneos não é contundente, havendo a necessidade de uma discriminação subjetiva baseada nas médias dos lotes. 


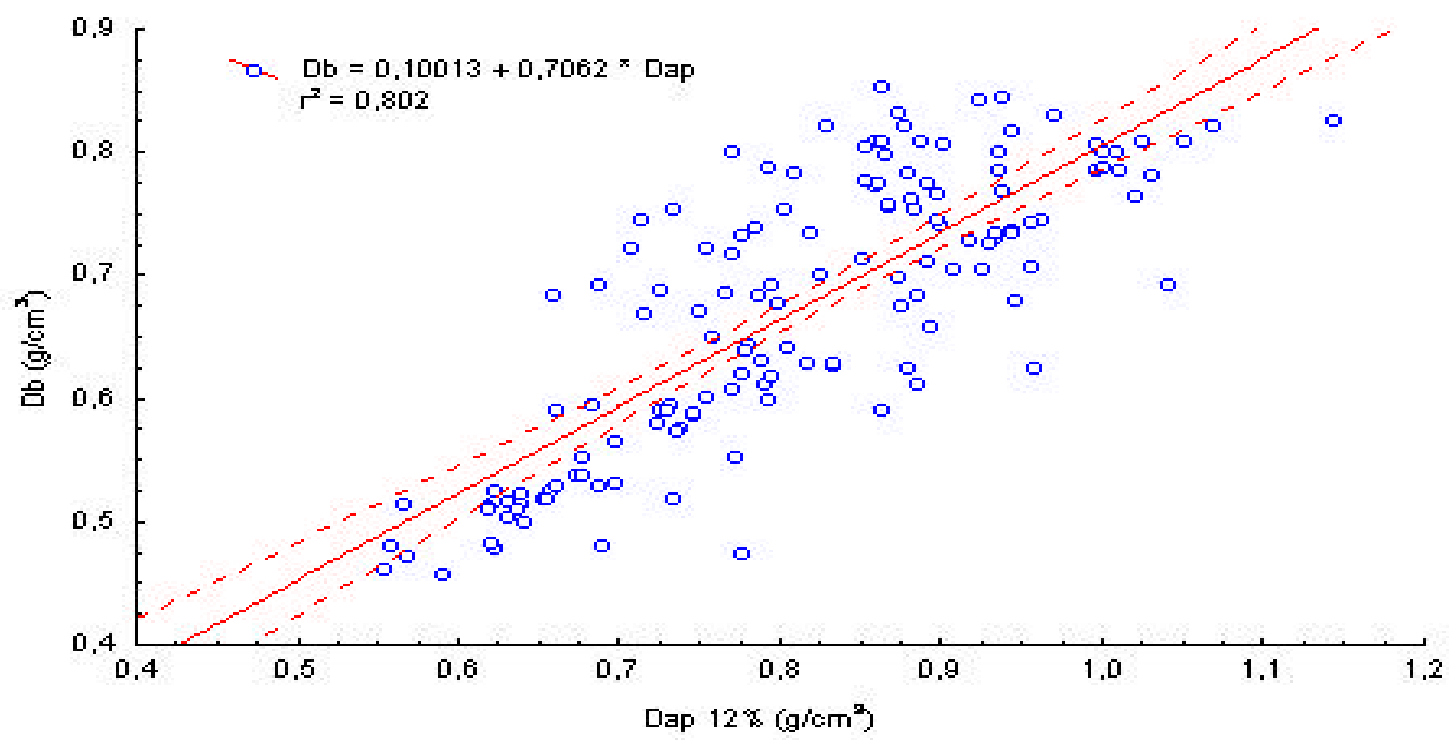

Figura 19 - Correlação linear entre densidade aparente 12\% e densidade básica.

A Figura 19 mostra que existe uma relação linear muito boa $\left(r^{2}=0,802\right)$, encontrada entre os valores médios de densidade básica e a aparente da madeira de eucalipto, visto que foram utilizados corpos de prova gêmeos para determinação destas propriedades. 


\subsection{Flexão estática}

Os valores médios do módulo de ruptura $\left(\mathrm{f}_{\mathrm{M}}\right)$ e do módulo de elasticidade $\left(\mathrm{E}_{\mathrm{M}}\right)$ no ensaio de flexão encontram-se na Tabela 6 e ilustrados na Figura 20.

Tabela 6. Módulos de ruptura médio $\left(\mathrm{f}_{\mathrm{M}, \mathrm{m}}\right)$, característicos $\left(\mathrm{f}_{\mathrm{Mk}}\right)$, de cálculo $\left(\mathrm{f}_{\mathrm{M}, \mathrm{d}}\right) \mathrm{e}$ módulos de elasticidade médio $\left(\mathrm{E}_{\mathrm{M}, \mathrm{m}}\right)$ na flexão da madeira de eucalipto a $12 \%$ de umidade.

\begin{tabular}{ccccccc}
\hline Lotes & $\begin{array}{c}\mathbf{f}_{\mathbf{M}, \mathbf{m}} \\
(\mathrm{MPa})\end{array}$ & $\begin{array}{c}\mathbf{f}_{\mathbf{M k}} \\
(\mathrm{MPa})\end{array}$ & $\begin{array}{c}\mathbf{f}_{\mathbf{M}, \mathbf{d}} \\
(\mathrm{MPa})\end{array}$ & $\begin{array}{c}\text { C.V. } \\
(\%)\end{array}$ & $\begin{array}{c}\mathbf{E}_{\mathbf{M}, \mathbf{m}} \\
(\mathrm{MPa})\end{array}$ & $\begin{array}{c}\text { C.V. } \\
(\%)\end{array}$ \\
\hline 1G & 106,87 & 96,03 & 33,61 & 8,93 & 18642 & 7,97 \\
2H & 148,32 & 122,63 & 42,92 & 12,59 & 25088 & 15,99 \\
3G & 116,20 & 101,77 & 35,62 & 10,27 & 20371 & 8,19 \\
3S & 107,88 & 105,97 & 37,09 & 10,18 & 18127 & 9,74 \\
4G & 141,90 & 140,05 & 49,02 & 6,09 & 20529 & 5,26 \\
4S & 138,09 & 137,98 & 48,29 & 6,81 & 20471 & 7,79 \\
4C & 154,83 & 147,01 & 51,45 & 7,45 & 22830 & 5,12 \\
5B & 150,70 & 136,44 & 47,75 & 9,77 & 21988 & 10,72 \\
5V & 118,53 & 116,42 & 40,75 & 9,07 & 15658 & 6,34 \\
6V & 107,03 & 87,49 & 30,62 & 10,43 & 13796 & 11,59 \\
7C & 143,49 & 124,41 & 43,54 & 11,37 & 20870 & 9,77 \\
8V & 98,55 & 94,10 & 32,94 & 15,42 & 12328 & 16,08 \\
Total & 127,70 & 98,52 & 34,48 & & & \\
\hline
\end{tabular}

Para a resistência à flexão $\left(\mathrm{f}_{\mathrm{M}}\right)$, pode-se observar que a amplitude total para os valores médios foi de 56,28 $\mathrm{MPa}$, sendo que o menor valor médio (98,55 $\mathrm{MPa}$ ) foi observado para o lote $8 \mathrm{~V}$ representado por uma madeira com fibras totalmente reversas, e o maior valor médio(154,83 $\mathrm{MPa}$ ) foi observado para o lote $4 \mathrm{C}$ que representa o Eucalyptus citriodora. Os coeficientes de variação para a resistência ficaram entre $6,09 \%$ e $15,42 \%$ e para rigidez entre $5,12 \%$ e $16,08 \%$, dentro dos padrões encontrado na experimentação com madeira.

Para o módulo de elasticidade na flexão $\left(\mathrm{E}_{\mathrm{M}}\right)$, os valores médios foram superiores aos encontrados na literatura, variando de $12328 \mathrm{MPa}$ (lote 8) a $25088 \mathrm{MPa}$ (lote 2), sendo a amplitude total de $12760 \mathrm{MPa}$. Sales (1996) observou valores variando de 12250 a $18652 \mathrm{MPa}$ para 7 espécies de eucalipto, sendo a amplitude total de 6402 MPa. 

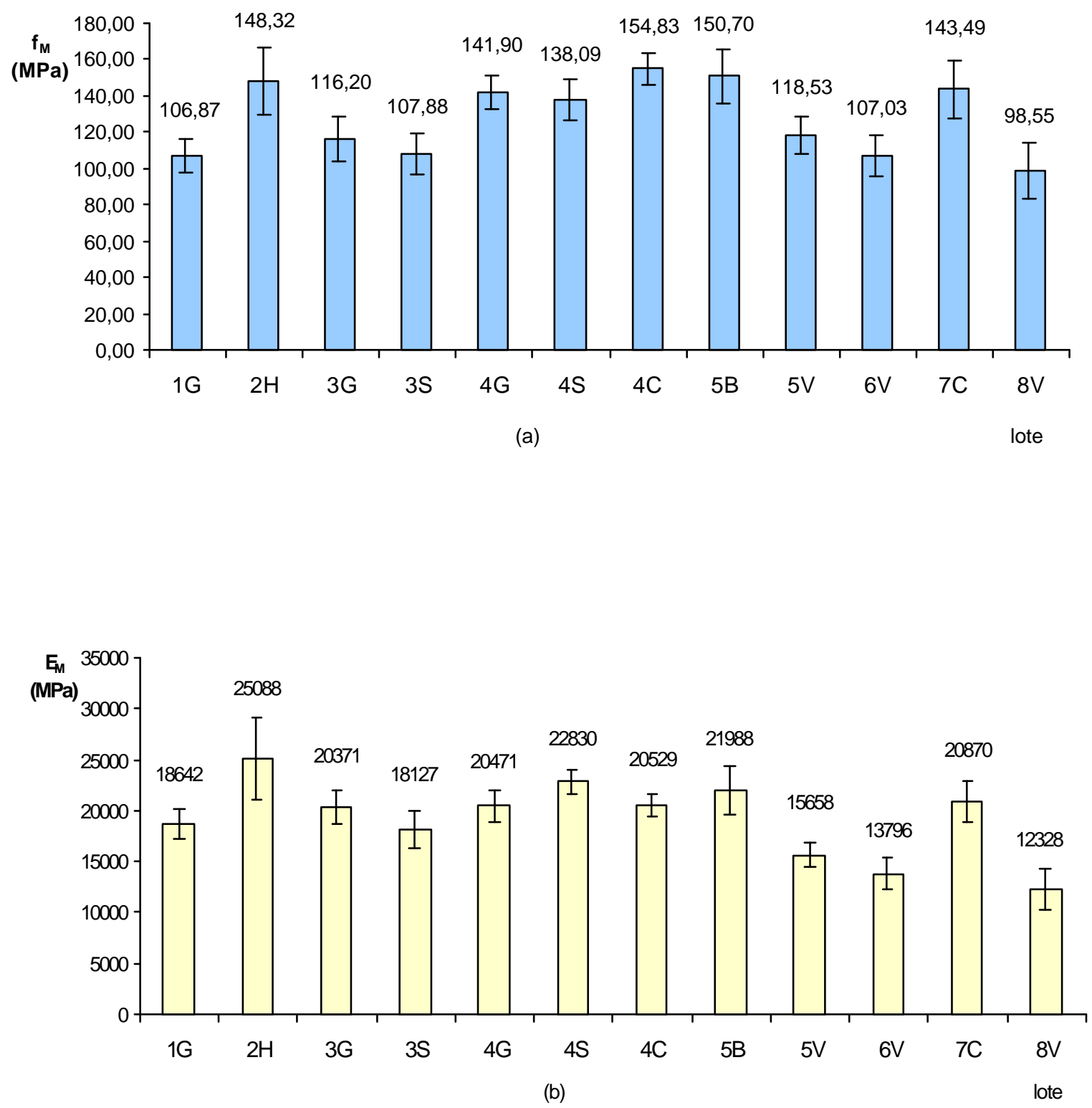

Figura 20 - Resistência ( $\left.f_{M}\right)$ (a) e módulo de elasticidade $\left(E_{M}\right)$ (b) na flexão estática de lotes de madeira de eucalipto. 
A Figura 21 permite verificar as dispersões dos valores da resistência à flexão $\left(f_{M}\right)$ e módulo de elasticidade $\left(E_{M}\right)$ dos lotes de madeira considerados no estudo.
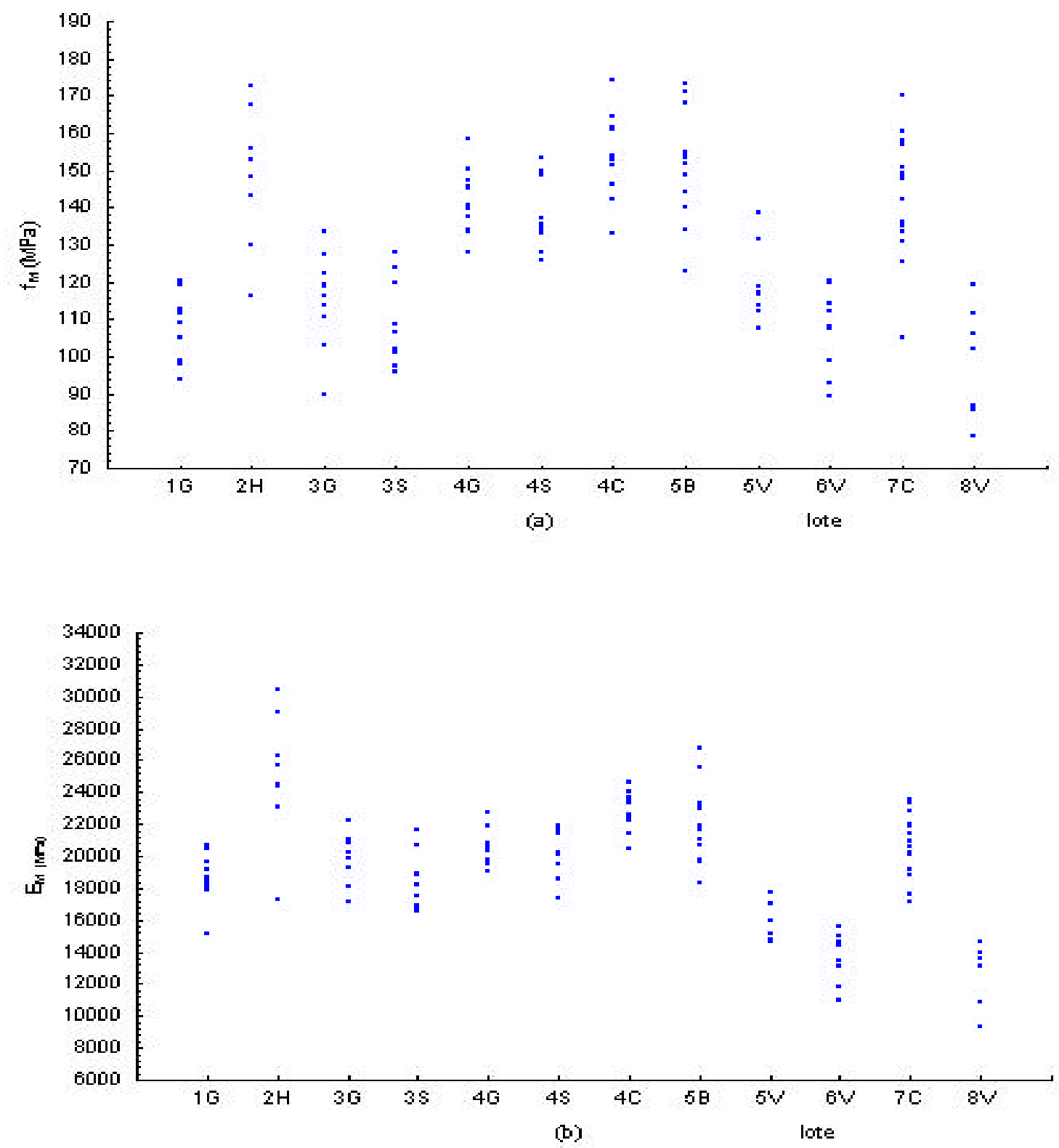

Figura 21 - Valores da resistência $\left(f_{M}\right)$ (a) e do módulo de elasticidade $\left(E_{M}\right)$ (b) na flexão da madeira de eucalipto. 
A Figura 22 apresenta as distribuições de frequiências para a resistência à flexão $\left(\mathrm{f}_{\mathrm{M}}\right)$ e módulo de elasticidade $\left(\mathrm{E}_{\mathrm{M}}\right)$.
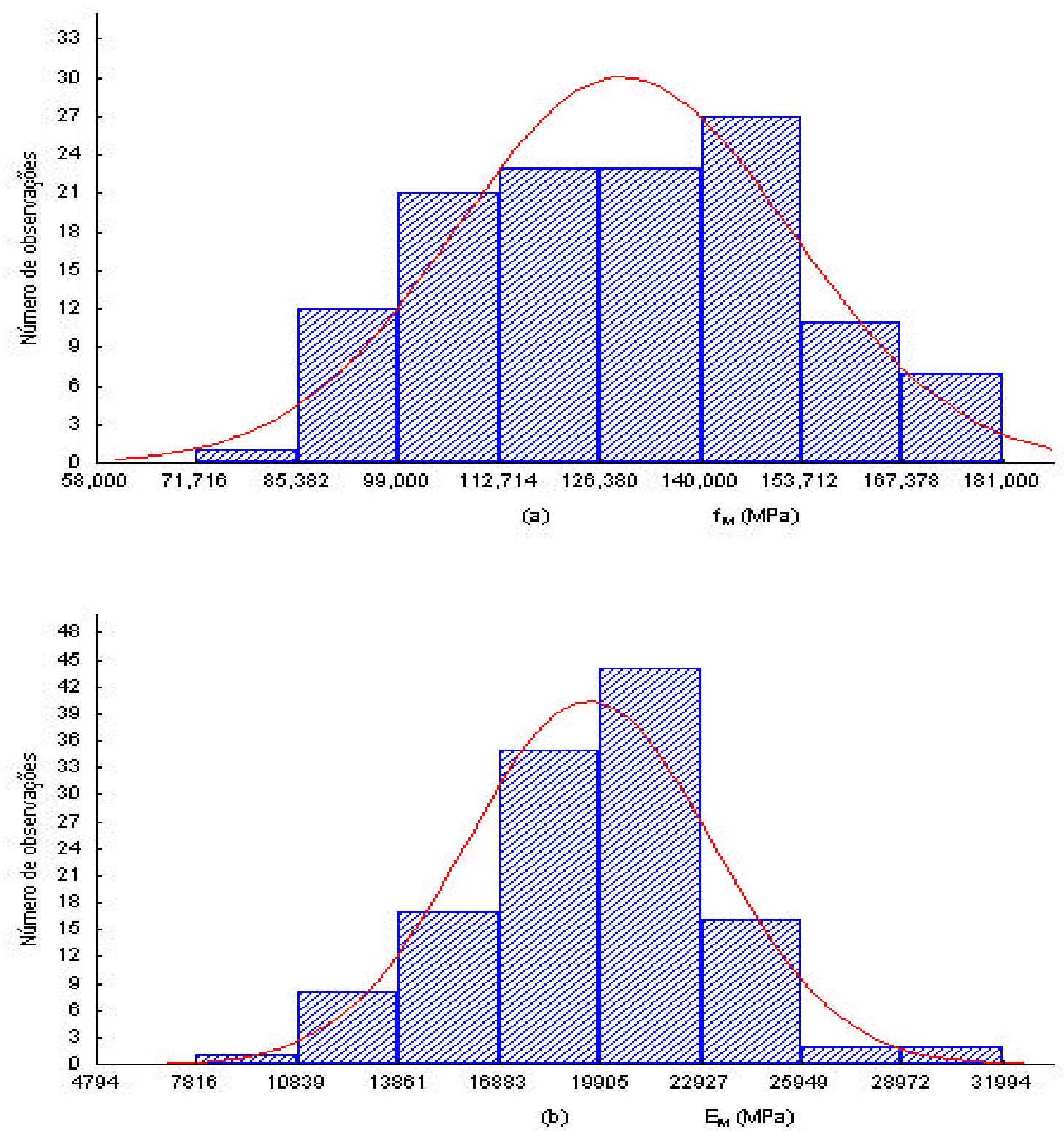

Figura 22 - Distribuição de freqüências dos valores da resistência $\left(f_{M}\right)$ (a) e do módulo de elasticidade $\left(\mathrm{E}_{\mathrm{M}}\right)(\mathrm{b})$ na flexão. 
O valor crítico experimental obtido no teste Kolmogorov-Smirnov foi de 0,036 para a resistência à flexão e de 0,057 para o módulo de elasticidade na flexão. $\mathrm{O}$ valor crítico tabelado é de $0,121(\mathrm{~d}=0,121)$ para um número total de observações de 125 $(\mathrm{n}=125)$. Portanto, como o valor crítico experimental é inferior ao valor crítico tabelado, pode-se admitir a distribuição normal de frequiência como satisfatória para representar os valores de resistência e do módulo de elasticidade obtidos no ensaio de flexão.

A Figura 23 representa a correlação linear existente entre o módulo de elasticidade $\left(\mathrm{E}_{\mathrm{M}}\right)$ e a resistência ( $\left.\mathrm{f}_{\mathrm{M}}\right)$ no ensaio de flexão, onde se observa que $80 \%$ da variação do $E_{M}$ pode ser explicada pela variação da resistência $f_{M}$.

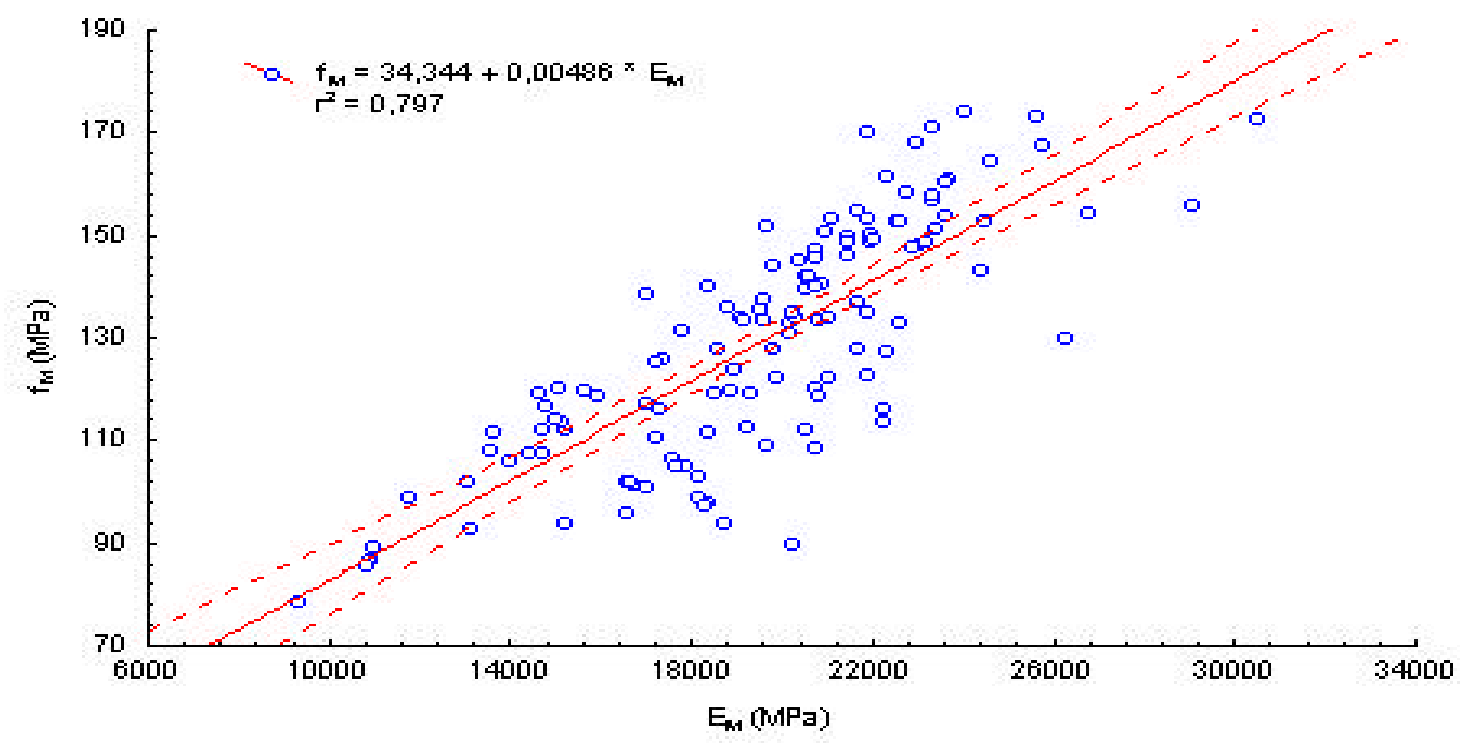

Figura 23 - Relação entre a resistência $\left(f_{M}\right)$ módulo de elasticidade $\left(E_{M}\right)$ na flexão da madeira de eucalipto.

Foi realizada a análise da variância com aplicação do teste Tukey, com um nível de confiança de $5 \%$, entre os lotes de madeira de eucalipto, na tentativa de agrupá-los em grupos homogêneos (Tabela 7). 
Tabela 7. Grupos homogêneos da resistência à flexão $\left(f_{M}\right)$, pelo teste de Tukey, de lotes de madeira de eucalipto.

\begin{tabular}{|c|c|c|c|c|c|}
\hline \multirow{2}{*}{ Lotes } & \multirow{2}{*}{$\begin{array}{l}\mathrm{F}_{\mathrm{M}, \mathrm{m}} \\
(\mathrm{MPa})\end{array}$} & \multicolumn{4}{|c|}{ Grupos } \\
\hline & & 1 & 2 & 3 & Adotado \\
\hline $8 \mathrm{~V}$ & 98,6 & XXXX & & & 1 \\
\hline $1 G$ & 106,9 & $\mathrm{xxxx}$ & & & 1 \\
\hline $6 \mathrm{~V}$ & 107,0 & xxxx & & & 1 \\
\hline $3 \mathrm{~S}$ & 107,9 & $\mathrm{xxxx}$ & & & 1 \\
\hline $3 G$ & 116,2 & $\mathrm{xxxx}$ & & & 1 \\
\hline $5 \mathrm{~V}$ & 119,6 & $\mathrm{xxxx}$ & XXXX & & 2 \\
\hline $4 \mathrm{~S}$ & 138,1 & & $\mathrm{xxxx}$ & $\mathrm{xxXx}$ & 2 \\
\hline $4 G$ & 141,9 & & & Xxxx & 3 \\
\hline $7 \mathrm{C}$ & 143,5 & & & $\mathrm{xxxx}$ & 3 \\
\hline $2 \mathrm{H}$ & 148,3 & & & $\mathrm{xxxx}$ & 3 \\
\hline $5 B$ & 150,7 & & & $\mathrm{xxxx}$ & 3 \\
\hline $4 \mathrm{C}$ & 154,0 & & & $\mathrm{xxxx}$ & 3 \\
\hline
\end{tabular}

Pode-se observar na Tabela 7 que no grupo 3, de resistência mais alta, estão dois lotes de madeira de Eucalyptus citriodora (4C e 7C), o lote do híbrido Eucalyptus saligna x Eucalyptus alba $(2 \mathrm{H})$, o lote identificado simplesmente por madeira branca (5B) e um lote de Eucalyptus grandis. No grupo 2, de resistência intermediária, estão os lotes $5 \mathrm{~V}$ e $4 \mathrm{~S}$, sendo o primeiro identificado como madeira vermelha e o segundo representa o Eucalyptus saligna. No grupo 1, de resistência inferior, estão dois lotes identificados como madeira vermelha $(6 \mathrm{~V}$ e $8 \mathrm{~V})$, dois lotes de Eucalyptus grandis (1G e 3G) e um lote de Eucalyptus saligna.

A classificação do lote $4 \mathrm{G}$ no grupo 3 , bem como o lote $4 \mathrm{~S}$ no grupo 2 , ou seja, resistências altas para as espécies E. grandis e E. saligna, podem estar relacionadas à idade avançada da madeira comercializada pelo produtor 4 . Neste caso, o lote de $E$. citriodora desse mesmo fornecedor apresentou a maior média para a resistência àflexão.

Percebe-se que a hierarquização dos lotes para a resistência à flexão não é a mesma observada para a densidade aparente a $12 \%$, onde as características anatômicas e químicas da madeira devem exercer influências na determinação da propriedade. 
Os lotes $6 \mathrm{~V}$ e $8 \mathrm{~V}$, apesar de terem uma densidade relativamente alta, se enquadraram no grupo 1 de resistência àflexão, por apresentarem fibras reversas.

Pela análise de variância com aplicação do teste Tukey (alfa=0,05), pode-se observar para o módulo de elasticidade na flexão o agrupamento de seis classes de lotes de madeira (Tabela 8), o dobro das classes obtidas para resistência à flexão.

Tabela 8. Grupos homogêneos do módulo de elasticidade na flexão $\left(\mathrm{E}_{\mathrm{M}}\right)$, pelo teste de Tukey, de lotes de madeira de eucalipto.

\begin{tabular}{|c|c|c|c|c|c|c|c|c|}
\hline \multirow{2}{*}{ Lotes } & \multirow{2}{*}{$\begin{array}{l}\text { Médias } \\
\text { (MPa) }\end{array}$} & \multicolumn{7}{|c|}{ Grupos } \\
\hline & & 1 & 2 & 3 & 4 & 5 & 6 & Adotado \\
\hline $8 \mathrm{~V}$ & 12328 & $\mathrm{XXXX}$ & & & & & & 1 \\
\hline $6 \mathrm{~V}$ & 13796 & $\mathrm{xxxx}$ & XXXX & & & & & 2 \\
\hline $5 \mathrm{~V}$ & 15921 & & $\mathrm{xxxx}$ & $\mathrm{XXXX}$ & & & & 2 \\
\hline $3 \mathrm{~S}$ & 18127 & & & $\operatorname{xxxx}$ & $\mathrm{xxxx}$ & & & 3 \\
\hline $1 G$ & 18642 & & & $\mathrm{xxxx}$ & $\mathrm{xxxx}$ & & & 3 \\
\hline $3 \mathrm{G}$ & 20371 & & & & $\mathrm{xxxx}$ & $\mathrm{xxxx}$ & & 4 \\
\hline $4 \mathrm{~S}$ & 20471 & & & & $\mathrm{xxxx}$ & XXXX & & 4 \\
\hline $4 \mathrm{G}$ & 20529 & & & & $\mathrm{xxxx}$ & $\mathrm{xxxx}$ & & 4 \\
\hline $7 \mathrm{C}$ & 20870 & & & & $\mathrm{xxxx}$ & $\mathrm{xxxx}$ & & 4 \\
\hline $5 B$ & 21988 & & & & & XXXX & XXXX & 5 \\
\hline $4 \mathrm{C}$ & 22830 & & & & & XXXX & Xxxx & 5 \\
\hline $2 \mathrm{H}$ & 25088 & & & & & & $\mathrm{xxxx}$ & 6 \\
\hline
\end{tabular}

\subsection{Compressão paralela às fibras}

Os valores médios encontrados para o ensaio de compressão paralela às fibras (resistência e módulo de elasticidade), realizados de acordo com a NBR 7190/97, bem como os valores característicos para cada lote estudado, encontram-se na Tabela 9 e ilustrados nas Figuras 23 e 24. 
Tabela 9. Valores médios, coeficiente de variação, valor característico para resistência à compressão paralela e módulo de elasticidade na condição de umidade de $12 \%$, segundo a NBR 7190/97.

\begin{tabular}{cccccc}
\hline Lotes & $\begin{array}{c}\mathbf{f}_{\mathbf{c 0}} \\
(\mathrm{MPa})\end{array}$ & $\begin{array}{c}\text { C.V. } \\
(\%)\end{array}$ & $\begin{array}{c}\mathbf{E}_{\mathbf{c 0}} \\
(\mathrm{MPa})\end{array}$ & $\begin{array}{c}\text { C.V. } \\
(\%)\end{array}$ & $\begin{array}{c}\mathbf{f}_{\mathbf{c 0 k}} \\
(\mathrm{MPa})\end{array}$ \\
\hline $1 \mathrm{G}$ & 59,72 & 9,44 & 20591 & 11,38 & 52,42 \\
$2 \mathrm{H}$ & 80,39 & 12,84 & 25598 & 16,42 & 66,37 \\
$3 \mathrm{G}$ & 66,70 & 9,02 & 20060 & 12,99 & 61,98 \\
$3 \mathrm{~S}$ & 62,03 & 11,26 & 18250 & 10,89 & 57,73 \\
$4 \mathrm{G}$ & 74,07 & 6,36 & 28219 & 11,12 & 70,85 \\
$4 \mathrm{~S}$ & 73,76 & 10,40 & 27688 & 13,58 & 62,43 \\
$4 \mathrm{C}$ & 67,89 & 10,12 & 23741 & 8,37 & 66,25 \\
$5 \mathrm{~B}$ & 81,81 & 7,14 & 22860 & 10,95 & 79,20 \\
$5 \mathrm{~V}$ & 68,62 & 13,14 & 20027 & 6,01 & 53,56 \\
$6 \mathrm{~V}$ & 63,65 & 7,19 & 18589 & 20,06 & 60,67 \\
$7 \mathrm{C}$ & 70,90 & 10,30 & 21150 & 10,16 & 60,65 \\
$8 \mathrm{~V}$ & 54,12 & 13,19 & 11685 & 25,20 & 47,22 \\
\hline
\end{tabular}

O valor médio de menor resistência à compressão foi de 54,12 MPa para o lote $8 \mathrm{~V}$ e o valor mais alto foi de $81,81 \mathrm{MPa}$ para o lote $5 \mathrm{~B}$, uma amplitude total de 27,69 MPa. Os coeficientes de variação ficaram entre 7,14\% e 13,19\%, dentro dos padrões encontrados na experimentação com madeiras. A Figura 25 permite verificar a dispersão dos valores da resistência à compressão paralela às fibras dos lotes de madeira considerados no estudo.

Para o módulo de elasticidade, o lote 4G apresentou a maior média com 28219 MPa enquanto que o lote $8 \mathrm{~V}$ apresentou a menor média com $11685 \mathrm{MPa}$, amplitude de $16534 \mathrm{MPa}$; os coeficientes de variação ficaram entre 6,01\% e 25,20 \%. A dispersão dos valores esta apresentada na Figura 26. Estes valores são superiores aos encontrados na literatura para diferentes espécies de eucalipto. Sales (1996) encontrou uma variação de $12814 \mathrm{MPa}$ (Eucalyptus grandis) a $19881 \mathrm{MPa}$, amplitude de $7067 \mathrm{MPa}$ (Eucalyptus paniculata). A NBR 7190/97, apresenta valores entre 13166 MPa a 19881 MPa para 17 espécies de eucalipto. 
Considerando os valores característicos para resistência à compressão paralela e as classes de resistência para as dicotilêdoneas indicada na NBR 7190/97, cinco lotes estudados enquadram-se na classe C $40(1 \mathrm{G}, 3 \mathrm{~S}, 5 \mathrm{~V}$ e $8 \mathrm{~V})$ e sete lotes na C $60(2 \mathrm{H}, 3 \mathrm{G}$, $4 \mathrm{~S}, 4 \mathrm{G}, 4 \mathrm{C}, 5 \mathrm{~B}, 6 \mathrm{~V}, 7 \mathrm{C})$.

Para o valor médio do módulo de elasticidade, o lote $8 \mathrm{~V}$ enquadrou-se na classe C20; os lotes 3S e 6V na classe C30; os lotes $1 \mathrm{G}, 3 \mathrm{G}, 4 \mathrm{C}, 5 \mathrm{~B}, 5 \mathrm{~V}$ e $7 \mathrm{C}$ na classe $\mathrm{C} 40$ e os lotes $2 \mathrm{H}, 4 \mathrm{~S}$ e $4 \mathrm{G}$ na classe C60. Esta distribuição pode ser melhor observada na Tabela 17, no final do capítulo.

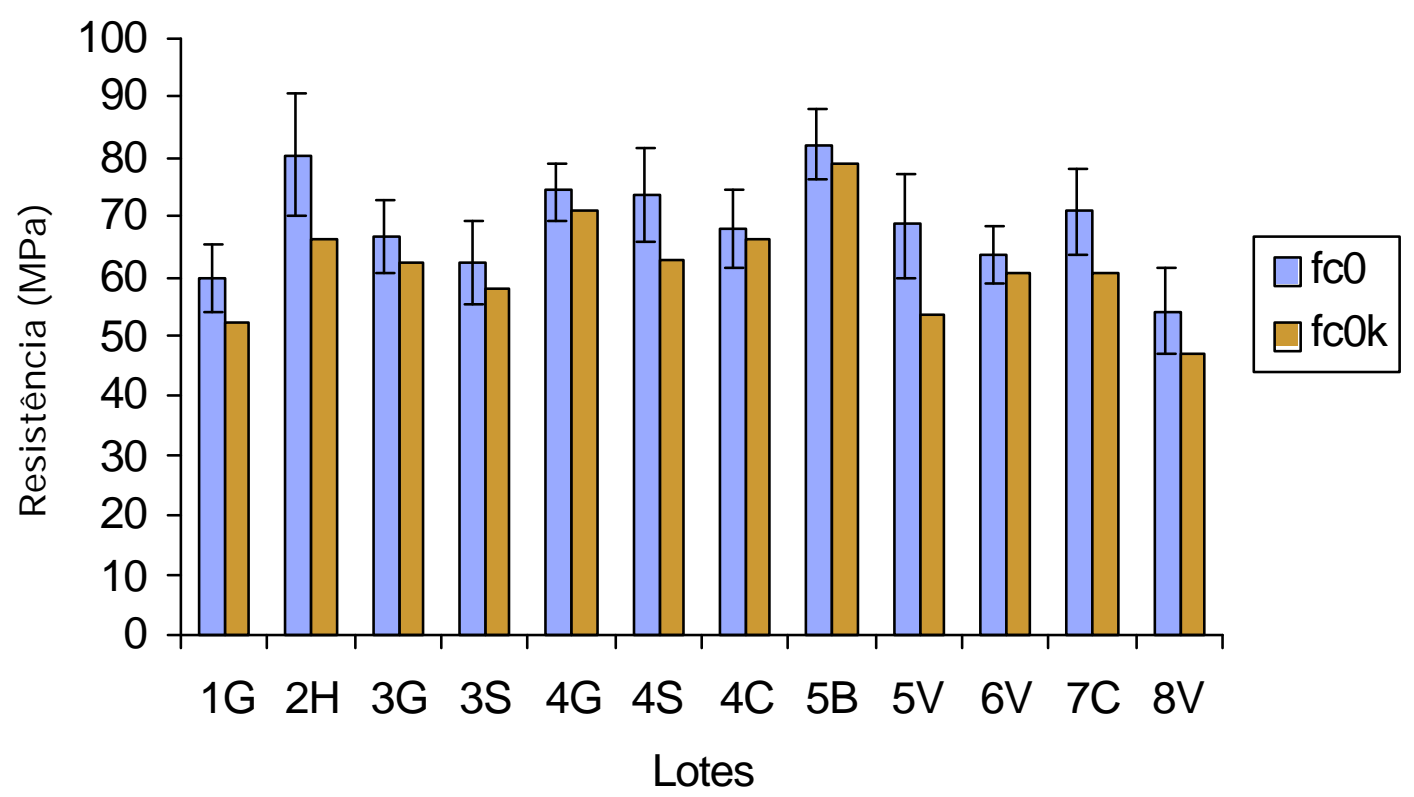

Figura 23 - Valores médios $\left(\mathrm{f}_{\mathrm{c} 0}\right)$ e característicos $\left(\mathrm{f}_{\mathrm{c} 0 \mathrm{k}}\right)$ da resistência à compressão paralela às fibras na umidade $12 \%$ de lotes de madeira de eucalipto. 


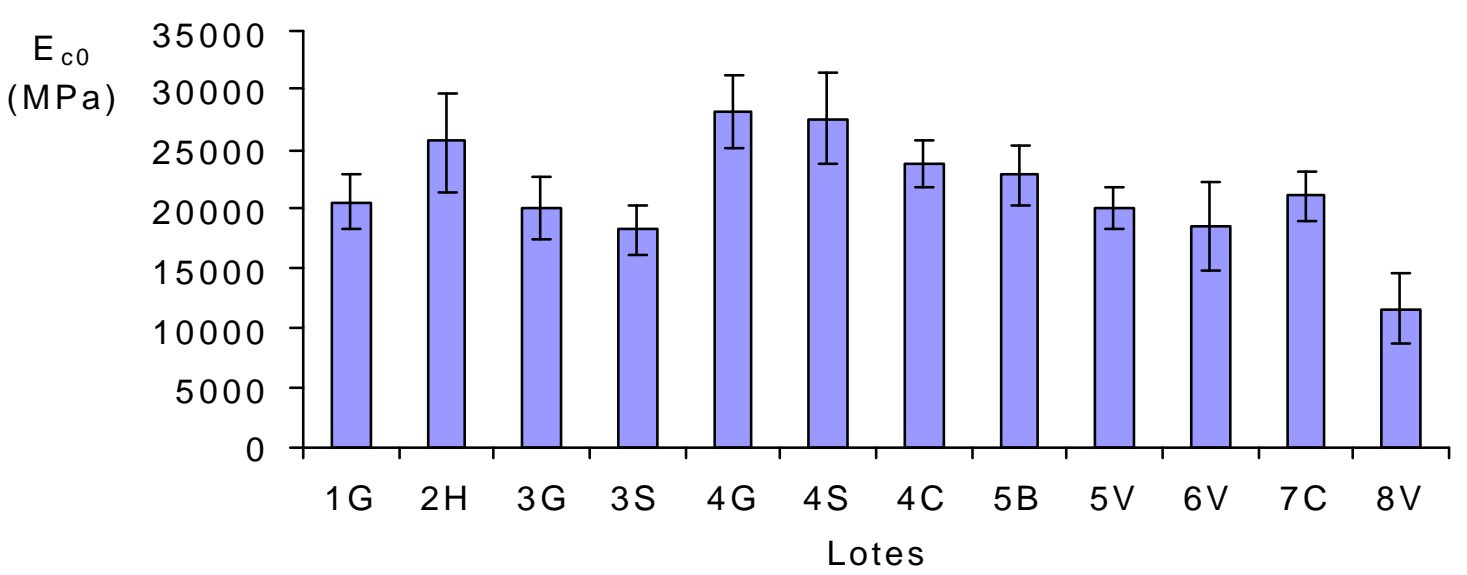

Figura 24 - Valores médios do módulo de elasticidade $\left(\mathrm{E}_{\mathrm{c} 0}\right)$ na compressão paralela às fibras de lotes de madeira de eucalipto.

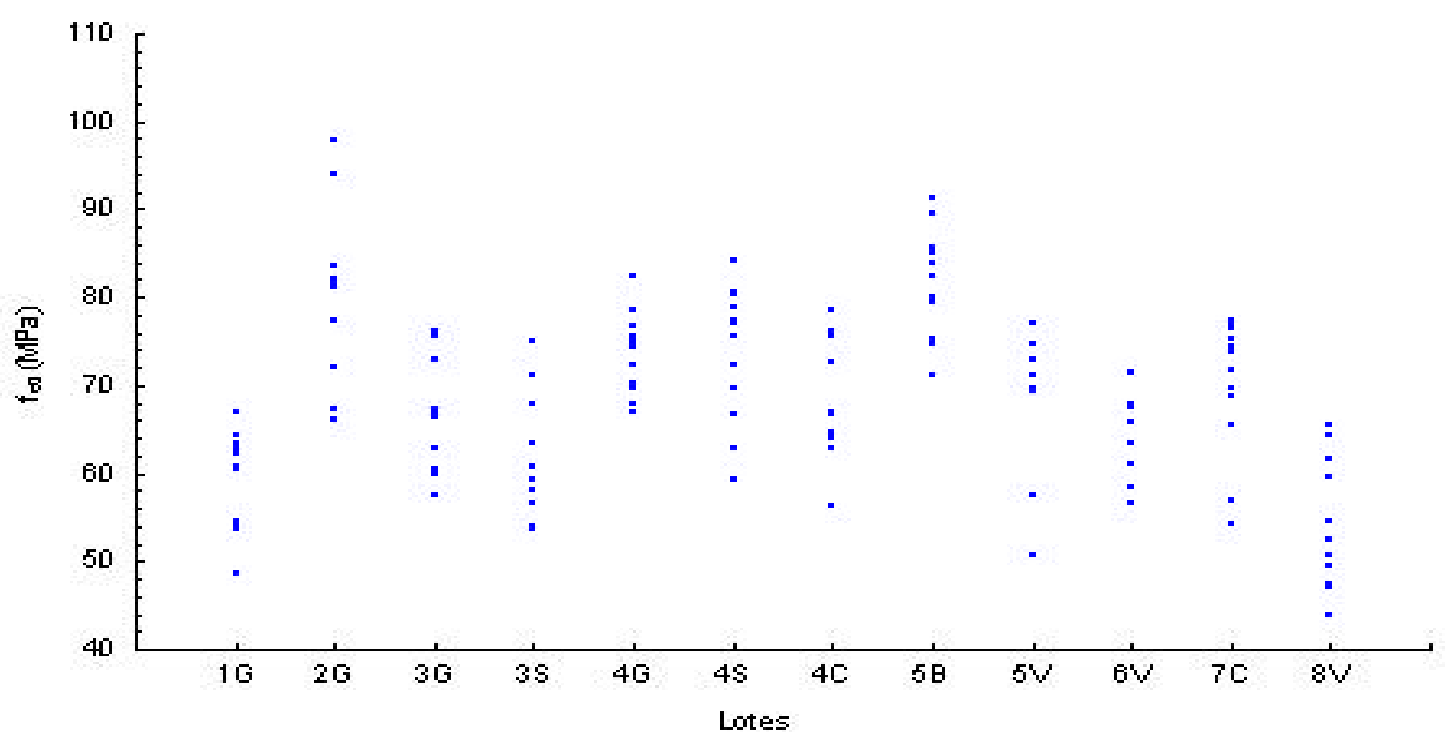

Figura 25 - Dispersão dos valores obtidos no ensaio de resistência $\left(\mathrm{f}_{\mathrm{c} 0}\right)$ à compressão paralela às fibras 12\% (NBR7190/97) de lotes de madeira de eucalipto. 


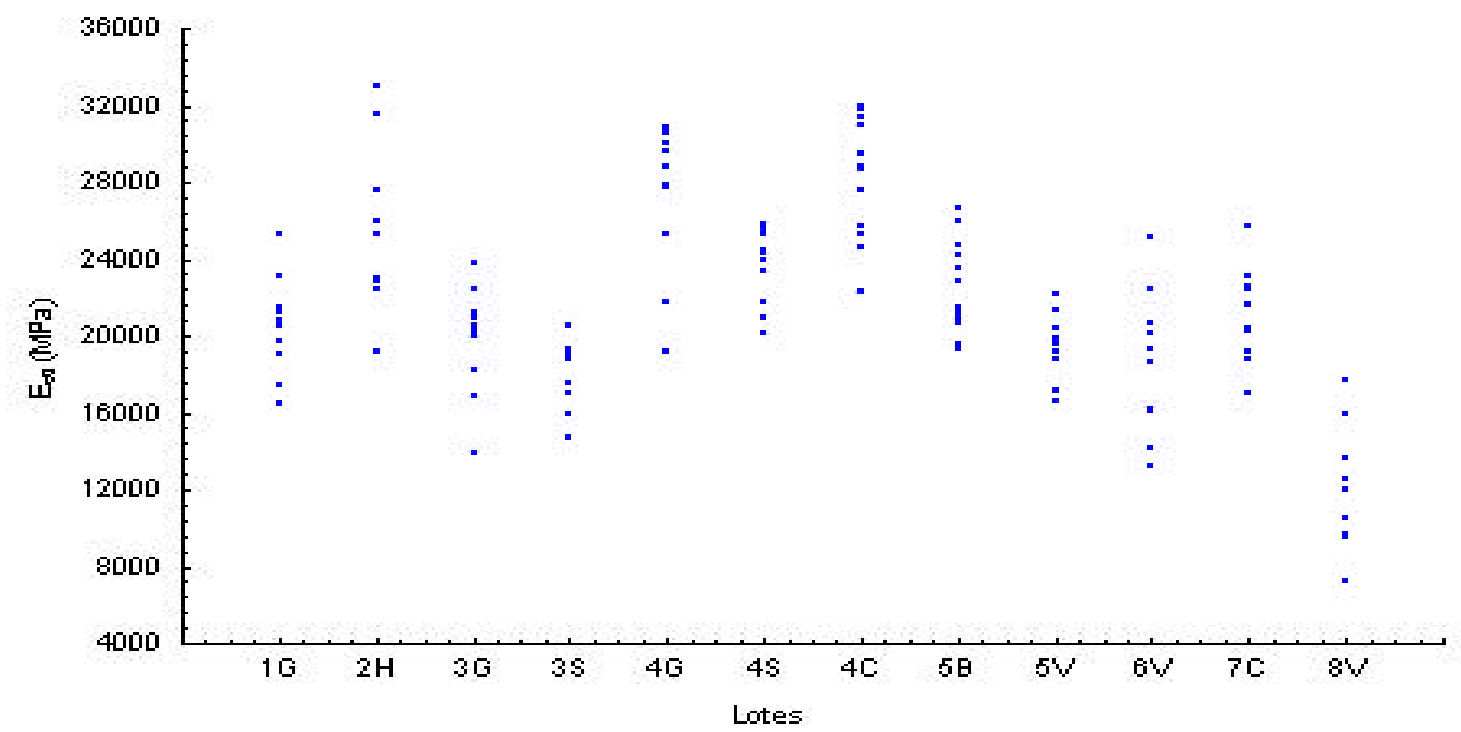

Figura 26 - Dispersão dos valores obtidos para módulo de elasticidade $\left(\mathrm{E}_{\mathrm{c} 0}\right)$ na compressão paralela às fibras $12 \%$ (NBR7190/97) de lotes de madeira de eucalipto.

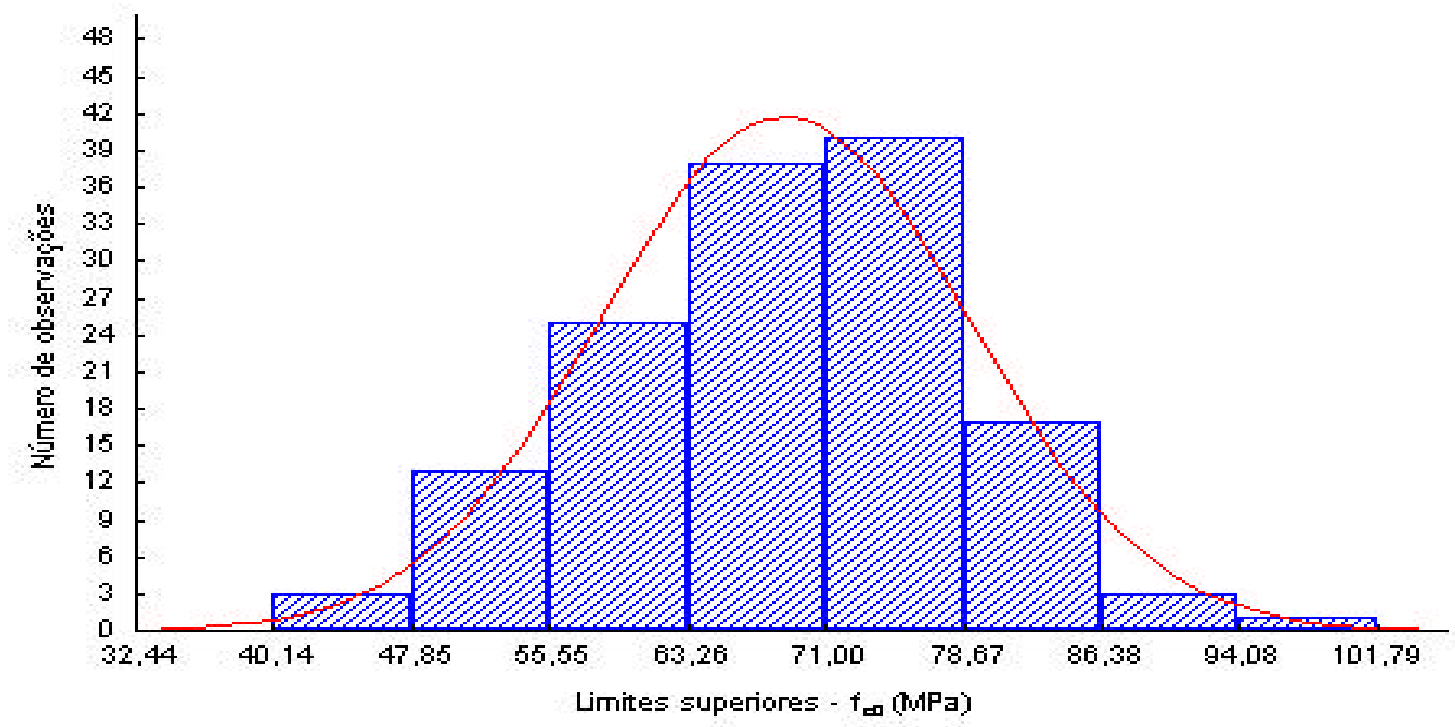

Figura 27 - Distribuição de freqüências dos valores da resistência à compressão paralela $\left(f_{c 0}\right)$ de lotes de madeira de eucalipto. 


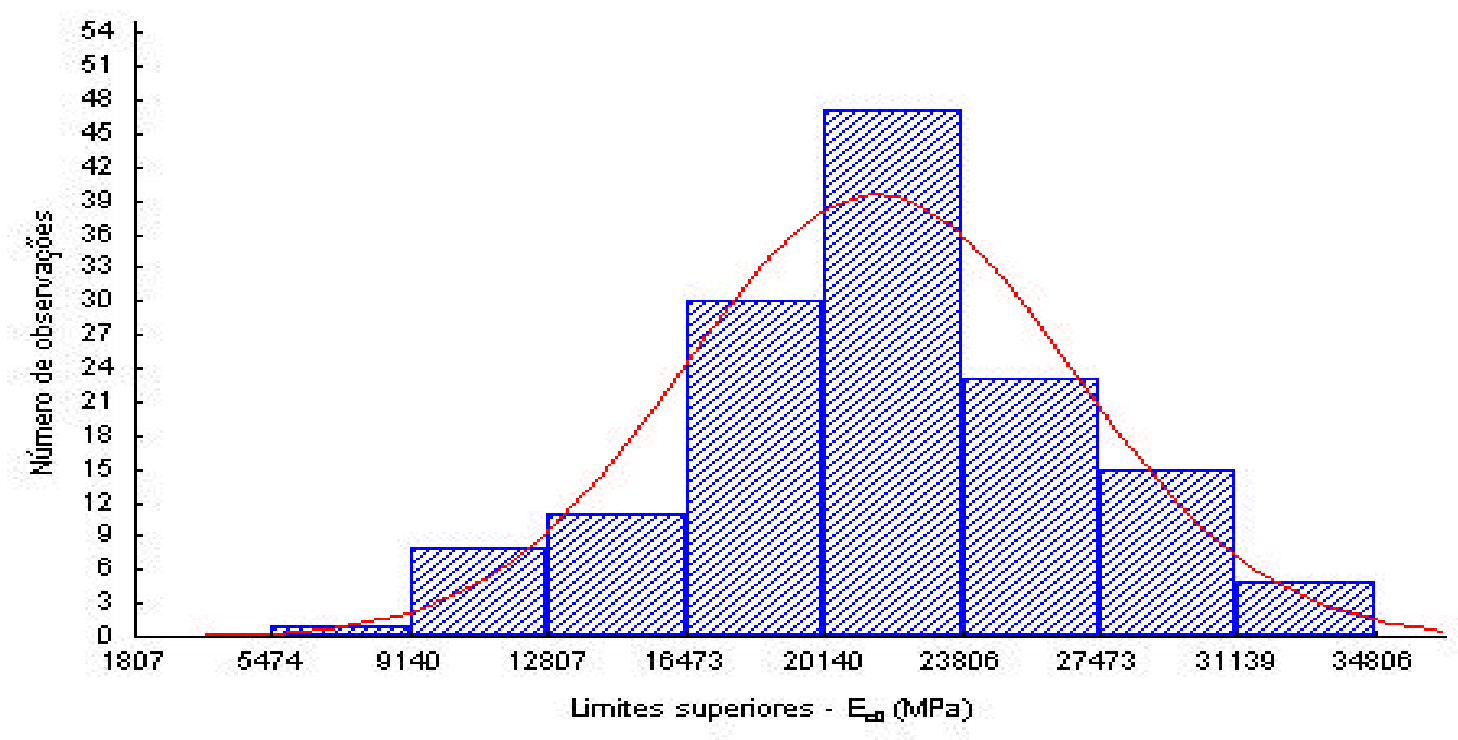

Figura 28 - Distribuição de frequiência dos valores do módulo de elasticidade na compressão paralela às fibras $\left(\mathrm{E}_{\mathrm{c} 0}\right)$ de lotes de madeira de eucalipto.

O valor crítico experimental obtido no teste Kolmogorov-Smirnov foi de 0,014 para a resistência à compressão paralela e de 0,040 para o módulo de elasticidade. $\mathrm{O}$ valor crítico tabelado para $\mathrm{n}=140$ é de 0,115 . Como o valor crítico experimental é inferior ao valor crítico tabelado, pode-se admitir a distribuição normal de freqüência como satisfatória para representar os valores obtidos nos ensaios de resistência e módulo na compressão paralela às fibras.

Foi feita a análise de variância com aplicação do teste Tukey, para a resistência e para o módulo de elasticidade na compressão paralela, cujos resultados se encontram nas Tabelas 10 e 11. 
Tabela 10. Grupos homogêneos da resistência à compressão paralela às fibras $\left(\mathrm{f}_{\mathrm{c} 0}\right)$, pelo teste de Tukey, de lotes de madeira de eucalipto.

\begin{tabular}{|c|c|c|c|c|c|c|c|c|}
\hline \multirow{2}{*}{ Lotes } & \multirow{2}{*}{$\begin{array}{c}\mathrm{F}_{\mathrm{c} 0, \mathrm{~m}} \\
(\mathrm{MPa})\end{array}$} & \multicolumn{7}{|c|}{ Grupos } \\
\hline & & 1 & 2 & 3 & 4 & 5 & 6 & Adotado \\
\hline $8 \mathrm{~V}$ & 54,1 & $\mathrm{xxxx}$ & & & & & & 1 \\
\hline $1 G$ & 59,7 & $\mathrm{xxxx}$ & $\mathrm{xxxx}$ & & & & & 2 \\
\hline $3 \mathrm{~S}$ & 62,0 & $\mathrm{xxxx}$ & Xxxx & $\mathrm{xxxx}$ & & & & 3 \\
\hline $6 \mathrm{~V}$ & 63,6 & Xxxx & $\mathrm{xxxx}$ & XXXX & & & & 3 \\
\hline $3 G$ & 66,7 & & $\mathrm{xxxx}$ & $\mathrm{xxxx}$ & $\mathrm{xxxx}$ & & & 4 \\
\hline $4 \mathrm{C}$ & 67,8 & & $\mathrm{xxxx}$ & $\mathrm{xxxx}$ & $\mathrm{xxxx}$ & & & 4 \\
\hline $5 \mathrm{~V}$ & 68,4 & & $\mathrm{xxxx}$ & xxxx & $\mathrm{xxxx}$ & & & 4 \\
\hline $7 \mathrm{C}$ & 70,9 & & & $\mathrm{xxxx}$ & $\mathrm{xxxx}$ & $\mathrm{xxXx}$ & & 4 \\
\hline $4 \mathrm{~S}$ & 73,8 & & & & $\mathrm{xxxx}$ & $\mathrm{xxxx}$ & $\operatorname{xxxx}$ & 5 \\
\hline $4 G$ & 74,1 & & & & $\mathrm{xxxx}$ & $\mathrm{xxxx}$ & $\mathrm{xxxx}$ & 5 \\
\hline $2 \mathrm{H}$ & 80,4 & & & & & $\mathrm{xxxx}$ & $\mathrm{xxxx}$ & 5 \\
\hline $5 B$ & 81,8 & & & & & & $\mathrm{xxxx}$ & 6 \\
\hline
\end{tabular}

Tabela 11. Grupos homogêneos do módulo de elasticidade na compressão paralela às fibras $\left(\mathrm{E}_{\mathrm{c} 0}\right)$, pelo teste de Tukey, de lotes de madeira de eucalipto.

\begin{tabular}{|c|c|c|c|c|c|c|c|c|}
\hline \multirow{2}{*}{ Lotes } & \multirow{2}{*}{$\begin{array}{c}\mathrm{E}_{\mathrm{c} 0, \mathrm{~m}} \\
(\mathrm{MPa})\end{array}$} & \multicolumn{7}{|c|}{ Grupos } \\
\hline & & 1 & 2 & 3 & 4 & 5 & 6 & Adotado \\
\hline $8 \mathrm{~V}$ & 11685 & $\mathrm{xxxx}$ & & & & & & 1 \\
\hline $3 \mathrm{~S}$ & 18250 & & $\mathrm{xxxx}$ & & & & & 2 \\
\hline $6 \mathrm{~V}$ & 18589 & & $\mathrm{xxxx}$ & & & & & 2 \\
\hline $5 \mathrm{~V}$ & 19488 & & $\operatorname{xxxx}$ & $\mathrm{XXXX}$ & & & & 3 \\
\hline $3 G$ & 20060 & & $\mathrm{xxxx}$ & $\mathrm{xxxx}$ & & & & 3 \\
\hline $1 \mathrm{G}$ & 20591 & & $\mathrm{XXXX}$ & $\mathrm{XXXX}$ & XXXX & & & 4 \\
\hline $7 \mathrm{C}$ & 21150 & & $\mathrm{xxxx}$ & $\mathrm{xxxx}$ & XXXX & & & 4 \\
\hline $5 B$ & 22860 & & & $\mathrm{xxxx}$ & $\operatorname{xxxx}$ & XXXX & & 4 \\
\hline $4 \mathrm{~S}$ & 23895 & & & & XXXX & XXXX & & 5 \\
\hline $2 \mathrm{H}$ & 25598 & & & & & Xxxx & $\mathrm{XxXX}$ & 5 \\
\hline $4 G$ & 27688 & & & & & & Xxxx & 6 \\
\hline $4 \mathrm{C}$ & 28219 & & & & & & $\mathrm{xxxx}$ & 6 \\
\hline
\end{tabular}

O teste de Tukey não permite uma completa distinção de grupos homogêneos, havendo sempre a necessidade de uma ação subjetiva baseada na média para definir-se os limites dos grupos. Entretanto, uma vez definidos esses limites os grupos podem ser considerados homogêneos. 
Foram realizados ensaios de compressão paralela às fibras com madeira verde (U>35\%) seguindo a norma NBR 6230, que difere da NBR 7190/97 principalmente pelas dimensões e pela condição de umidade dos corpos de prova. Os valores médios encontrados para resistência $\left(\mathrm{f}_{\mathrm{c} 0 \text {,verde }}\right)$ e módulo de elasticidade $\left(\mathrm{E}_{\mathrm{c} 0 \text {,verde }}\right)$, neste ensaio, encontram-se na Tabela 12.

Para a resistência foram observados valores médios variando de 34,42 $\mathrm{MPa}$ (lote $8 \mathrm{~V}$ ) até 59,52 MPa (lote 5B), com coeficientes de variação dentro do esperado (7\% a $20 \%$ ). Para a rigidez foi observado o menor valor para o lote 8V (9164 MPa) e o maior valor para o lote (22554 MPa), com coeficientes de variação entre $13 \%$ e $23 \%$. A Figura 29 ilustra os valores médios e respectivos desvios.

Tabela 12. Valores médios para resistência $\left(\mathrm{f}_{\mathrm{c} 0}\right)$ e módulo de elasticidade $\left(\mathrm{E}_{\mathrm{c} 0}\right)$ no ensaio de compressão paralela às fibras - madeira verde ( $U>35 \%)$.

\begin{tabular}{ccccc}
\hline Lotes & $\begin{array}{r}\mathrm{f}_{\mathrm{c} 0, \text { verde }} \\
(\mathrm{Mpa})\end{array}$ & $\begin{array}{c}\mathrm{C} . \mathrm{V} . \\
(\%)\end{array}$ & $\begin{array}{c}\mathrm{E}_{\mathrm{c} 0, \text { verde }} \\
(\mathrm{Mpa})\end{array}$ & $\begin{array}{c}\mathrm{C} . \mathrm{V} . \\
(\%)\end{array}$ \\
\hline $1 \mathrm{G}$ & 35,52 & 16,28 & 15792 & 23,15 \\
$2 \mathrm{H}$ & 42,12 & 13,27 & 21880 & 14,66 \\
$3 \mathrm{G}$ & 40,12 & 9,58 & 19049 & 18,16 \\
$3 \mathrm{~S}$ & 32,92 & 20,01 & 13771 & 18,72 \\
$4 \mathrm{G}$ & 42,13 & 10,89 & 20316 & 15,16 \\
$4 \mathrm{~S}$ & 48,96 & 15,97 & 19781 & 13,55 \\
$4 \mathrm{C}$ & 48,55 & 13,01 & 20938 & 16,99 \\
$5 \mathrm{~B}$ & 59,52 & 10,25 & 22554 & 15,60 \\
$5 \mathrm{~V}$ & 41,18 & 14,94 & 15752 & 15,87 \\
$6 \mathrm{~V}$ & 37,97 & 13,67 & 13016 & 21,29 \\
$7 \mathrm{C}$ & 34,96 & 7,01 & 20112 & 13,31 \\
$8 \mathrm{~V}$ & 34,42 & 8,72 & 9164 & 20,79 \\
\hline
\end{tabular}



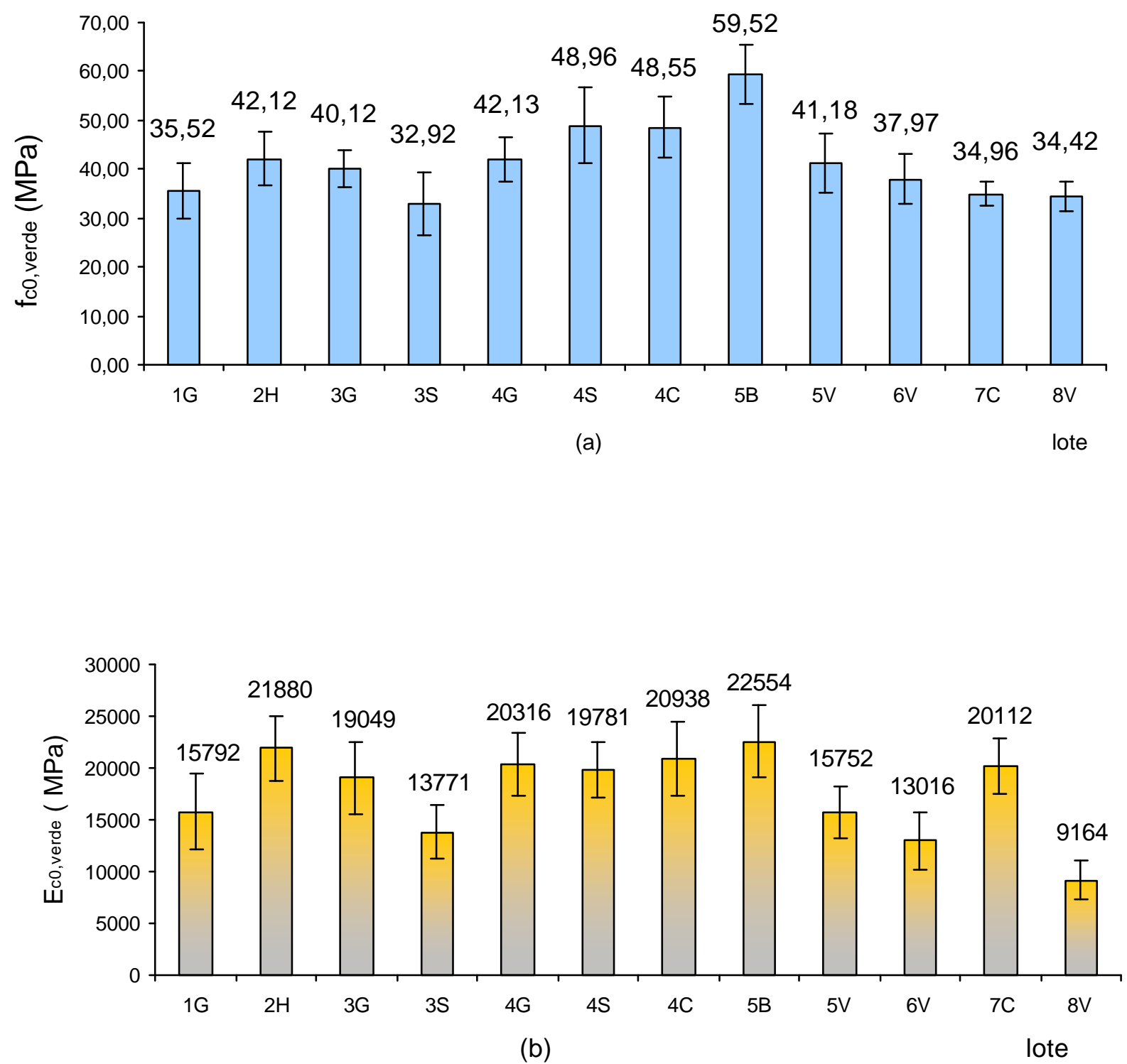

Figura 29 - Valores médios da resistência $\left(f_{c 0, v e r d e}\right)$ (a) e do módulo de elasticidade $\left(\mathrm{E}_{\mathrm{c} 0 \text {,verde }}\right)$ (b).na compressão paralela - madeira verde de lotes de madeira de eucalipto. 
Foram feitas as correlações lineares entre o ensaio realizado com madeira verde e madeira a $12 \%$, sendo que para a resistência à compressão paralela $\left(\mathrm{f}_{\mathrm{c} 0}\right)$, o coeficiente de determinação foi de 0,523 e para o módulo de elasticidade $\left(\mathrm{E}_{\mathrm{c} 0}\right)$ este coeficiente foi de 0,703. Portanto, para as propriedades medidas no ensaio de compressão há boas correlações entre os resultados obtidos na condição verde com aqueles medidos na condição seca, embora os corpos de prova tenham sido de dimensões diferentes de uma para outra.

\subsubsection{Compressão paralela às fibras - qualificação}

Com o intuito de se observar o comportamento de corpos de prova com seção reduzida sobre a resistência à compressão paralela, foram observados os resultados apresentados na Tabela 13.

Tabela 13. Valores médios e coeficientes de variação para a resistência à compressão paralela às fibras- qualificação - madeira verde (U>35\%) e madeira a12\% de umidade de lotes de madeira de eucalipto.

\begin{tabular}{cccccc}
\hline \multirow{2}{*}{ Lotes } & \multicolumn{2}{c}{ madeira verde } & & \multicolumn{2}{c}{ madeira 12\% } \\
\cline { 2 - 3 } \cline { 5 - 6 } & $\mathrm{f}_{\mathrm{c} 0}(\mathrm{MPa})$ & C.V. $(\%)$ & & $\mathrm{f}_{\mathrm{c} 0}(\mathrm{MPa})$ & C.V. $(\%)$ \\
\hline 1G & 36,35 & 13,46 & & 55,12 & 8,64 \\
2H & 44,68 & 15,96 & & 82,92 & 13,58 \\
3G & 36,01 & 14,05 & & 62,24 & 12,64 \\
3S & 34,13 & 18,21 & & 55,91 & 13,26 \\
4G & 38,84 & 15,82 & & 72,26 & 15,64 \\
4S & 40,91 & 14,56 & & 76,54 & 10,81 \\
4C & 48,13 & 15,74 & & 70,82 & 11,37 \\
5B & 62,17 & 4,91 & & 87,65 & 9,89 \\
5V & 42,42 & 13,40 & & 70,47 & 10,55 \\
6V & 35,30 & 19,77 & & 64,00 & 17,56 \\
7C & 48,63 & 17,45 & & 81,55 & 12,22 \\
8V & 36,79 & 6,34 & & 59,87 & 12,80 \\
\hline
\end{tabular}


Para o ensaio com madeira verde ( $\mathrm{U}>35 \%$ ), os valores médios obtidos ficaram entre 34,13 MPa (lote 3S) e 62,17 MPa (lote 5B), uma amplitude de 28,04 MPa. Os coeficientes de variação ficaram entre $4,91 \%$ e $19,77 \%$. Nos ensaios com madeira a $12 \%$ de umidade, o menor valor médio observado foi para o lote $1 \mathrm{G}(55,12 \mathrm{MPa})$ e o maior valor foi de $87,65 \mathrm{MPa}$ para o lote $5 \mathrm{~B}$, uma amplitude de 32,53 $\mathrm{MPa}$ superior à encontrada no ensaio de compressão com seção transversal de $25 \mathrm{~cm}^{2}$. Estes valores estão ilustrados na Figura 30.

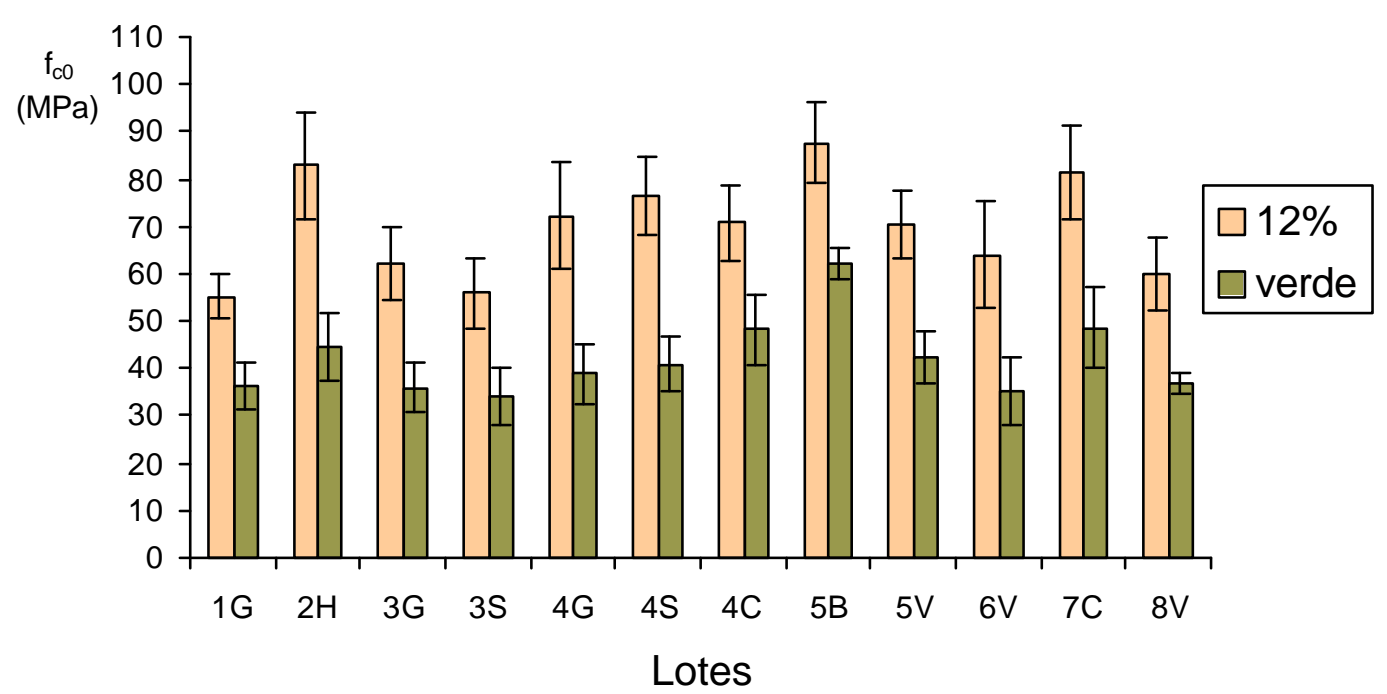

Figura 30 - Valores médios para resistência a compressão paralela - qualificação, madeira verde ( $\mathrm{U}>35 \%)$ e madeira a $12 \%$ de umidade de lotes de madeira de eucalipto. 


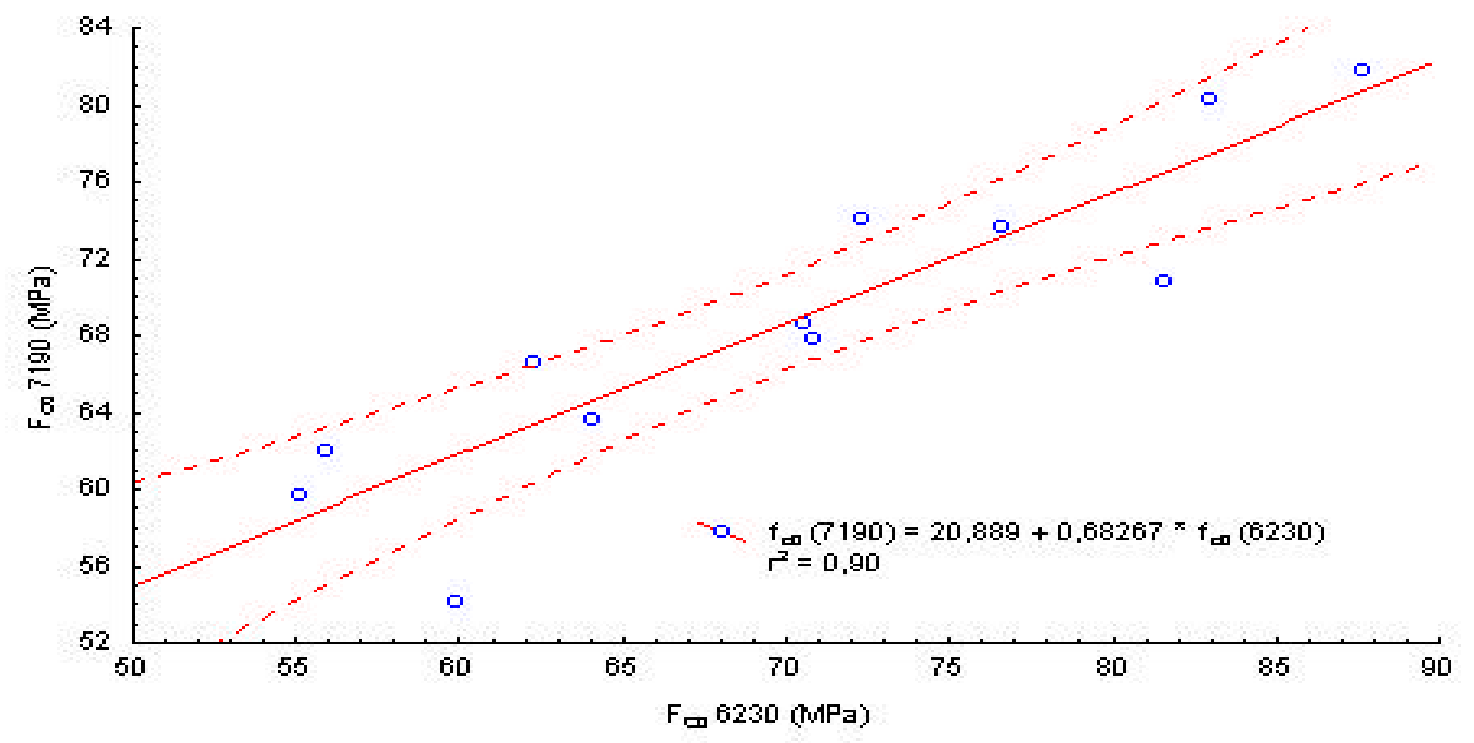

Figura 31 - Relação entre a compressão paralela (NBR 7190) e a compressão qualificação (NBR 6230), valores médios de lotes de madeira de eucalipto.

Pela observação da Figura 31, percebe-se a boa correlação entre valores médios obtidos nos ensaios de compressão paralela com corpos de prova de seção de 5 x $5 \mathrm{~cm}$ com os corpos de prova de seção reduzida ( 2 x $2 \mathrm{~cm}$ ), na condição de umidade $12 \%$. Isto permite afirmar que $90 \%$ da variação da resistência à compressão paralela no ensaio, segundo a NBR 7190/97, podem ser explicados pela resistência à compressão qualificação, nos ensaios com madeira com teor de umidade de $12 \%$.

Este fato é importante pois através de ensaios de corpos de prova de pequenas dimensões, pode-se estimar a resistência à compressão paralela com a vantagem de economia de material e tempo de ensaio. 


\subsection{Cisalhamento}

A Tabela 14 apresenta os valores médios, coeficiente de variação e valor característico para os ensaios de resistência ao cisalhamento de acordo com a NBR 7190/97.

O menor valor característico encontrado no trabalho foi de 7,94 MPa (lote 1G), que representa a classe C 40 da norma brasileira quando o valor característico para o cisalhamento é o fator de escolha. Os demais lotes foram qualificados na classe C 60 com valores característicos variando de 8,71 $\mathrm{MPa}$ a 15,92 $\mathrm{MPa}$.

Tabela 14. Valores médios, coeficiente de variação e valores característicos da resistência ao cisalhamento de lotes de madeira de eucalipto.

\begin{tabular}{cccc}
\hline Lotes & $\begin{array}{c}\mathbf{f}_{\mathbf{v}} \\
(\mathrm{MPa})\end{array}$ & $\begin{array}{c}\mathrm{C} . \mathrm{V} . \\
(\%)\end{array}$ & $\begin{array}{c}\mathbf{f}_{\mathbf{v k}} \\
(\mathrm{MPa})\end{array}$ \\
\hline $1 \mathrm{G}$ & 10,22 & 14,67 & 7,94 \\
$2 \mathrm{H}$ & 13,35 & 8,49 & 12,00 \\
$3 \mathrm{G}$ & 12,58 & 18,20 & 10,14 \\
$3 \mathrm{~S}$ & 11,26 & 16,82 & 8,87 \\
$4 \mathrm{G}$ & 9,99 & 12,43 & 8,71 \\
$4 \mathrm{~S}$ & 13,49 & 12,63 & 10,68 \\
$4 \mathrm{C}$ & 15,25 & 11,90 & 14,00 \\
$5 \mathrm{~B}$ & 14,98 & 17,73 & 11,05 \\
$5 \mathrm{~V}$ & 15,56 & 4,85 & 15,68 \\
$6 \mathrm{~V}$ & 14,43 & 16,47 & 10,42 \\
$7 \mathrm{C}$ & 15,10 & 6,87 & 14,19 \\
$8 \mathrm{~V}$ & 17,49 & 10,98 & 15,92 \\
\hline
\end{tabular}

Sales (1996) observou valores médios da resistência ao cisalhamento variando de 7,0 MPa a $13 \mathrm{MPa}$, enquanto que a NBR 7190/97 (Anexo E) apresenta valores entre 8,3 $\mathrm{MPa}$ a 12,9 $\mathrm{MPa}$. Os valores médios observados para os 12 lotes do estudo ficaram entre 9,99 $\mathrm{MPa}$ a $17,49 \mathrm{MPa}$. 


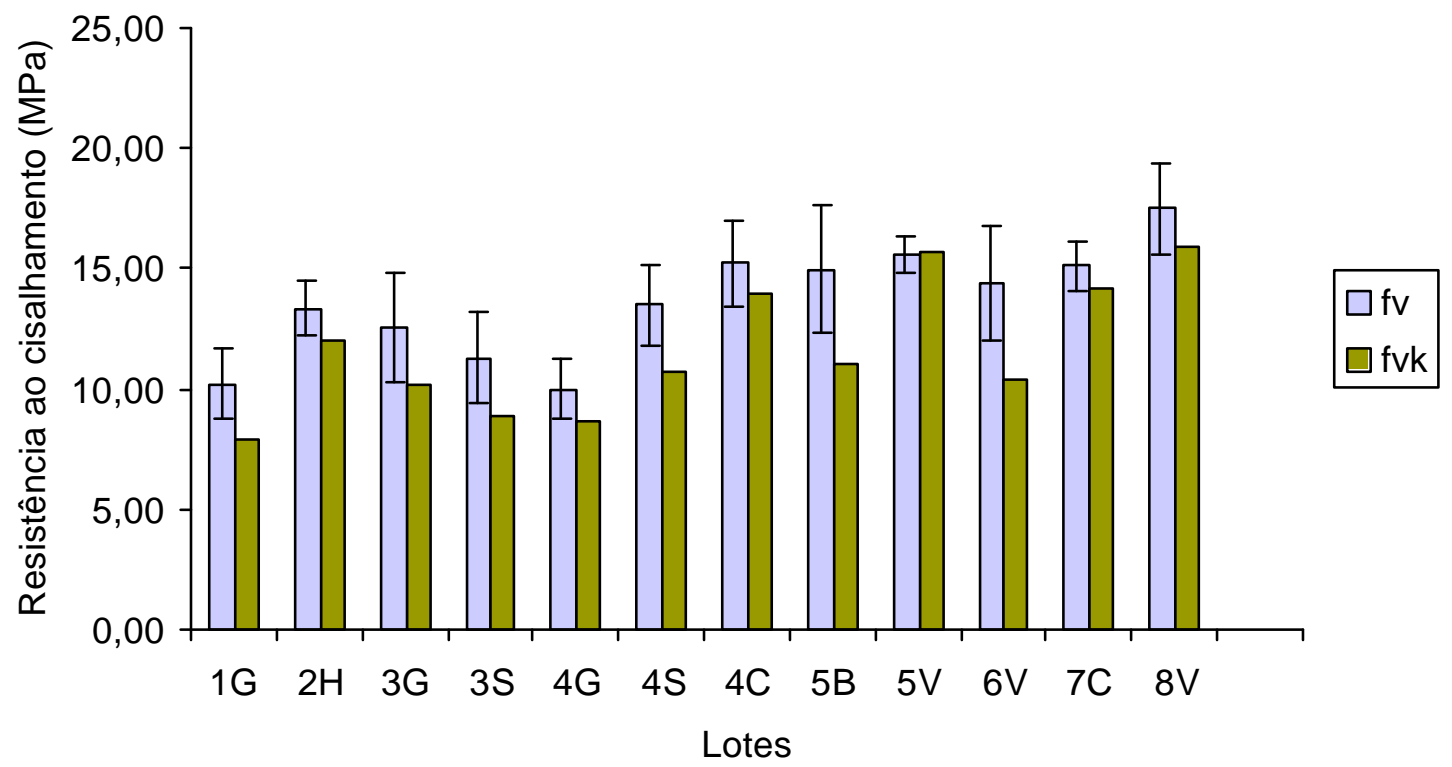

Figura 32 - Valores médios da resistência ao cisalhamento $\left(f_{v}\right)$ e valores característicos $\left(f_{\mathrm{vk}}\right)$ de lotes de madeira de eucalipto.

Pode-se observar na Figura 32, que o valor característico para o lote 5V é ligeiramente superior ao valor médio, o que deve estar relacionado ao número pequeno de corpos de prova ensaiados para este lote $(n=8)$.

A dispersão dos valores obtidos no ensaio de resistência ao cisalhamento está apresentada na Figura 33. 


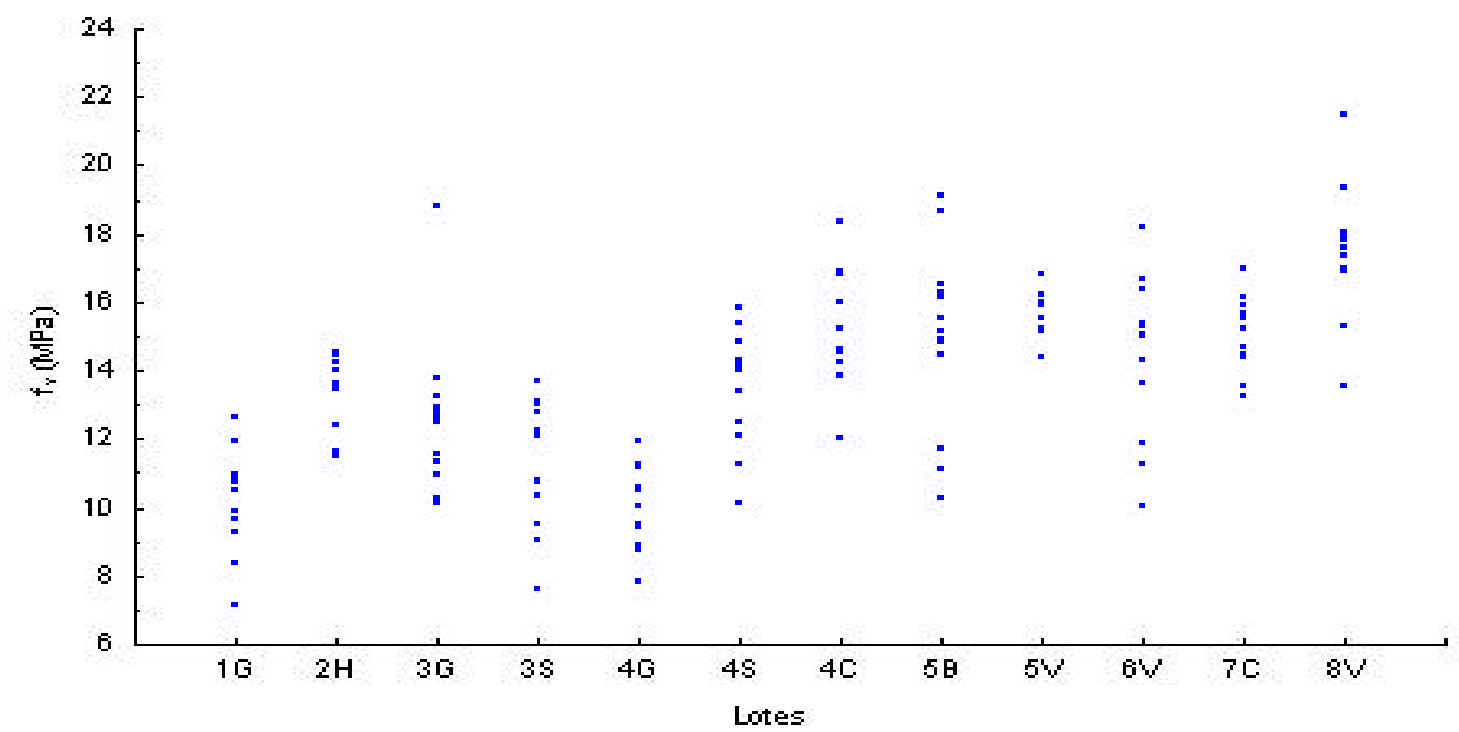

Figura 33 - Dispersão dos valores obtidos no ensaio de resistência ao cisalhamento $\left(f_{v}\right)$ de lotes de madeira de eucalipto.

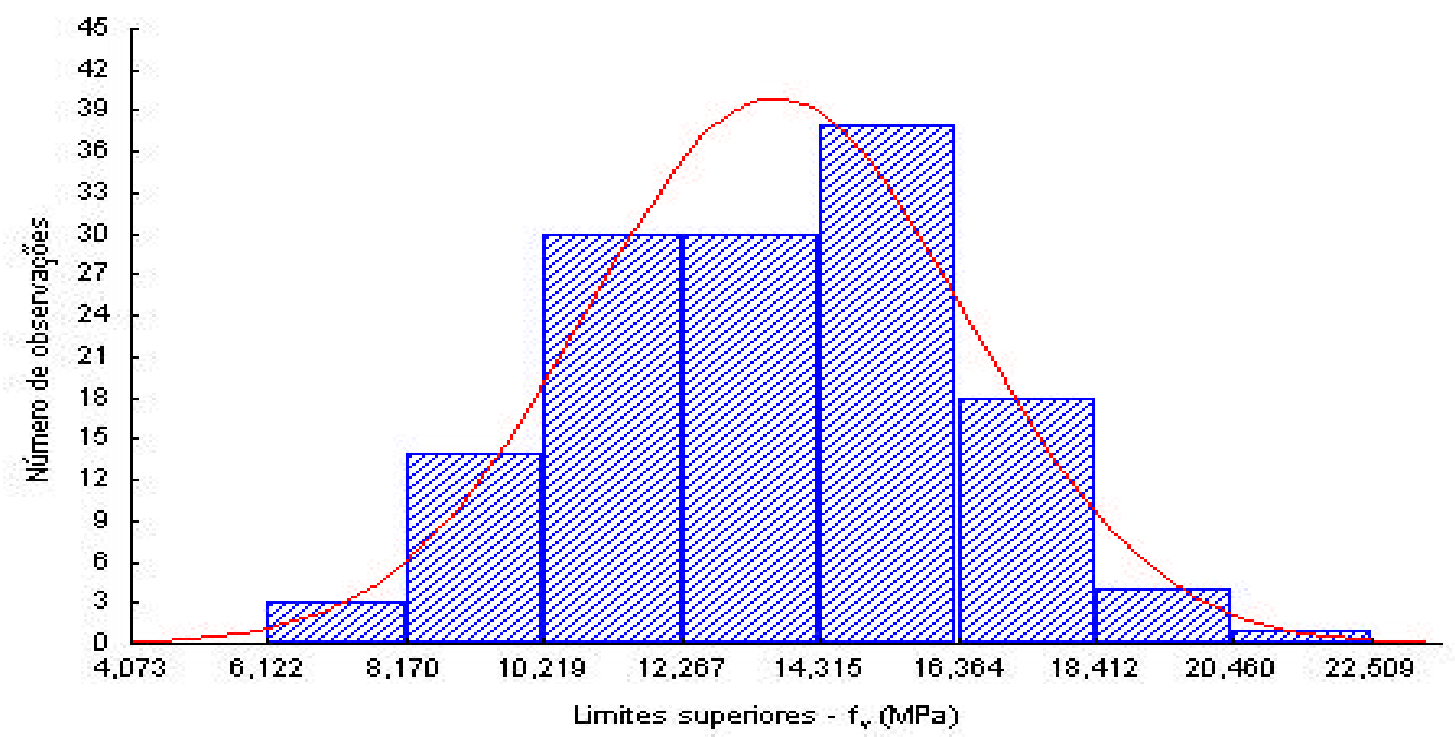

Figura 34 - Distribuição de frequiência dos valores da resistência ao cisalhamento $\left(f_{v}\right)$ de lotes de madeira de eucalipto.

O valor crítico experimental obtido no teste Kolmogorov-Smirnov foi 0,050 para a resistência ao cisalhamento. $O$ valor crítico tabelado para $n=138$ é de 0,115 . Como o valor crítico experimental é inferior ao valor crítico tabelado, pode-se admitir a 
distribuição normal de freqüência (Figura 40) como satisfatória para representar os valores obtidos nos ensaios de cisalhamento.

$\mathrm{Na}$ tentativa de classificar os lotes em grupos homogêneos para resistência ao cisalhamento, foi realizada a análise de variância com aplicação do Teste Tukey com um nível de segurança de 5\%, cujo resultado é apresentado na Tabela 15.

Tabela 15. Grupos homogêneos da resistência ao cisalhamento, pelo teste de Tukey, de lotes de madeira de eucalipto.

\begin{tabular}{|c|c|c|c|c|c|c|c|c|}
\hline \multirow{2}{*}{ Lotes } & \multirow{2}{*}{$\begin{array}{c}\mathrm{F}_{\mathrm{v}, \mathrm{m}} \\
(\mathrm{MPa})\end{array}$} & \multicolumn{7}{|c|}{ Grupos } \\
\hline & & 1 & 2 & 3 & 4 & 5 & 6 & Adotado \\
\hline $4 G$ & 9,99 & XXXX & & & & & & 1 \\
\hline $1 G$ & 10,22 & $\mathrm{xxxx}$ & XXXX & & & & & 2 \\
\hline $3 S$ & 11,26 & $\mathrm{xxxx}$ & $\mathrm{xxxx}$ & $\mathrm{XXXX}$ & & & & 2 \\
\hline $3 G$ & 12,58 & & $\mathrm{xxxx}$ & $\mathrm{xxxx}$ & XXXX & & & 3 \\
\hline $2 \mathrm{H}$ & 13,35 & & & XXXX & $\mathrm{xxxx}$ & $\mathrm{XXXX}$ & & 3 \\
\hline $4 S$ & 13,49 & & & $\mathrm{xxxx}$ & $\mathrm{xxxx}$ & $\mathrm{XxXX}$ & & 3 \\
\hline $6 \mathrm{~V}$ & 14,43 & & & & $\mathrm{xxxx}$ & $\mathrm{XxXX}$ & & 4 \\
\hline $5 B$ & 14,98 & & & & Xxxx & XXXX & & 4 \\
\hline $7 \mathrm{C}$ & 15,10 & & & & & $x x x x$ & XXXX & 5 \\
\hline $4 C$ & 15,40 & & & & & $\mathrm{xxxx}$ & $\mathrm{xxxx}$ & 5 \\
\hline $5 \mathrm{~V}$ & 15,66 & & & & & XXXX & $\mathrm{XXXX}$ & 5 \\
\hline $8 \mathrm{~V}$ & 17,49 & & & & & & $\mathrm{XXXX}$ & 6 \\
\hline
\end{tabular}

Pode-se observar que o lote $8 \mathrm{~V}$, caracterizado por madeira de cor vermelha e fibras bastante reversas, apresentou uma média superior aos demais btes, com um nível de significância de 0,01 , enquanto que para a resistência compressão paralela às fibras e, principalmente, para a resistência à flexão este lote foi classificado com as menores médias.

Foram realizados ensaios de cisalhamento com madeira verde (U>35\%) com aplicação de carga nos planos longitudinal-tangencial e longitudinal-radial para verificar a influência na resistência ao cisalhamento paralelo às fibras. Os valores obtidos são apresentados na Tabela 16 e ilustrados graficamente na Figura 35. 
Tabela 16. Resistência ao cisalhamento nos planos longitudinal-tangencial e longitudinal-radial para madeira verde $(\mathrm{U}>35 \%)$ de lotes de madeira de eucalipto.

\begin{tabular}{cccccc}
\hline \multirow{2}{*}{ Lotes } & \multicolumn{2}{c}{ tangencial } & & \multicolumn{3}{c}{ radial } \\
\cline { 2 - 3 } \cline { 5 - 6 } \cline { 5 - 6 } $1 \mathrm{G}$ & $\mathrm{f}_{\mathrm{v}}(\mathrm{MPa})$ & $\mathrm{C} . \mathrm{V} .(\%)$ & & $\mathrm{f}_{\mathrm{v}}(\mathrm{MPa})$ & $\mathrm{C} . \mathrm{V} .(\%)$ \\
\hline $2 \mathrm{H}$ & 8,3 & 15,62 & & 7,2 & 12,30 \\
$3 \mathrm{G}$ & 10,4 & 5,90 & & 8,7 & 8,40 \\
$3 \mathrm{~S}$ & 9,2 & 18,05 & & 8,3 & 15,21 \\
$4 \mathrm{G}$ & 7,6 & 18,43 & & 7,8 & 19,96 \\
$4 \mathrm{~S}$ & 8,7 & 14,70 & & 7,6 & 11,24 \\
$4 \mathrm{C}$ & 9,4 & 9,88 & & 8,2 & 9,36 \\
$5 \mathrm{~B}$ & 13,1 & 14,35 & & 9,9 & 7,73 \\
$5 \mathrm{~V}$ & 13,2 & 8,52 & & 12,7 & 5,34 \\
$6 \mathrm{~V}$ & 9,4 & 17,66 & & 9,3 & 15,69 \\
$7 \mathrm{~V}$ & 10,6 & 11,00 & & 10,8 & 11,21 \\
$8 \mathrm{~V}$ & 13,6 & 16,94 & & 13,0 & 19,68 \\
\hline
\end{tabular}

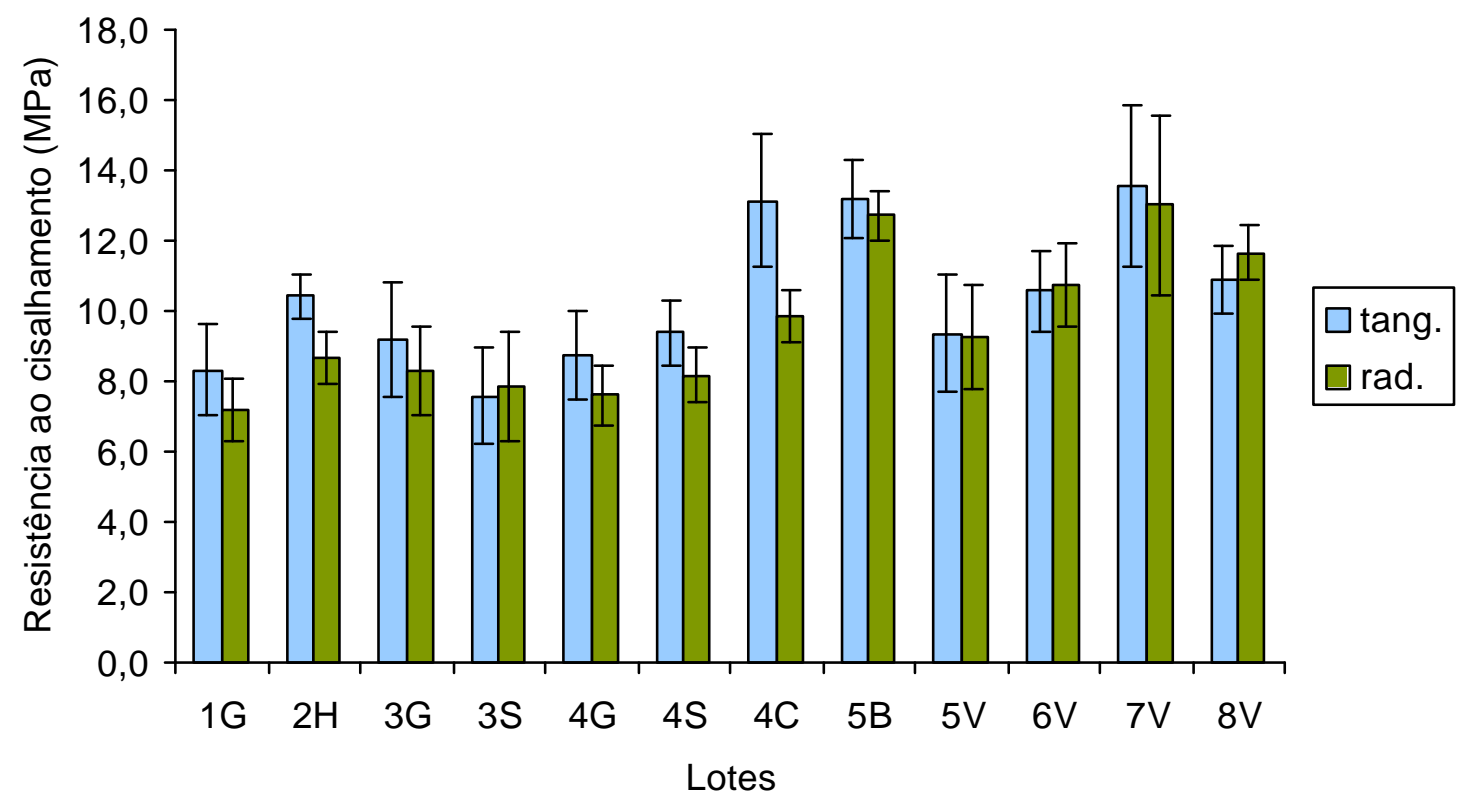

Figura 35 - Valores médios para a resistência ao cisalhamento nos sentidos longitudinal e radial. 
Pela análise da variância foi observada uma diferença significativa a uma probabilidade de $2 \%$, entre os valores obtidos nos dois métodos de ensaio, sendo a média dos ensaios com aplicação de carga no plano longitudinal-tangencial maior que para o plano longitudinal-radial. Os lotes $6 \mathrm{~V}$ e $8 \mathrm{~V}$ apresentaram valores médios maiores para o ensaio de cisalhamento no plano longitudinal-radial, que deve estar relacionado à disposição das fibras da madeira.

Analisando-se os dados referentes aos corpos de prova com disposição dos raios à $45^{\circ}$ do plano de aplicação da carga, juntamente com os dados apresentados acima, foi observada diferença significativa a uma probabilidade de $6 \%$ entre os três grupos, sendo que os valores médios para os corpos de prova com $45^{\circ}$ ocupou a posição intermediária.

\subsection{Discussões gerais}

A amostragem realizada neste trabalho buscou a representação da madeira do gênero Eucalyptus que está efetivamente sendo comercializada para fins estruturais, e o objetivo principal foi a classificação dos lotes de madeira serrada nas classes de resistência proposta pela NBR 7190/97. Deste modo não houve preocupação com a identificação das espécies estudadas, sendo a amostragem realizada em lotes considerados aparentemente homogêneos.

Os coeficientes de variação para as propriedades de resistência e de rigidez da madeira estão de acordo com os valores apresentados por Freitas (1978) e Rocco Lahr (1990). Os valores médios e característicos para as propriedades estudadas de acordo com a NBR 7190/97 estão apresentados na Tabela 17.

A Tabela 18, na qual os lotes de madeira estão classificados em classes de resistência para as propriedades indicadas na NBR 7190/97, foi elaborada pelos valores característicos da resistência à compressão paralela $\left(\mathrm{f}_{\mathrm{c} 0 \mathrm{k}}\right)$ e resistência ao cisalhamento $\left(\mathrm{f}_{\mathrm{vk}}\right)$ e valores médios para o módulo de elasticidade na compressão $\left(\mathrm{E}_{\mathrm{c} 0}\right)$, densidade básica (Db) e aparente (Dap). 
Tabela 17. Valores médios e característicos das propriedades da madeira de lotes de eucalipto obtidos nos ensaios segundo a NBR 7190/97.

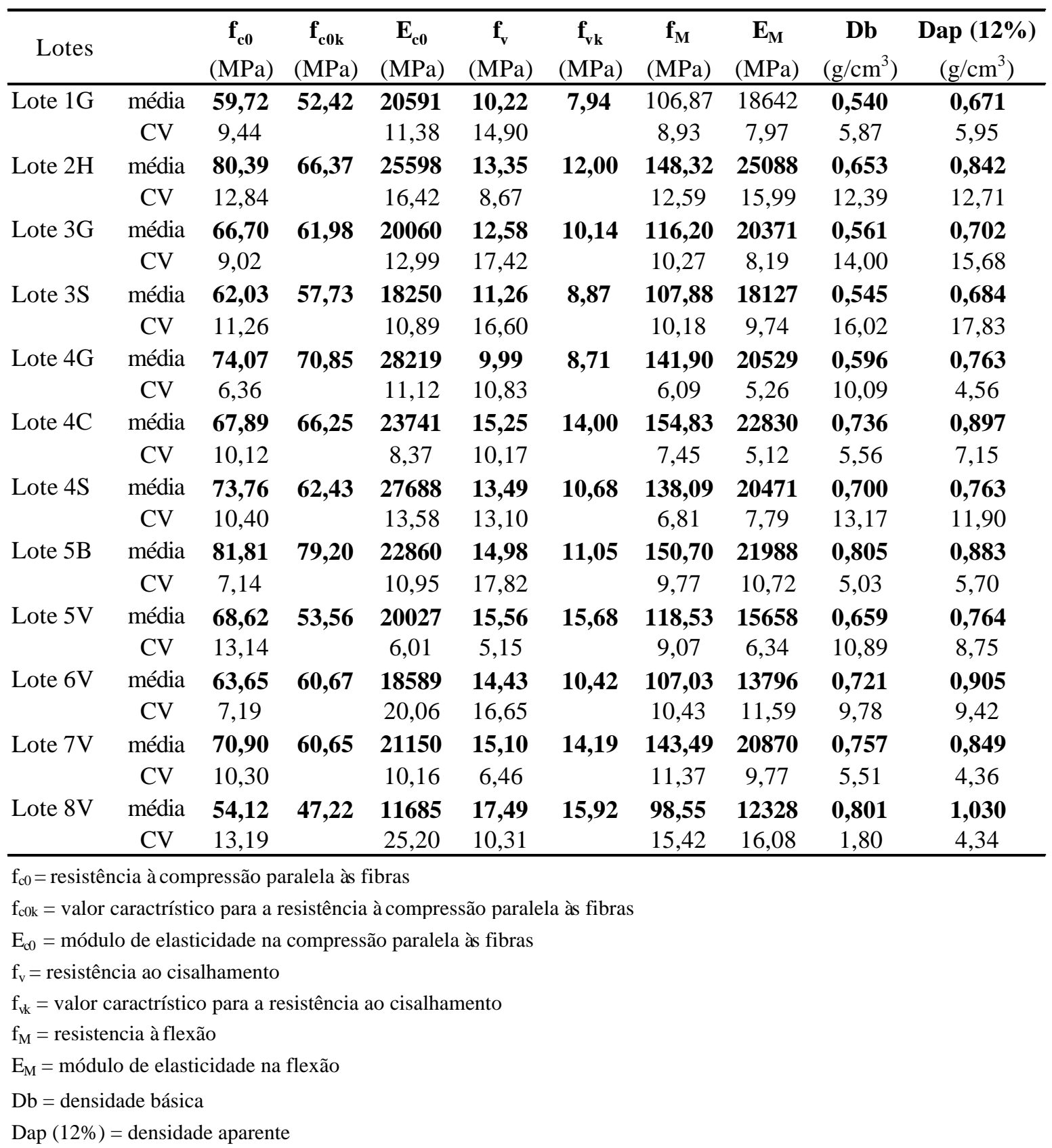


Tabela 18. Classificação dos lotes de madeira serrada nas classes de resistência.

\begin{tabular}{cccccc}
\hline Lotes & $\begin{array}{c}\mathbf{f}_{\mathbf{c 0 k}} \\
(\mathrm{MPa})\end{array}$ & $\begin{array}{c}\mathbf{E}_{\mathbf{c 0}} \\
(\mathrm{MPa})\end{array}$ & $\begin{array}{c}\mathbf{f}_{\mathbf{v k}} \\
(\mathrm{MPa})\end{array}$ & $\begin{array}{c}\text { Db } \\
\left(\mathrm{g} / \mathrm{cm}^{3}\right)\end{array}$ & $\begin{array}{c}\text { Dap (12\%) } \\
\left(\mathrm{g} / \mathrm{cm}^{3}\right)\end{array}$ \\
\hline $1 \mathrm{G}$ & $\mathbf{C ~ 4 0}$ & $\mathbf{C ~ 4 0}$ & $\mathbf{C ~ 4 0}$ & $\mathbf{C ~ 2 0}$ & $\mathbf{C ~ 2 0}$ \\
$2 \mathrm{H}$ & $\mathbf{C ~ 6 0}$ & $\mathbf{C ~ 6 0}$ & $\mathbf{C ~ 6 0}$ & $\mathbf{C ~ 3 0}$ & $\mathbf{C ~ 3 0}$ \\
$3 \mathrm{G}$ & $\mathbf{C ~ 6 0}$ & $\mathbf{C ~ 4 0}$ & $\mathbf{C ~ 6 0}$ & $\mathbf{C ~ 2 0}$ & $\mathbf{C ~ 2 0}$ \\
$3 \mathrm{~S}$ & $\mathbf{C ~ 4 0}$ & $\mathbf{C ~ 3 0}$ & $\mathbf{C ~ 6 0}$ & $\mathbf{C ~ 2 0}$ & $\mathbf{C ~ 2 0}$ \\
$4 \mathrm{G}$ & $\mathbf{C ~ 6 0}$ & $\mathbf{C ~ 6 0}$ & $\mathbf{C ~ 6 0}$ & $\mathbf{C ~ 2 0}$ & $\mathbf{C ~ 2 0}$ \\
$4 \mathrm{C}$ & $\mathbf{C ~ 6 0}$ & $\mathbf{C ~ 4 0}$ & $\mathbf{C ~ 6 0}$ & $\mathbf{C ~ 3 0}$ & $\mathbf{C ~ 3 0}$ \\
$4 \mathrm{~S}$ & $\mathbf{C ~ 6 0}$ & $\mathbf{C ~ 6 0}$ & $\mathbf{C ~ 6 0}$ & $\mathbf{C ~ 3 0}$ & $\mathbf{C ~ 2 0}$ \\
$5 \mathrm{~B}$ & $\mathbf{C ~ 6 0}$ & $\mathbf{C ~ 4 0}$ & $\mathbf{C ~ 6 0}$ & $\mathbf{C ~ 6 0}$ & $\mathbf{C ~ 3 0}$ \\
$5 \mathrm{~V}$ & $\mathbf{C ~ 4 0}$ & $\mathbf{C ~ 4 0}$ & $\mathbf{C ~ 6 0}$ & $\mathbf{C ~ 3 0}$ & $\mathbf{C ~ 2 0}$ \\
$6 \mathrm{~V}$ & $\mathbf{C ~ 6 0}$ & $\mathbf{C ~ 3 0}$ & $\mathbf{C ~ 6 0}$ & $\mathbf{C ~ 3 0}$ & $\mathbf{C ~ 3 0}$ \\
$7 \mathrm{C}$ & $\mathbf{C ~ 6 0}$ & $\mathbf{C ~ 4 0}$ & $\mathbf{C ~ 6 0}$ & $\mathbf{C ~ 4 0}$ & $\mathbf{C ~ 3 0}$ \\
$8 \mathrm{~V}$ & $\mathbf{C ~ 4 0}$ & $\mathbf{C ~ 2 0}$ & $\mathbf{C ~ 6 0}$ & $\mathbf{C ~ 6 0}$ & $\mathbf{C ~ 6 0}$ \\
\hline
\end{tabular}

Observa-se nessa tabela que o lote $1 \mathrm{G}$ se qualificou na classe C 40 para as propriedades mecânicas e na classe C 20 para as densidades. O mesmo aconteceu com o lote $2 \mathrm{H}$ (classe C 60 para as propriedades mecânicas e C 30 para densidade) e com o lote 4G que, de acordo com as propriedades mecânicas ficou na classe C 60 e pelas densidades ficou na classe C 20, ou seja, o lote 4G foi colocado na classe superior para as propriedades mecânicas e na classe inferior pela suas densidades.

Os lotes 3G, 4C, 5B e 7C tiveram o mesmo comportamento para as propriedades mecânicas, qualificando-se nas classes C 60, C 40 e C60 para o valor característico na resistência à compressão paralela às fibras, valor médio para o módulo de elasticidade na compressão paralela às fibras e valor característico na resistência ao cisalhamento, respectivamente.

Os demais lotes tiveram um comportamento variável entre as classes de resistência, como é o caso do lote $3 \mathrm{~S}$ que se qualificou na classe C 60 pelo seu valor característico de resistência à compressão paralela às fibras, na classe C 30 pelo valor médio de seu módulo de elasticidade na compressão paralela às fibras, na classe C 60 de seu valor característico da resistência ao cisalhamento e na classe C 20 pela suas densidades. 
A grande variação na qualificação dos lotes nas classes de resistência sugere uma maior investigação dessas classes para o gênero em questão.

Os coeficientes de correlação linear obtidos a partir das relações entre densidade e propriedades mecânicas, foram significativamente inferiores ao valor comumente citado em tabela de experimentações com madeiras.

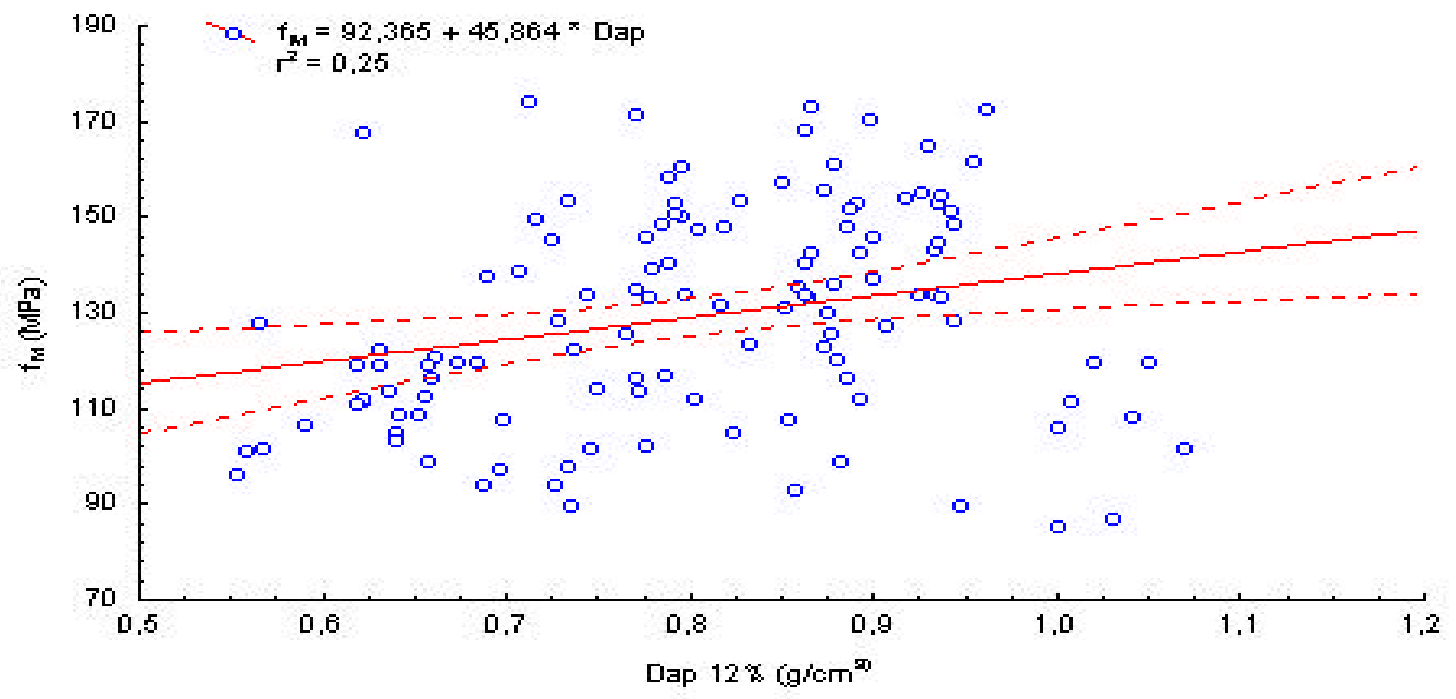

Figura 36 - Regressão linear entre densidade aparente (Dap) e resistência à flexão $\left(\mathrm{f}_{\mathrm{M}}\right)$, ambos a $12 \%$ de umidade.

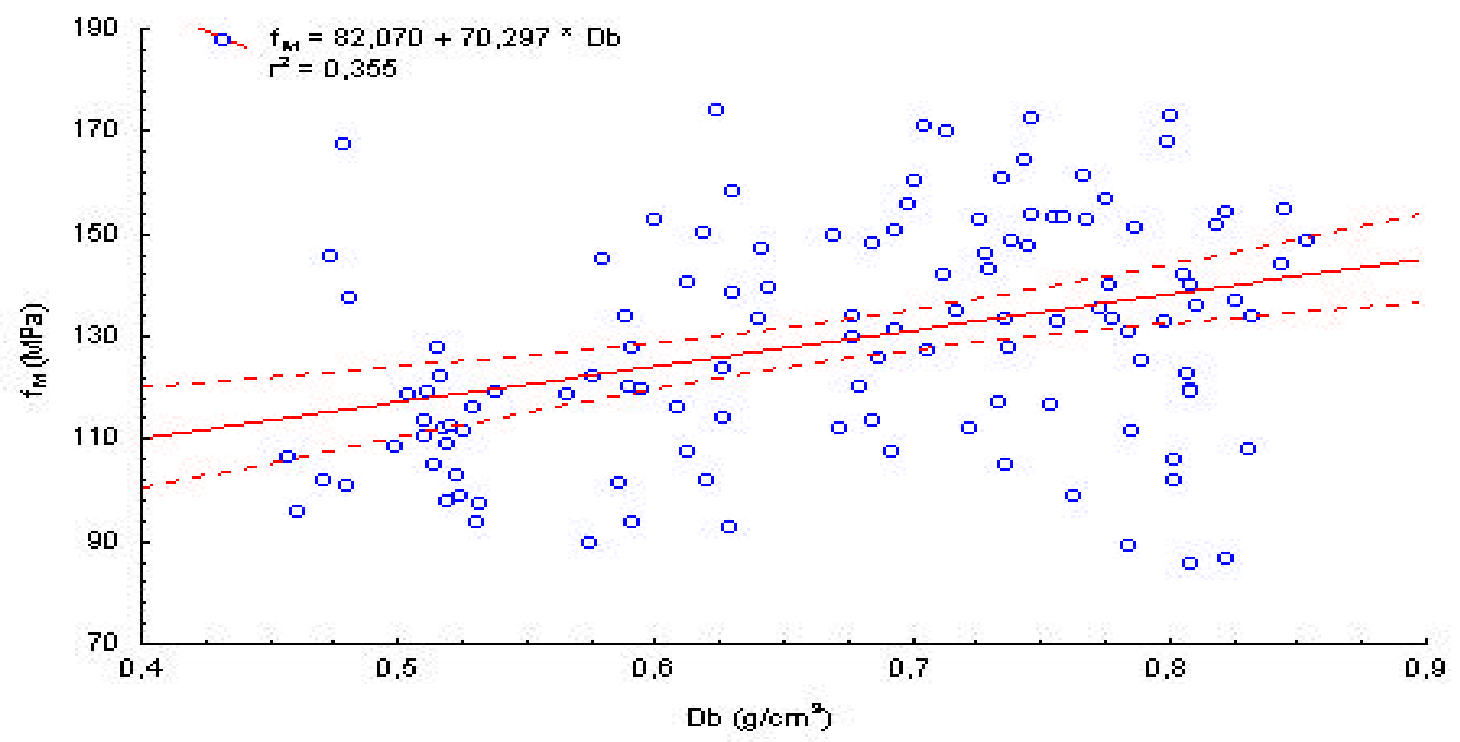

Figura 37 - Regressão linear entre a densidade básica $(\mathrm{Db})$ e a resistência à flexão $\left(\mathrm{f}_{\mathrm{M}}\right)$. 


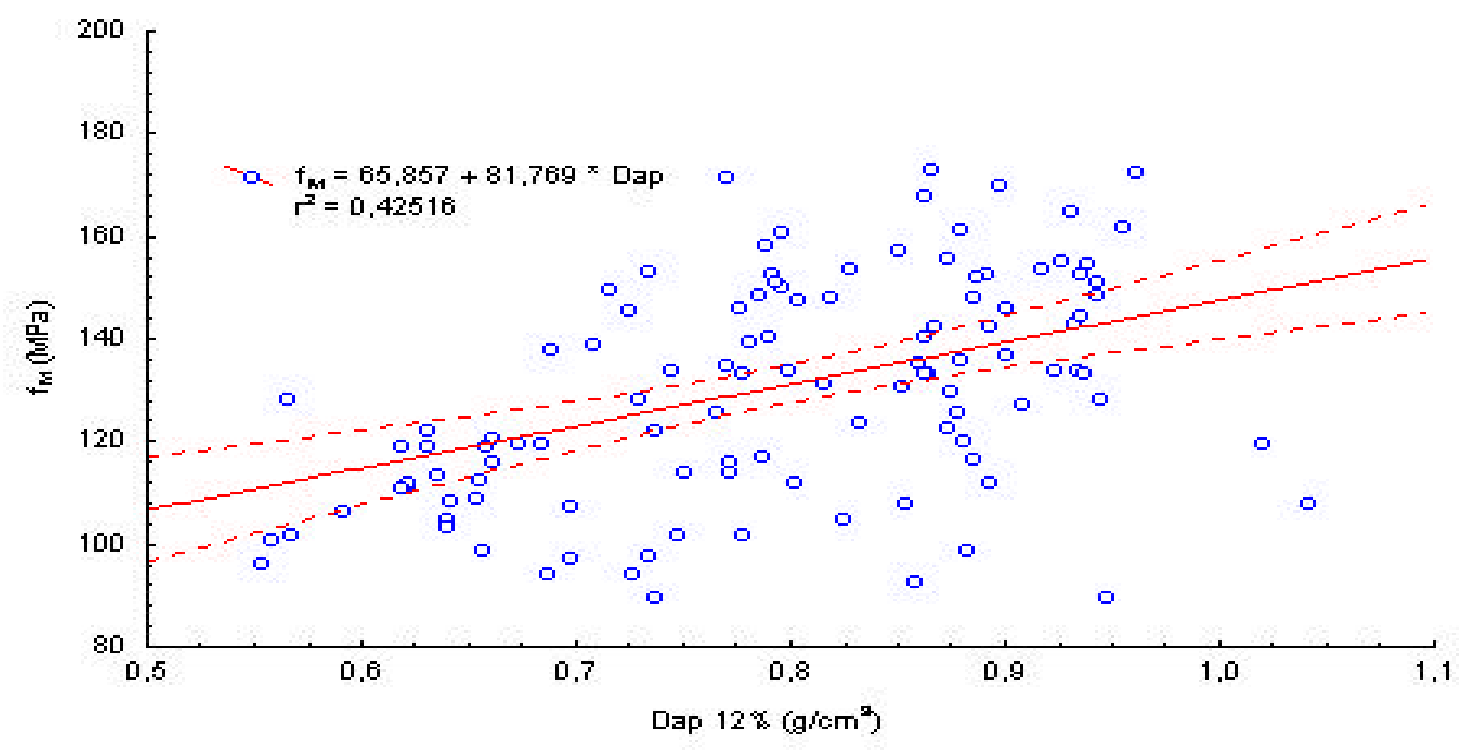

Figura 38 - Regressão linear entre densidade aparente a 12\% (Dap) e resistência à flexão, excluído o lote $8 \mathrm{~V}$.

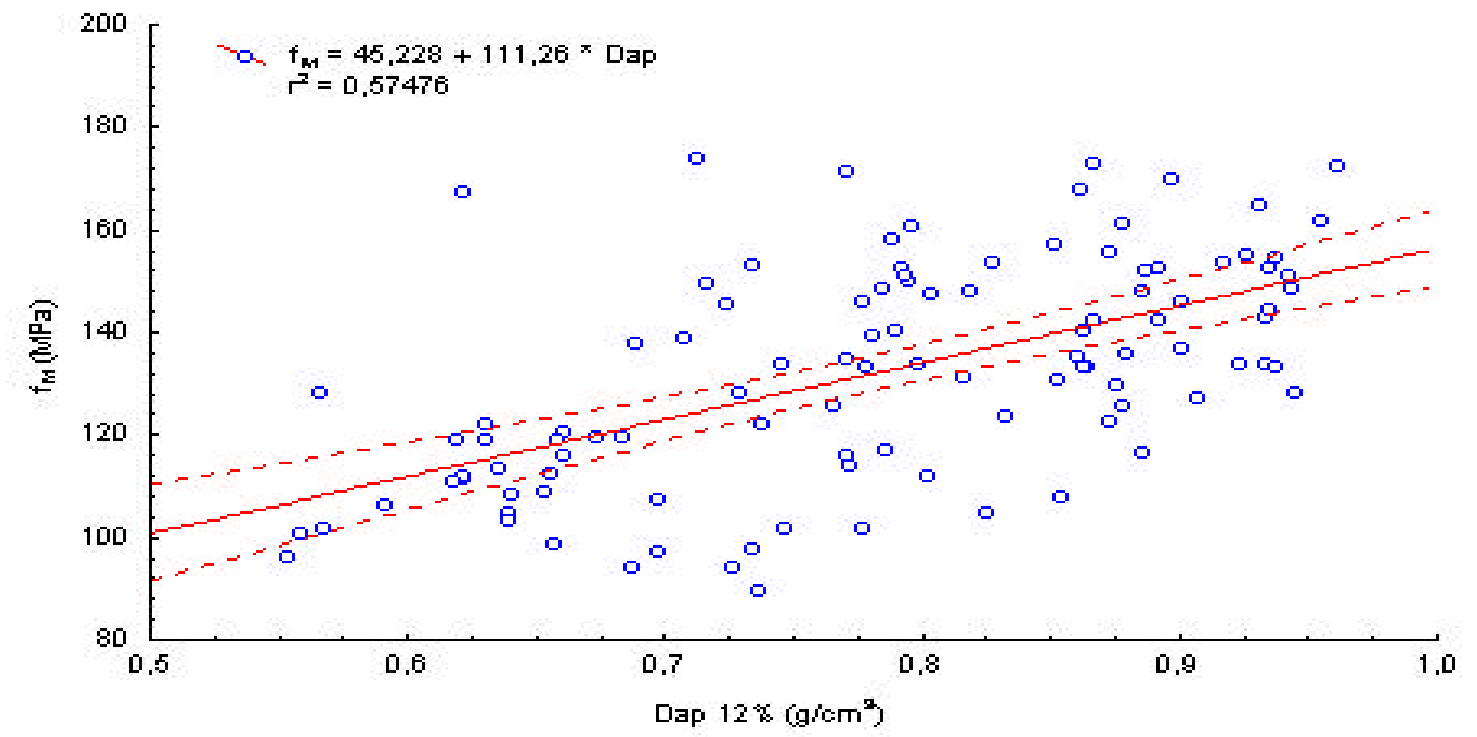

Figura 39 - Regressão linear entre densidade aparente a 12\% (Dap) e resistência à flexão $\left(\mathrm{f}_{\mathrm{M}}\right)$, excluídos os lotes $8 \mathrm{~V}$ e $6 \mathrm{~V}$. 
A Figura 39 apresenta a correlação linear entre a resistência à flexão e a densidade aparente, ambas a $12 \%$ de umidade, onde não estão computados os dados dos lotes $8 \mathrm{~V}$ e $6 \mathrm{~V}$ que apresentaram densidades altas e resistências baixas, devidas à má orientação da grã da madeira. Assim o coeficiente de determinação passou de 0,25 para 0,57. Eliminando-se ainda mais um corpo de prova, nas mesmas condições, do lote $2 \mathrm{H} \mathrm{e}$ um corpo de prova, do lote 7C, o coeficiente subiu para 0,63.

Para a relação entre densidade aparente a $12 \%$ e compressão paralela às fibras, o coeficiente de determinação da regressão linear foi insignificante quando computados todos os dados. A Figura 40 apresenta a correlação linear desta relação, tendo sido excluído os valores do lote $8 \mathrm{~V}$.

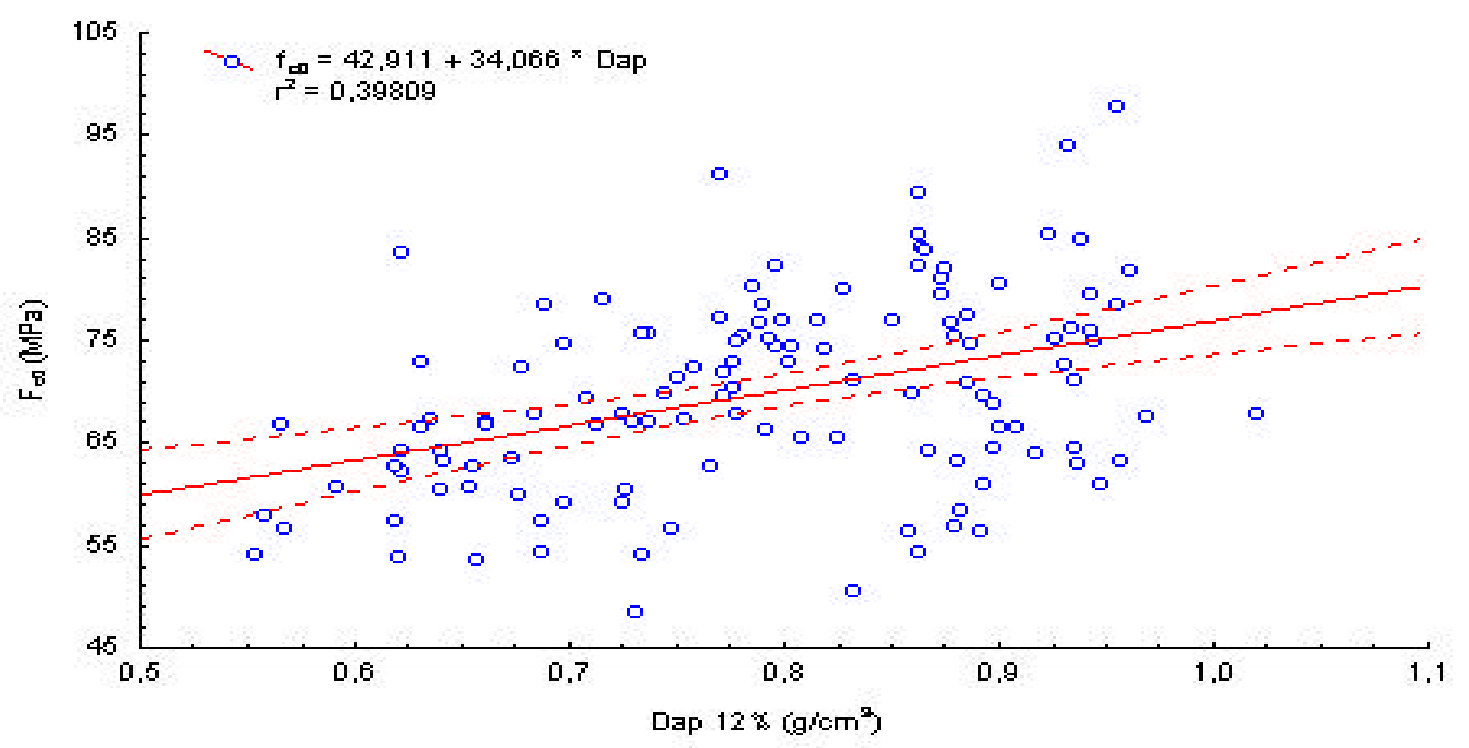

Figura 40 - Regressão linear entre densidade aparente a 12\% (Dap) e resistência à compressão paralela $\left(\mathrm{f}_{\mathrm{c} 0}\right)$, excluido o lote $8 \mathrm{~V}$.

A correlação entre a densidade aparente a $12 \%$ e a resistência ao cisalhamento, também a $12 \%$ de umidade, apresentou um coeficiente de determinação de 0,53 (Figura 41), para todos os dados observados, sendo que a característica de má orientação das fibras do lote $8 \mathrm{~V}$ exerceu uma influência positiva nesta relação. Excluindo um corpo de prova do lote $3 \mathrm{~S}$ e um do lote $6 \mathrm{~V}$ este coeficiente subiu para 0,64 . 


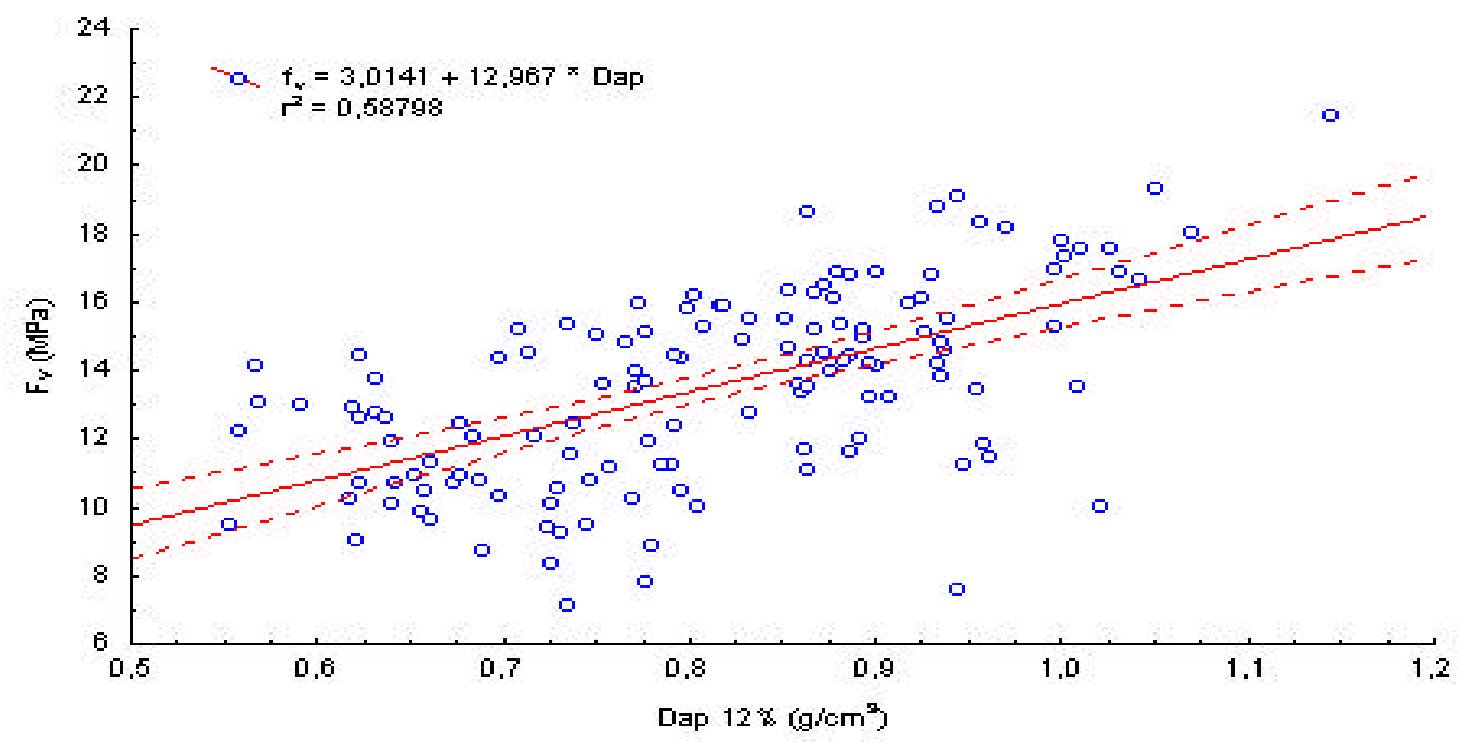

Figura 41 - Regressão linear entre densidade aparente a 12\% (Dap) e resistência ao cisalhamento $\left(f_{\mathrm{V}}\right)$.

Devido a grande variabilidade das características da madeira entre e dentro de lotes, as correlações entre as densidades e as propriedades de resistência da madeira de modo geral apresentaram coeficientes de determinação inferiores aos encontrados em outras pesquisas.

Pelos resultados apresentados neste trabalho, pode-se afirmar que o gênero Eucalyptus apresenta um grande potencial para substituir as espécies tradicionalmente utilizadas na construção civil, pois apresenta características físicas e mecânicas iguais ou superiores a estas. Os estudos a respeito da variabilidade das características da madeira deste gênero devem ser intensificados, principalmente, quando trata-se de lotes de madeira serrada.

Outras características do gênero também devem ser analisadas como presença de nós, rachaduras, bolsas de resina e empenamentos. Portanto, recomenda-se além da classificação mecânica dos lotes de madeira serrada , uma cuidadosa inspeção visual. 


\section{CONCLUSÕES}

Os valores médios encontrados para as densidades básica e aparente estão dentro dos padrões encontrados na literatura. As metodologias usadas para determinação do volume do corpo de prova foram estatisticamente iguais, recomendando-se a metodologia proposta na NBR 7190/97.

Os lotes de madeira de eucalipto ensaiados, pôr apresentar grande variabilidade de resistência e rigidez entre lotes, atende satisfatoriamente aos requisitos necessários para a utilização estrutural.

Ceca de $40 \%$ dos lotes apresentaram qualidade mecânica média e cerca de $60 \%$ deles enquadraram-se na classe de alta qualidade mecânica.

Não foi possível a classificação dos lotes de madeira nas classes de resistência da NBR 7190/97, porque um determinado lote se enquadra em classes diferentes.

Segundo a classificação de lotes pela densidade básica ou aparente, subestima a qualidade mecânica da madeira. 


\section{REFERÊNCIAS BIBLIOGRÁFICAS}

ALBINO, J. C. Características de crescimento e variação da densidade básica da madeira em 12 espécies de Eucalyptus em 3 regiões do Estado de Minas Gerais. Piracicaba, 1983. 90p. Dissertação (Mestrado) - Escola Superior de Agricultura “Luiz de Queiroz”, Universidade de São Paulo.

ANDRADE, E. N. de. O eucalipto. 2.ed. Jundiaí: Companhia Paulista de Estradas de Ferro, 1961, 667p.

ASSOCIAÇÃO BRASILEIRA DE NORMAS TÉCNICAS - Projeto de estruturas de madeira: NBR - 7190. Rio de Janeiro, 1997. 107p.

BAUER, L. A. F. Materiais de construção: a madeira como material de construção. Rio de Janeiro: Livros Técnicos e Científicos, 1985. cap 14, p. 36-48.

BRASIL, M. A. M. Variação da densidade básica da madeira de Eucalyptus propinqua Deane ex Maiden em função do local e do espaçamento. Piracicaba 1972. 75p. Dissertação (Mestrado) - Escola Superior de Agricultura "Luiz de Queiroz", Universidade de São Paulo.

BRASIL, M. A. M.; FERREIRA, M. Variação da densidade básica da madeira de Eucalyptus saligna, E. alba Reinw e E. grandis Hill ex Maiden aos 5 anos de idade, em função do local e do espaçamento. IPEF, n..2/3, p. 129-149, 1971. 
BRASIL, M. A. M.; FERREIRA, M. Variação da densidade básica e das características das fibras em Eucalyptus grandis Hill ex Maiden ao nível do DAP. IPEF, n.4, p 8190, 1972.

BUSNARDO, C. A.; GONZAGA, J. V.; FOELKEL, C. E. B.; et al. Em busca da qualidade ideal da madeira de eucalipto para produção de celulose. VI Altura ideal de amostragem para avaliação da densidade média para árvores de Eucalyptus grandis. In: CONGRESSO ANUAL DA ASSOCIAÇÃO BRASILEIRA DE CELULOSE E PAPEL, São Paulo, 1987. Anais. São Paulo: ABCP, 1987. p. 17-33.

ESTADOS UNIDOS. FOREST PRODUCTS LABORATORY. Wood handbook: Wood as an engineering material. Washington, 1974. v.1.

FERREIRA, C. A .; FREITAS, M.; FERREIRA, M. Densidade básica da madeira de plantações comerciais de eucaliptos, na região de Mogi-Guaçu, SP. IPEF, n.18, p. 106-117, 1979.

FERREIRA, M. Estudo da variação da densidade básica da madeira de Eucalyptus alba e Eucalyptus saligna Smith. Piracicaba, 1968. Tese (Doutorado) - Escola Superior de Agricultura “Luiz de Queiroz”, Universidade de São Paulo.

FERREIRA, M. Estudo da variação da densidade básica de povoamentos de Eucalyptus grandis Hill ex Maiden. Piracicaba, 1970. Tese (Livre-Docência) - Escola Superior de Agricultura “Luiz de Queiroz”, Universidade de São Paulo.

FRANCO, N.; RABELO, M. Estudo comparativo entre os métodos para ensaio de madeira apresentados nas normas COPANT e ABNT. São Paulo: IPT, 1986. $48 \mathrm{p}$. 
FREITAS, A. R. Probabilistic approach in the design of wood strutures in Brazil based on the variability of 23 species. Blacksburg: Virginia Polytechnic Institute, 1978. 79p.

FUSCO, P. B. Estruturas de concreto: fundamentos estatísticos das segurança das estruturas. São Paulo: Mcgraw-Hill do Brasil; EDUSP, 1976, 256p.

HELLMEISTER, J. C. Madeira e suas características. In: ENCONTRO BRASILEIRO EM MADEIRAS E EM ESTRUTURAS DE MADEIRA, São Carlos, 1983. Anais. São Carlos: USP, EESC, SET, LaMEM,1983. v.1. p. 37-42.

KOLLMANN, F. E. P.; CÔTÉ JR., W. A. Principles of wood science and technology. New York: Springer-Verlag, 1968. 528p.

OLIVEIRA, J. T. S. Caracterização da madeira de Eucalipto para a construção civil. São Paulo,1997. 447p. Tese (Doutorado) - Escola Politécnica, Universidade de São Paulo.

PONCE, R. H. Madeira serrada de eucalipto: desafios e perspectivas. In: SEMINÁRIO INTERNACIONAL DE UTILIZAÇÃO DA MADEIRA DE EUCALIPTO PARA SERRARIA, São Paulo, 1995. Anais. Piracicaba: IPEF, 1995. p.50-58.

RIBEIRO, F. A ; ZANI FILHO, J. Variação da densidade básica da madeira em espécies/procedências de Eucalyptus spp. IPEF, n.46, p. 76-85, 1993.

ROCCO LAHR, F. A . Considerações a respeito da variabilidade de propriedades de resistência e de elasticidade da madeira. São Carlos, 1990. Tese (Livre Docência) Escola de Engenharia de São Carlos, Universidade de São Paulo. 
SALES, A. Proposição de classes de resistência para madeiras. São Paulo, 1996. 223p. Tese (Doutorado) - Escola Politécnica, Universidade de São Paulo.

SOCIEDADE BRASILEIRA DE SILVICULTURA - Subsídios para um Programa de Reflorestamento no Brasil. São Paulo, 1996. 136p.

TOMAZELLO FILHO, M. Variação radial da densidade básica e da estrutura anatômica da madeira do Eucalyptus gummifera, E. microcorys e E. pilulares. IPEF, n.30, p. 45-54, 1985.

VITAL, B. R.; PEREIRA, A. R.; DELLA LUCIA, R. M. et al. Efeito da idade da árvore na densidade da madeira de Eucalyptus grandis cultivado na região do cerrado de Minas Gerais. IBDF, 1984, cap.9, p.49-52 (Boletim Técnico n.8). 